Board of Governors of the Federal Reserve System

International Finance Discussion Papers

Number 1318

May 2021

\title{
The Global Determinants of International Equity Risk Premiums
}

\author{
Juan M. Londono and Nancy R. Xu
}

Please cite this paper as:

Londono, Juan M. and Nancy R. Xu (2021). "The Global Determinants of International Equity Risk Premiums," International Finance Discussion Papers 1318. Washington: Board of Governors of the Federal Reserve System, https://doi.org/10.17016/IFDP.2021.1318.

NOTE: International Finance Discussion Papers (IFDPs) are preliminary materials circulated to stimulate discussion and critical comment. The analysis and conclusions set forth are those of the authors and do not indicate concurrence by other members of the research staff or the Board of Governors. References in publications to the International Finance Discussion Papers Series (other than acknowledgement) should be cleared with the author(s) to protect the tentative character of these papers. Recent IFDPs are available on the Web at www.federalreserve.gov/pubs/ifdp/. This paper can be downloaded without charge from the Social Science Research Network electronic library at www.ssrn.com. 


\title{
The Global Determinants of International Equity Risk Premiums*
}

\author{
Juan M. Londono ${ }^{\dagger}$ \\ Nancy R. Xu $u^{\ddagger}$ \\ Federal Reserve Board \\ Boston College
}

April 22, 2021

\begin{abstract}
We examine the commonality in international equity risk premiums by linking empirical evidence for the international stock return predictability of US downside and upside variance risk premiums (DVP and UVP, respectively) with implications from an international asset pricing framework, which takes the perspective of a US/global investor and features asymmetric global macroeconomic, financial market, and risk aversion shocks. We find that DVP and UVP predict international stock returns through different global equity risk premium determinants: bad and good macroeconomic uncertainties, respectively. Across countries, US investors demand lower macroeconomic risk compensation but higher financial market risk compensation for more-integrated countries.
\end{abstract}

JEL Classification: F36, G12, G13, G15.

Keywords: Downside variance risk premium, Upside variance risk premium, International stock markets, Asymmetric state variables, Stock return predictability.

${ }^{*}$ The views expressed in this document do not necessarily reflect those of the Federal Reserve System or its staff. We would like to thank Max Croce, Kasper Joergensen (MFA discussant), Mete Kilic (AEA discussant), Terry Pan (CIRF discussant), Frank Warnock (Federal Reserve's International Finance Discussion Paper series discussant/reviewer), Dacheng Xiu, Guofu Zhou, Hao Zhou, and seminar/conference participants at the 2021 AEA meeting, the 2019 Stanford SITE "Session 7: Asset Pricing Theory", 2019 NASMES Summer Meeting, 2019 ECWFC at WFA, 2019 EFA, 2019 MFA, 2019 FMA, 2019 Global Conference in Latin America, 2018 China International Risk Forum, 2018 Econometric Society European winter meeting, Boston College (Carroll) and Boston Macro Juniors Workshop (MIT Sloan). The paper was previously circulated under title "Variance Risk Premium Components and International Stock Return Predictability". All errors are our own.

${ }^{\dagger}$ Division of International Finance, Federal Reserve Board US, 20th Street and Constitution Avenue N.W., Washington, DC 20551; phone: 202-230-6938; email: juan.m.londono@frb.gov

${ }^{\ddagger}$ Boston College, Carroll School of Management, 140 Commonwealth Avenue, Chestnut Hill, MA, 02467, US; phone: 617-552-2713; email: nancy.xu@bc.edu Corresponding author. 


\section{Introduction}

Joining extensive discussions in the literature on how global shocks transmit across international equity markets (see, for instance, Colacito, Croce, Gavazzoni, and Ready (2018)), we propose a new approach to examine which, and to what extent, common risk variables drive equity risk premiums across countries at short (within-one-year) horizons from the perspective of a US investor. The main intuition of our analysis is that international stock return predictability should be driven by economic determinants that are common to both the global predictors and the global equity risk compensations across countries. An asset pricing framework with the perspective of a US (global) investor should help motivate these common economic determinants and infer their relative importance in driving global equity risk compensations at various horizons. We formalize this intuition in this paper. In particular, we link empirical evidence for the dynamics and international stock return predictability of global predictors with implications from a parsimonious no-arbitrage asset pricing framework featuring time-varying and asymmetric economic uncertainties, pure financial market uncertainties, and risk aversion.

We find that $70-80 \%$ of the dynamics of the global equity risk premium for horizons under seven months may be driven by US economic uncertainties, while US risk aversion and financial market uncertainties may matter more for the global risk premium at longer horizons. Interestingly, both US good and bad economic uncertainties have positive effects on the global equity risk premium, with the bad uncertainty effect being more persistent. The global equity risk compensation exhibits countercyclical dynamics and a downward-sloping term structure particularly during downturns. Our framework also allows us to study cross-country variations in global risk compensations. We find that US investors demand a lower global macroeconomic risk compensation but a higher global pure financial market risk compensation for countries with higher global integration.

For our empirical evidence, we consider the US variance risk premium's downside and upside components (DVP and UVP, respectively) as our two main global predictors, aiming to maximally infer information about short-horizon global equity risk compensations, in light of the recent evidence (see, e.g., Kilic and Shaliastovich (2019), Bollerslev, Marrone, Xu, and Zhou (2014), and Feunou, Jahan-Parvar, and Okou (2017)). In the first part of the paper, we calculate DVP and UVP as the difference between the risk-neutral and physical expectations of onemonth-ahead stock return variance, conditional on whether the one-month-ahead stock price is 
below (bad states) or above (good states) the current stock price, respectively. We approximate the risk-neutral expectation of the downside (upside) stock return variance using puts (calls) on the S\&P 500 index at different strikes and maturities; and we obtain the physical expectation of the downside (upside) stock return variation using the best forecast of the downside (upside) realized variance given a set of forecasting models. Our sample spans from April 1991 to December 2019. We find that DVP and UVP behave quite differently. The total VP and its downside component are highly correlated, significantly positive, and countercyclical with large positive spikes around key episodes of market stress and economic turmoil. In contrast, UVP is positive but smaller in magnitude, less persistent, and procyclical with occasional negative spikes, some of which coincide with major positive DVP spikes.

We then examine the predictive power of DVP and UVP for the excess returns of 22 countries' headline stock indexes expressed in US dollars. Considering both pooled and countrylevel predictive frameworks, we find evidence that decomposing the US VP into its asymmetric components yields gains in predicting international stock returns, and that DVP and UVP together dominate other US predictors such as the US Treasury bill rate and the earnings yield (Rapach, Strauss, and Zhou (2013), Bollerslev, Marrone, Xu, and Zhou (2014)) at short horizons. In addition, the predictability patterns of DVP and UVP are considerably different along several dimensions. The international stock return predictability improves the most at horizons of less than seven months, and this improvement is mainly explained by UVP at very short horizons and by DVP at horizons between four and seven months. The predictive power of DVP follows a hump-shaped pattern peaking at mid four- to seven-month horizons, while that of UVP follows a decreasing pattern after peaking at the one-month horizon. The predictability patterns are robust to using alternative estimates of the VP components and controlling for other US predictors.

The second part of the paper formalizes the main intuition of our exercise using minimum structural assumptions, therefore allowing the data to speak for themselves. We first motivate potential economic determinants of both US VP(s) and international equity risk premiums in a conceptual framework. Given the empirical focus and the US investor perspective of this paper, we write down a flexible US log pricing kernel that is sensitive to changes in macroeconomic conditions, investor risk aversion, and stock market illiquidity. These reducedform kernel state variables and shocks can be motivated from both consumption-based (see e.g. Campbell and Cochrane (1999), Bansal and Yaron (2004), Segal, Shaliastovich, and Yaron 
(2015), Bekaert, Engstrom, and Xu (forthcoming $)$ ) and intermediary-based asset pricing literature (see e.g. Gromb and Vayanos (2002), Brunnermeier and Pedersen (2009), Adrian, Etula, and Muir (2014)). Moreover, the interplay between macroeconomic uncertainty and investors' attitudes toward risk has also played a prominent role in the variance premium literature (rare disaster models in, e.g., Gabaix (2012), long-run risk models in, e.g., Bollerslev, Tauchen, and Zhou (2009), models with habit formation and bad environment-good environment dynamics, as in Bekaert and Engstrom (2017), and models with time-varying fear in, e.g., Drechsler (2013)). Recently, an intermediary-based explanation for the dynamics of the variance risk premium can also be found in Fan, Imerman, and Dai (2016). We construct parsimonious state variable processes with VAR and composite heteroskedastic gamma shock assumptions in order to flexibly describe the tail behaviors of our key state variables. For instance, we follow Bekaert and Engstrom (2017) and model changes in macroeconomic conditions with two centered heteroskedastic gamma shocks with their second moments capturing "good" and "bad" economic uncertainties, respectively. We similarly assume asymmetry and heteroskedasticity in market illiquidity and risk aversion shocks. Lastly, to model the transmission of global/US shocks to other countries, we allow for country cash flow growths to be exposed to common (US) state variables and shocks.

The model solution has two relevant implications for our research objective. First, both the dynamics of US VP (and its components) and the global compensation part of international equity risk premiums should be driven by the second moments of kernel shocks. Second, this commonality implies the various excess return predictability channels. When confronted with the data, our model allows us to identify the relative importance of these common risk premium state variables in DVP and UVP and in international equity risk premiums at various horizons, which is the main contribution of the paper.

We first find that $62 \%$ of the DVP variability is explained by risk aversion and $30 \%$ by bad economic uncertainty. Under volatile economic conditions, DVP becomes more sensitive to high market illiquidity uncertainty, a source of pure financial market risk in our framework. UVP, on the other hand, increases with the procyclical good economic uncertainty through the hedging demand of upside risk, as well as countercyclical state variables (such as risk aversion and illiquidity uncertainty) through the general hedging demand for variance risk. These two channels counteract, resulting in the relatively less persistent and smaller UVP than DVP.

We then identify the relative importance of common economic determinants in interna- 
tional equity risk premiums using the economic interpretations of the VP components and their international stock return predictive coefficients. We utilize the whole cross-country of predictive coefficients; to avoid heavy parameterization, we use two integration measures to describe the cross-country differences in the predictive coefficients: economic integration, proxied by the ratio of total imports and exports to GDP, and financial integration, proxied by the ratio of total asset and liability holdings from one country to the rest of the world to GDP.

For our global-level inferences, we calibrate a country with a median level of economic and financial integration. We find that global equity risk premium's sensitivities to the common risk premium determinants - US economic uncertainty, risk aversion, and illiquidity uncertainty change over the horizon. Both US good and bad economic uncertainties contribute positively to the global equity risk premium, which may be consistent with the recent domestic (US) intuition in Segal, Shaliastovich, and Yaron (2015). However, the US bad uncertainty effects appear the strongest for four- to seven-month global risk premiums. Risk aversion and pure financial uncertainty (stock market illiquidity uncertainty), on the other hand, have a stable and positive impact for all horizons, with one SD increase leading to a two to three annualized percent increase in the average country's equity risk premium. Consistently, a Jackknife exercise shows that DVP predicts international stock excess returns mostly through their common determinant, bad economic uncertainty, while the good economic uncertainty channel is potentially crucial for explaining the pattern of the international predictability of UVP.

As a result, our evidence shows that good and bad US economic risk compensations may be crucial in driving the commonality in international equity premiums, explaining 70 $80 \%$ at horizons under seven months, while financial risk and risk aversion may matter more for driving the commonality in the longer-horizon international equity premiums. The global equity risk compensation exhibits countercyclical dynamics and a downward-sloping term structure, particularly during economic downturns, adding to recent discussions for the US equity market (see, e.g., Boguth, Carlson, Fisher, and Simutin (2011), Van Binsbergen, Brandt, and Koijen (2012), Van Binsbergen, Hueskes, Koijen, and Vrugt (2013), Croce, Lettau, and Ludvigson (2015)).

Finally, we complement our global-level inference by examining, through the lens of our framework, how global investors demand different global risk compensations for holding assets in countries with different integration levels. We find that, for countries with higher integration (especially financial integration), global investors demand lower global macro risk compensation 
but higher global pure financial risk compensation. The former result is potentially consistent with the international risk sharing intuition given a lower cost of capital, greater firm and fundamental investment opportunities, and higher potential growth (Bekaert and Harvey (2003); Carrieri, Errunza, and Hogan (2007)); the latter result is likely due to the increasing chance of higher systemic risk exposure that cannot be diversified away.

Our research contributes to several strands of the literature:

First, our exploration of the global determinants of international equity risk premiums contributes to the ongoing discussion of how global shocks matter and transmit across international equity markets (see, e.g., Colacito, Croce, Gavazzoni, and Ready (2018); Bonciani and Ricci (2020); Bekaert, Hoerova, and Xu (2020); Avdjiev, Gambacorta, Goldberg, and Schiaffi (2020); Aldasoro, Avdjiev, Borio, and Disyatat (2020); Xu (2019) and many others). Different from existing research, our framework exploits empirical evidence from international stock return predictability, which allows us to look at global risk compensations using cross-sectional information at various horizons.

Our research contributes to the literature on understanding and estimating the dynamics of equity risk premiums, including a voluminous empirical literature on time-series predictability regressions; a literature on asset pricing models, as in Martin (2017) and Bekaert, Engstrom, and $\mathrm{Xu}$ (forthcoming); and surveys, as in Graham and Harvey (2005). We exploit several approaches combining empirical evidence from stock return predictability with model implications from an asset pricing framework. Our model estimation strategy, which constitutes one of our core contributions of this paper, highlights two innovations. First, in an asset pricing framework, both US VP and international equity risk premiums should be driven by common risk premium state variables. Empirically, we observe their covariance relationship (i.e., predictability results) and the dynamics of the VP components. By predetermining the loadings of the VP components on these premium state variables, the loadings of international equity premiums hence become the only unknowns in the estimation. Second, considering multiple predictors and multiple countries in a unified framework provides more information in the estimation.

Considering the US VP and its asymmetric components as our main global predictors also contributes to the literature on international stock return predictability. Broadly, we add to a branch of the literature that investigates the predictive power of US financial variables for international stock returns (see Rapach, Strauss, and Zhou (2013) and papers cited therein). More specifically, we add to the literature documenting the robust predictability of the US 
VP for international stock returns (Londono (2015) and Bollerslev, Marrone, Xu, and Zhou (2014)) 1 1 A more recent strand of the VP predictability literature finds that compensations for bearing stock return variations associated with good and bad states are potentially different and that acknowledging for asymmetry in the variance risk premium significantly increases its stock return predictability. This literature has focused only on the predictability for US stock returns (Kilic and Shaliastovich (2019) and Feunou, Jahan-Parvar, and Okou (2017)). Given our goal to improve our understanding of global equity risk compensations through predictive coefficients, we contribute to this strand of the literature by showing that decomposing the US variance risk premium into its downside and upside components also yields higher predictability for international stock returns.

Finally, while we are agnostic about the exact global transmission channels (e.g., central banks, firms, households) of risk premium state variables, our cross-country calibration suggests that US/global investors may demand more (less) financial market risk compensation (macroeconomic risk compensation) from countries with higher integration, shedding light on the non-trivial asset pricing implications of globalization (see, e.g., Kose, Prasad, Rogoff, and Wei (2009); Rapach, Strauss, and Zhou (2013); and Bekaert, Harvey, Kiguel, and Wang (2016)).

The remainder of the paper is organized as follows. Section 2 provides the empirical evidence to be used in our main estimation: the dynamics and international stock return predictability of US downside and upside variance risk premium. Section 3 proposes a conceptual framework to formally motivate our core estimation strategy, that international stock return predictability should be determined by primitive common economic determinants that drive both US VPs and international equity risk premiums. Bringing the model solution to the empirical evidence, Section 4 presents the estimation results for common risk premium determinants, and Section 5 discusses the relative importance of these economic determinants in international equity risk premiums. Concluding remarks are included in Section 6 .

\section{Empirical Evidence}

In this section, we explore the commonality in short-term international equity risk premiums by examining the predictive power of the US variance risk premium (VP) and its downside and upside components for international stock excess returns for horizons between one and

\footnotetext{
${ }^{1}$ Several papers have documented the robust domestic predictability of the US VP (e.g., Bollerslev, Tauchen, and Zhou (2009), Drechsler and Yaron (2010), Bekaert and Hoerova (2014); see Zhou (2018) for a detailed review).
} 
twelve months. In the first part of the section, we construct and discuss the dynamic properties of the downside and upside components of the US VP; then, we examine their predictive power for international stock excess returns, followed by robustness checks.

\subsection{Definitions}

We follow the notation in Bollerslev, Tauchen, and Zhou (2009) and define the total one-month-ahead VP as the difference between the risk-neutral $(Q)$ and the physical $(P)$ expectations of the total variance of one-month-ahead stock returns,

$$
V P_{t, t+1}=V_{t}^{Q}\left(r_{t+1}\right)-V_{t}^{P}\left(r_{t+1}\right)
$$

where $r_{t+1}$ denotes the $\log$ stock return between months $t$ and $t+1$. We decompose VP into its downside and upside components, which we label DVP and UVP, respectively. These components allow us to disentangle the compensations for bearing downside and upside variance risks. The general expression for this decomposition is as follows:

$$
V P_{t, t+1}=\underbrace{V_{t}^{Q}\left(r_{t+1} 1_{<0}\right)-V_{t}^{P}\left(r_{t+1} 1_{<0}\right)}_{D V P}+\underbrace{V_{t}^{Q}\left(r_{t+1} 1_{>0}\right)-V_{t}^{P}\left(r_{t+1} 1_{>0}\right)}_{U V P},
$$

where $1_{<0}\left(1_{>0}\right)$ is a dummy equal to 1 when the one-month-ahead return is below (above) 0 (see Feunou, Jahan-Parvar, and Okou (2017); Kilic and Shaliastovich (2019); Baele, Driessen, Ebert, Londono, and Spalt (2019); and Held, Kapraun, Omachel, and Thimme (2020)).

We estimate the risk-neutral and physical components of DVP and UVP separately. The risk-neutral components of DVP and UVP are extracted from option prices using what is usually known as the model-free methodology (see Britten-Jones and Neuberger (2000); Andersen and Bondarenko (2009)). Specifically, we approximate the risk-neutral components of DVP and UVP using the option-implied downside and upside variances, respectively, as follows:

$$
\begin{aligned}
& i v_{t, t+1}^{D}=\left(\int_{0}^{S_{t}} \frac{2\left(1+\log \left(S_{t} / K\right)\right.}{K^{2}} P(t+1, K) d K\right)^{2}, \\
& i v_{t, t+1}^{U}=\left(\int_{S_{t}}^{\infty} \frac{2\left(1-\log \left(K / S_{t}\right)\right.}{K^{2}} C(t+1, K) d K\right)^{2},
\end{aligned}
$$

where $S_{t}$ is the current stock index price and $P(K)(C(K))$ is the price of a put (call) with strike $K$ and a one-month maturity. Intuitively, the option-implied downside (upside) variance is identified by put (call) options that pay off when the return realization is negative (positive). Next, we approximate the physical components of DVP and UVP using the expected values of one-month-ahead downside and upside realized variances, respectively. Intuitively, we separate 
the return variability due to intradaily negative and positive price movements, and the realized semivariances are obtained as follows:

$$
\begin{aligned}
& r v_{t+1}^{D}=\sum_{\tau=1}^{N} r_{\tau}^{2} 1_{r_{\tau}<0}, \\
& r v_{t+1}^{U}=\sum_{\tau=1}^{N} r_{\tau}^{2} 1_{r_{\tau}>0},
\end{aligned}
$$

where $r_{\tau}$ represents the instantaneous return calculated using stock prices sampled at intradaily frequencies between months $t$ and $t+1$ and $N$ is the total number of high-frequency return observations within the month. The physical expectations of downside and upside realized variances are obtained using linear projections, as follows:

$$
E_{t}\left(r v_{t+1}^{i}\right)=\hat{\alpha}^{i}+\hat{\gamma}^{i} \boldsymbol{X}_{\boldsymbol{t}}^{i}
$$

where $i=D$ or $U$ for downside and upside, respectively, and $\mathbf{X}_{\mathbf{t}}^{\mathbf{i}}$ is a chosen set of predictors observable at time $t$. We allow $\mathbf{X}_{\mathbf{t}}^{\mathbf{i}}$ to be different in predicting downside and upside realized variances. Therefore, DVP and UVP are obtained, respectively, as follows:

$$
\begin{aligned}
& v p_{t, t+1}^{D}=i v_{t, t+1}^{D}-E_{t}\left(r v_{t+1}^{D}\right), \\
& v p_{t, t+1}^{U}=i v_{t, t+1}^{U}-E_{t}\left(r v_{t+1}^{U}\right) .
\end{aligned}
$$

\subsection{The dynamics of variance risk premiums}

We use daily prices for options on the S\&P 500 index at different strikes and maturities (source: OptionMetrics) to obtain the risk-neutral components of DVP and UVP, and we use intradaily prices sampled every 15 minutes for this stock index (source: TICKDATA) to obtain the realized semivariances. Our sample period runs between April 1991 and December 2019.

Figure 1 shows the time variation in the option-implied total variance (top) and its downside and upside components (bottom). The dynamics of option-implied variances confirm the statistics reported in Kilic and Shaliastovich (2019). The downside implied variance accounts for a larger fraction of the total implied variance than the upside component for almost all months in our sample; the average downside to total implied variance ratio is $68.3 \%$. The total implied variance is highly correlated with its components (0.99 and 0.97 with the downside and upside component, respectively). All three time series spike around crisis periods in our sample, including the Long-Term Capital Management (LTCM) fund crisis in the late 1990s, the corporate scandals in the early 2000s, the collapse of Lehman Brothers during the global 
financial crisis, and the European debt crisis in the late 2011.

Next, we measure the physical expectations of return semivariances. While the literature has proposed and compared various models for predicting the total realized variance (see Bekaert and Hoerova (2014) for a thorough discussion), there is limited research on predicting the downside and upside realized variances. Table 1 explores five forecast specifications of one-month-ahead realized semivariances at the daily frequency using the regression framework in Equation (5). The specification in measure (1) assumes that realized semivariances follow a Martingale process, as in Kilic and Shaliastovich (2019); that is, $E_{t}\left(r v_{t+1}^{i}\right)=r v_{t}^{i}$. From columns (2) to (5), we consider various combinations of predictors including past realized variance and semivariances calculated at various horizons. Simple AR(1) forecasts of downside and upside realized variances (measure (2)) yield considerable improvements in terms of adjusted $R^{2} \mathrm{~s}$ with respect to the Martingale specification. Including the total variance to the simple AR(1) specification, as seen in column (3), does not significantly improve the adjusted $R^{2}$ s. According to column (4), a heterogeneous autoregressive (HAR) framework using the past monthly $\left(r v_{t-1 m, t}^{i}\right)$, weekly $\left(r v_{t-5 d, t}^{i}\right)$, and daily $\left(r v_{t-1 d, t}^{i}\right)$ realized semivariances significantly improves the goodness of fit for both downside and upside realized variances ${ }^{2}$

In column (5), we include downside and upside option-implied variances and evaluate their predictive performance for downside and upside realized semivariances, respectively. This last specification yields the best predictive performance for both downside and upside realized semivariances $3^{3}$ Therefore, we use measure (5) to estimate the downside and upside expected physical variances. With the risk-neutral and physical expected variance estimates, we obtain DVP and UVP as in Equation (6). The sum of the two VP components yields the total VP. In the remainder of the paper, we use the end-of-month estimates as our benchmark DVP and UVP measures.

We find that our benchmark monthly DVP and UVP measures differ in their unconditional and time-series properties. First, as can be seen from the summary statistics in Table 2, the

\footnotetext{
${ }^{2}$ This HAR framework for realized semivariances extends Corsi (2009), who focuses on forecasting the total realized variance. Feunou, Jahan-Parvar, and Okou (2017) also consider the HAR framework to approximate the expectations of downside and upside realized variances. However, they do not report the coefficients associated with the HAR components or the fit of the model, and they conclude that the results for the HAR specification are qualitatively similar to those for the Martingale specification.

${ }^{3}$ We are able to replicate and confirm the main result in Bekaert and Hoerova (2014) using our daily data: that is, option-implied variance contains information about future total realized variance, and, therefore, the best forecast specification uses both past realized variances (as in the original Corsi model) and implied variance as predictors. However, neither Corsi (2009) nor Bekaert and Hoerova (2014) forecast downside and upside realized variances as we do here. Additional evidence on our total realized variance forecast results is shown in Table A1 of Appendix A
} 
option-implied downside variance is on average higher than the expected downside realized variance, yielding a positive DVP with an average of 15.97 squared percent in our chosen model (column (5)). The positive nature of DVP holds for all other measures considered and is consistent with the evidence in the existing literature. DVP is prone to large positive. For instance, our DVP measure reaches a value of 93.05 squared percent during the peak of the 2007-08 financial crisis, as shown in Figure 2. The option-implied upside variance is found to be, on average, higher than the expected upside realized variance; the average UVP (1.26) is significantly different from zero but is significantly smaller than the average DVP (15.97). As shown in Figure 2, UVP displays negative spikes in a few episodes. For instance, UVP reached -35.48 squared percent during the Lehman Brothers aftermath, which is almost 11 standard deviations away from its historical average $4^{5}$

Second, we find that the total VP comoves closer to DVP than to UVP. Panel C of Table 2 shows that the correlation between VP and DVP using our chosen model is 0.97 , while that between UVP and VP is 0.26 . Moreover, our DVP and UVP measures are statistically uncorrelated, which stands in contrast to the high correlation between UVP and DVP documented by Kilic and Shaliastovich (2019) using the Martingale measure. Table A2 in the Appendix shows that both DVP and UVP are highly correlated across measures, with a correlation coefficient ranging from 0.74 to 0.99 for DVP and from 0.74 to 0.95 for UVP.

Third, DVP exhibits a negative correlation with monthly US industrial production growth $(\rho=-0.29)$, rendering a countercyclical DVP; in contrast, UVP is positively correlated with the growth rate $(\rho=0.17)$, suggesting weakly procyclical dynamics. Both correlations are statistically significant at the $1 \%$ confidence level.

Finally, UVP is more transitory than DVP. At the monthly frequency, the AR(1) coeffi-

${ }^{4}$ Kilic and Shaliastovich $(2019)$ define VP as the difference between the current realized variance and the risk-neutral expectations of the variance, whereas we define VP as risk-neutral minus physical expectation. Both DVP and UVP measures in Kilic and Shaliastovich (2019) (see their Figure 3) exhibit major negative spikes (given our definition of VP) during this crisis period, with the negative spikes in UVP much more pronounced. This phenomenon is likely due to the Martingale assumption when obtaining the physical expectation; that is, according to Bekaert and Hoerova (2014), realized variance is likely to be high during economic turmoil, which however does not necessarily mean that the actual expectation of stock market variance continues to be this high in the near future. Figure A1 of Appendix A compares our replication of Kilic and Shaliastovich (2019) (dashed red lines) and our measures (solid blue lines); our DVP does not show negative spikes, and our UVP shows much milder negative spikes.

5 Held, Kapraun, Omachel, and Thimme (2020) extend the calculation for the variance premium and its components to 8 international markets and their evidence is similar to ours for US VPs; similar to Kilic and Shaliastovich (2019), they define VP as the difference between the physical and the risk-neutral expectation of the variance. In particular, they find that DVP is, on average, consistently positive for all markets and much larger in magnitude than UVP. UVP is, on average positive for the US, but turns negative for 4 countries in their sample. 
cient of our DVP measure is 0.80 , whereas that of our UVP measure is only 0.22 . These four empirical facts are robust across alternative measures. Taken together, our findings suggest that investors, in general, demand much higher compensations for downside shock exposures than for upside shock exposures, although both shocks lead to increases in total variance. On average, investors dislike risks emanating from both tails. However, compensations demanded for bearing downside and upside variance risks have different dynamics, in terms of their persistence and their relation with current economic conditions.

\subsection{International stock return predictability}

We now examine the international stock return predictability patterns of US DVP and UVP at the global level and at the country level. We take the perspective of a global investor whose asset values are denominated in US dollars. We consider US dollar excess returns of 22 countries' headline stock market indexes covering North America, Asia, and Europe. Log market returns are obtained from their total return indices (source: DataStream), and the risk free rate uses the zero-coupon yield of US Treasury bonds (source: FRED). As before, our sample runs from April 1991 to December 2019 ( $\mathrm{T}=345$ months).

The main predictability regression is as follows:

$$
\kappa^{-1} r_{i, t, t+\kappa}=a_{\kappa}+a_{i, \kappa}+b_{\kappa}^{D} v p_{t, t+1}^{D}+b_{\kappa}^{U} v p_{t, t+1}^{U}+\epsilon_{i, t+\kappa},
$$

where $t$ denotes the month; $r_{i, t, t+\kappa}$ denotes the $\kappa$-month-ahead log excess returns for country $i$; and $v p_{t, t+1}^{D}$ and $v p_{t, t+1}^{U}$ denote DVP and UVP estimates, respectively, as constructed in Section 2.2. A useful null regression specification imposes the predictive coefficients for DVP and UVP to be the same, which is equivalent to considering the total VP as the sole predictor 6

Table 3 compares the results of the null and the main predictability regressions at the 1-, 3-, 6-, and 12-month horizons; the full-horizon predictability patterns are shown in Figure3. Our results for the null model are consistent with those in the literature (see, e.g., Londono (2015); and Bollerslev, Marrone, Xu, and Zhou (2014)). In particular, the hump-shaped predictability pattern of the total VP peaks at around the 6-month horizon.

Our main empirical result is that acknowledging for asymmetry in VP improves the predictability for international stock returns and, therefore, offers more joint information in understanding the latent behaviors of global equity risk premiums. The adjusted R-squareds of

\footnotetext{
${ }^{6}$ The panel-data setting in Equation $\sqrt{7}$ is interpreted as our global and average-country result. Moreover, Ang and Bekaert (2007) find that a panel-data setting yields more reliable estimates for international stock return predictability.
} 
our main bivariate specification are larger than those of the null model for all within-one-year horizons considered. In addition, the predictability patterns of DVP and UVP are completely different. While DVP inherits the hump-shaped predictability pattern of the total VP, UVP is only a significant predictor at very-short horizons. The variance decomposition (row "VARC\%" in Table 3) confirms that the DVP contribution to predictability becomes dominant as the horizon increases, while the UVP contribution dominates mostly at horizons between one and three months. Our results thus suggest that decomposing US VP into its downside and upside components might introduce more flexibility in capturing mixed underlying dynamics of international equity risk premiums at different horizons.

We conduct and evaluate two robustness tests of our main results. First, we estimate the predictive regression in Equation (7) using the Martingale VP measures (see measure (1) in Tables 1 and 2 and Figure A1 in Appendix A). The results in panel A of Table 4 suggest that acknowledging for asymmetry in US VP using this Martingale measure still improves international stock return predictability, given the larger adjusted R-squareds. Moreover, the predictability patterns for DVP and UVP using the Martingale measure are similar to those in Figure 3, with some small but notable differences. In particular, for this alternative (Martingale) measure, the coefficient associated with UVP becomes marginally significant for the one-month horizon and negative and significant for horizons around one year 7 Second, to assess whether the predictive power of DVP and UVP is additional to that of some well-established macrofinance stock return predictors, we examine an augmented version of the specifications in Equation (7) in which we consider our VP measures and control for the three-month US Treasury bill rate and the US earnings yield (see Ang and Bekaert (2007), Rapach, Strauss, and Zhou (2013), Bollerslev, Marrone, Xu, and Zhou (2014)). These results are shown in panel B of Table 4. The predictability patterns remain almost unchanged with respect to our main results; DVP remains the main predictor of international stock returns at horizons around 6 months, while UVP remains the main predictor at shorter horizons. DVP and UVP together explain most of the predictive power at short horizons, according to the variance decomposition.

Next, we explore the predictability of DVP and UVP for stock returns at the country

\footnotetext{
${ }^{7}$ The predictability pattern of the Martingale UVP for international stock returns is similar to that documented by Kilic and Shaliastovich (2019) for US stock returns (negative and borderline significant coefficients associated with UVP at longer horizons), although we still obtain a positive and significant coefficient associated with UVP at the one-month horizon. In fact, using the Martingale measure and a shorter sample running from January 1996 to August 2014, we are able to replicate the results in Kilic and Shaliastovich (2019) for the predictive power of the VP components for US stock returns. Our results might suggest that the predictive power of UVP is more sensitive to the VP measure and the sample considered.
} 
level. Figures 4 and 5 show the predictive coefficient estimates associated with DVP and UVP, respectively, in the following country-level regression setting:

$$
\kappa^{-1} r_{i, t, t+\kappa}=a_{i, \kappa}+b_{i, \kappa}^{D} v p_{t, t+1}^{D}+b_{i, \kappa}^{U} v p_{t, t+1}^{U}+\epsilon_{i, t+\kappa} .
$$

Consistent with the panel evidence, Figure 4 shows similar hump-shaped predictability pattern with significant and positive predictive DVP coefficients for horizons around 6 months for almost all countries in our sample, with a few exceptions, such as Finland, the Netherlands, Ireland, Portugal, and Switzerland. Figure 5 shows that the predictive coefficients of UVP for most countries (except for Japan) exhibit a similar consistently positive but decreasing pattern. Although the shape of the predictability patterns of DVP and UVP is by large consistent across countries, the magnitude and significance of the estimates of the coefficients associated with DVP and UVP could vary across countries 8

In summary, we find that US DVP and UVP display different dynamics and are useful predictors of international stock excess returns, especially for horizons between one and seven months. When investors demand more compensations for bearing US downside (upside) variance risks, they bid down the prices of international risky assets and, moreover, demand high equity risk premiums at 4- to 7-month (1- to 3-month) horizons. This result suggests that US downside risks are priced as more persistent risk premium shocks to international stock markets than US upside risks. We also show that there are gains in acknowledging for asymmetric risk compensations in the return predictive regressions, driven mostly by UVP at very short horizons and by DVP at mid-term horizons. Finally, there is some degree of cross-country variation in the predictability patterns and significance of US DVP and UVP.

\section{Conceptual Framework}

In this section, we propose a conceptual framework to understand the international stock return predictability of US VPs documented in Section 2. The main intuition is that the observed international stock return predictability should be driven by common economic determinants of US VPs and international equity risk premiums (EPs). An asset pricing framework can help us motivate these common economic determinants and, when confronted with the data,

\footnotetext{
${ }^{8}$ For instance, while the DVP coefficients are small (often negative and insignificant) for Finland, Ireland, Japan, and Switzerland, for several countries in our sample, such as Australia, Canada, Hong Kong, and Singapore, estimated coefficients are larger than those for the US (domestic predictability). For UVP, estimated coefficients are small and not statistically significant for any of the horizons considered for several countries in our sample: Hong Kong, Japan, the Netherlands, New Zealand, Portugal, and Singapore.
} 
infer their relative importance in driving global equity risk compensations, which is the main contribution of this paper.

Our conceptual framework consists of a characterization of the state evolution and a pricing kernel for a US/global representative agent. The US state evolution process is characterized by kernel state variables, second moment state variables, and a pure cash flow state variable (dividend growth). The dynamic state process, $\boldsymbol{Y}_{\boldsymbol{t}}$, follows a vector autoregressive nature, and the shocks, $\boldsymbol{\omega}_{\boldsymbol{t}}$, are mutually-independent centered gamma shocks that introduce heteroskedasticity and non-Gaussianity in this affine state variable system:

$$
\begin{aligned}
Y_{t+1} & =\mu+A Y_{t}+\Sigma \omega_{t+1} \\
\omega_{t+1} & \sim \Gamma\left(\Omega Y_{t}+e, 1\right)-\left(\Omega Y_{t}+e\right),
\end{aligned}
$$

where $\boldsymbol{\mu}, \boldsymbol{A}, \boldsymbol{\Sigma}, \boldsymbol{\Omega}$ and $\boldsymbol{e}$ are constant matrices, and $\boldsymbol{\Omega} \boldsymbol{Y}_{\boldsymbol{t}}+\boldsymbol{e}$ denotes a vector of shape parameters which spans second (and higher-order) moments of these shocks. There is an increasing interest in using non-Gaussian and/or composite shocks in asset pricing models to realistically capture the second and higher-order moments as well as tail behaviors of the underlying fundamental or non-fundamental state variables (see, e.g., Eraker and Shaliastovich (2008), Bekaert, Engstrom, and Xing (2009), Fulop, Li, and Yu (2015), Segal, Shaliastovich, and Yaron (2015), De Groot (2015), Colacito, Ghysels, Meng, and Siwasarit (2016) among many others). We are not the first to model state variable processes in an equilibrium model with gamma-distributed shocks; both Bekaert and Engstrom (2017) and $\mathrm{Xu}$ (2021) show that specifying economic fundamental innovations using one or multiple gamma shocks is statistically and economically more realistic than using Gaussian shocks 9 And, of course, empirically, there may be more interesting patterns in fundamental variable volatilities and volatility comovements (e.g., Patton and Sheppard (2015)). However, further empirical assumptions may make an equilibrium pricing context fairly intractable. For the purpose of our research, we use the parsimonious gamma distribution for our shocks that (as we prove in the Appendix) result in quasi-closed-form expressions for US and international equity prices, variance risk premiums, and equity risk premiums. This greatly increases the appeal of the framework, as we can obtain useful intuition on the drivers of asset prices.

\footnotetext{
${ }^{9}$ In addition, Bekaert, Engstrom, and Ermolov (2015) conduct a more thorough model comparison and find that specifying S\&P 500 market returns using gamma-class innovations with AR(1) shape parameters driven by level shocks dominate 8 other non-Gaussian or asymmetric GARCH-class and regime-switching models.
} 
Next, we assume a general linear process of the log US real pricing kernel, as follows:

$$
m_{t+1}=m_{0}+\boldsymbol{m}_{\mathbf{1}} \boldsymbol{Y}_{\boldsymbol{t}}+\boldsymbol{m}_{\mathbf{2}} \boldsymbol{\Sigma} \boldsymbol{\omega}_{\boldsymbol{t}+\mathbf{1}}
$$

where $\boldsymbol{m}_{\mathbf{1}}$ and $\boldsymbol{m}_{\mathbf{2}}$ denote the loadings on the lagged state variables and innovations, respectively. Given the no-arbitrage condition and the conditional asset pricing framework, the US price-dividend ratio can be solved in an approximate affine framework, and the log US market return can be expressed in the following quasi-linear process (see Appendix B for the proof):

$$
r_{t+1}=\ln \left(\frac{P_{t+1}+D_{t+1}}{P_{t}}\right) \approx \xi_{0}+\boldsymbol{\xi}_{1} \boldsymbol{Y}_{\boldsymbol{t}}+\boldsymbol{\xi}_{\mathbf{2}} \boldsymbol{\Sigma} \boldsymbol{\omega}_{t+\mathbf{1}}
$$

We next assume that, for countries other than the US, there is a country-level dividend growth process that is sensitive to US macro and business conditions, $\boldsymbol{Y}_{\boldsymbol{t}}$, and shocks, $\boldsymbol{\omega}_{\boldsymbol{t + 1}}$. Thus, as shown in Appendix B, log stock returns for country $i$ can be written as:

$$
r_{t+1}^{i}=\ln \left(\frac{P_{t+1}^{i}+D_{t+1}^{i}}{P_{t}^{i}}\right) \approx \xi_{0}^{i}+\boldsymbol{\xi}_{1}^{i} \boldsymbol{Y}_{\boldsymbol{t}}+\boldsymbol{\xi}_{\mathbf{2}}^{i} \boldsymbol{\Sigma} \boldsymbol{\omega}_{t+\mathbf{1}}+\text { Idiosyncratic Parts. }
$$

Constant matrices $\boldsymbol{\xi}_{\mathbf{1}}\left(\boldsymbol{\xi}_{\mathbf{1}}^{\boldsymbol{i}}\right)$ and $\boldsymbol{\xi}_{\mathbf{2}}\left(\boldsymbol{\xi}_{\mathbf{2}}^{\boldsymbol{i}}\right)$ represent the loadings of US (country $i$ ) log returns on the lagged US/global state variables and shocks, respectively.

The model-implied US variance risk premium has the following expression (see Appendix C for the proof):

$$
V_{t}^{Q}\left(r_{t+1}\right)-V_{t}^{P}\left(r_{t+1}\right)=\left\{\left(\boldsymbol{\xi}_{\mathbf{2}} \boldsymbol{\Sigma}\right)^{\circ 2} \circ\left[\left(\mathbf{1}-\boldsymbol{m}_{\mathbf{2}} \boldsymbol{\Sigma}\right)^{\circ-2}-\mathbf{1}\right]\right\}\left(\boldsymbol{\Omega} \boldsymbol{Y}_{\boldsymbol{t}}+\boldsymbol{e}\right),
$$

where "o" denotes element-by-element matrix multiplication. Here are some economic insights from Equation (13). First, the dynamics of VP (and its components) should be driven by the shape parameters of kernel state variable shocks, as, for these shocks, the pricing kernel has non-zero loadings (that is, $m_{2} \neq 0$ ). Second, for shocks with positive $m_{2}$ loadings, their shape parameters (as captured in $\left(\boldsymbol{\Omega} \boldsymbol{Y}_{\boldsymbol{t}}+\boldsymbol{e}\right)$ ) contribute positively to VP, given $\left[\left(\frac{1}{1-m_{2} \sigma}\right)^{2}-1\right]>0$. Intuitively, for instance, in a standard habit formation model, the marginal utility increases with the relative risk aversion shock; in Segal, Shaliastovich, and Yaron (2015)'s long-run risk model, the kernel has positive exposure to a bad macroeconomic shock. Hence, our closed-form solution in Equation (13) would suggest that the variance risk premium may increase with investor risk aversion and bad macroeconomic uncertainty 10

\footnotetext{
${ }^{10}$ Note that it is not trivial to derive model-implied VP components that are consistent with definitions of downside and upside environments (negative and positive return realizations, respectively) because returns are endogenously determined, as shown in Equation (11). Therefore, our approach to determine the drivers of downside and upside VPs is entirely empirical, with minimum model assumptions; we relegate this discussion to Section 5
} 
Next, the US equity risk premium is given by:

$$
E_{t}\left(r_{t+1}\right)-r f_{t}=\left\{\boldsymbol{\xi}_{\mathbf{2}} \boldsymbol{\Sigma}+\ln \left[\mathbf{1}-\left(\boldsymbol{m}_{\mathbf{2}}+\boldsymbol{\xi}_{\mathbf{2}}\right) \boldsymbol{\Sigma}\right]-\ln \left(\mathbf{1}-\boldsymbol{m}_{\mathbf{2}} \boldsymbol{\Sigma}\right)\right\}\left(\boldsymbol{\Omega} \boldsymbol{Y}_{\boldsymbol{t}}+\boldsymbol{e}\right),
$$

which is determined by second moments of shocks that commonly drive the pricing kernel and asset returns. Similarly, these second moments also determine the global compensation part of country $i$ 's equity risk premium:

$$
\begin{aligned}
E_{t}\left(r_{t+1}^{i}\right)-r f_{t}^{i} & =\left\{\boldsymbol{\xi}_{\mathbf{2}}^{i} \boldsymbol{\Sigma}+\ln \left[\mathbf{1}-\left(\boldsymbol{m}_{\mathbf{2}}+\boldsymbol{\xi}_{\mathbf{2}}^{i}\right) \boldsymbol{\Sigma}\right]-\ln \left(\mathbf{1}-\boldsymbol{m}_{\mathbf{2}} \boldsymbol{\Sigma}\right)\right\}\left(\boldsymbol{\Omega} \boldsymbol{Y}_{\boldsymbol{t}}+\boldsymbol{e}\right) \\
& + \text { Idiosyncratic Parts. }
\end{aligned}
$$

The Gaussian approximation of Equation (14) is $-\left(\boldsymbol{m}_{\mathbf{2}} \boldsymbol{\Sigma} \circ \boldsymbol{\xi}_{\mathbf{2}} \boldsymbol{\Sigma}\right)\left(\boldsymbol{\Omega} \boldsymbol{Y}_{\boldsymbol{t}}+\boldsymbol{e}\right)$, or $-\operatorname{Cov}_{t}\left(r_{t+1}, m_{t+1}\right)$; similarly, for other countries, the global part of Equation 15) captures $-\operatorname{Cov}_{t}\left(r_{t+1}^{i}, m_{t+1}\right)$. Appendix $\mathrm{D}$ provides more details.

In summary, our conceptual framework suggests two important implications for our research objective. First, both the dynamics of US VP and the global part of international equity risk premiums should be driven by the second moments of kernel shocks that enter asset returns, which we refer to as "common risk premium determinants" in the rest of the paper. Second, this commonality implies various stock return predictability channels, which together attribute to the observed international predictive coefficients. Given the empirical focus of the paper, our estimation strategy starts with defining and estimating plausible common risk premium determinants in Section 4. In Section 5, we bring the model implications to the international stock return predictability evidence and infer the composition and dynamics of the global equity risk premium.

\section{Common Risk Premium Determinants}

As discussed in the Introduction, we motivate our choices of kernel state variables and shocks from both consumption-based and intermediary asset pricing branches of the literature. We focus on the following three main kernel state variables: real economic growth, denoted by $\theta_{t+1}$; risk aversion, $q_{t+1}$; and stock market illiquidity, $i l l i q_{t+1}$. These state variables determine the kernel shocks in our framework (see Appendix E for explicit expressions):

$$
\boldsymbol{\Sigma}_{\boldsymbol{m}} \boldsymbol{\omega}_{\boldsymbol{m}, \boldsymbol{t + 1}} \equiv\left[\begin{array}{c}
\theta_{t+1}-E_{t}\left(\theta_{t+1}\right) \\
q_{t+1}-E_{t}\left(q_{t+1}\right) \\
i l l i q_{t+1}-E_{t}\left(i l l q_{t+1}\right)
\end{array}\right]
$$


where we assume that,

$$
\begin{aligned}
\boldsymbol{\Sigma}_{\boldsymbol{m}} & =\left[\begin{array}{cccccc}
\delta_{\theta, \theta p} & -\delta_{\theta, \theta n} & 0 & 0 & 0 & 0 \\
\delta_{q, \theta p} & \delta_{q, \theta n} & \delta_{q, q h} & -\delta_{q, q l} & 0 & 0 \\
\delta_{i l l i q, \theta p} & \delta_{i l l i q, \theta n} & \delta_{i l l i q, q h} & \delta_{i l l i q, q l} & \delta_{\text {illiq,illiqh }} & -\delta_{\text {illiq }, \text { illiql }}
\end{array}\right], \\
\boldsymbol{\omega}_{\boldsymbol{m}, \boldsymbol{t + 1}} & =\left[\begin{array}{llllll}
\omega_{\theta p, t+1} & \omega_{\theta n, t+1} & \omega_{q h, t+1} & \omega_{q l, t+1} & \omega_{\text {illiqh }, t+1} & \omega_{\text {illiql }, t+1}
\end{array}\right]^{\prime} .
\end{aligned}
$$

We allow flexible tail behaviors of the three main state variables, given that their second (and higher) moments constitute the common risk premium determinants. Specifically, $\omega_{\theta p, t+1} \sim$ $\Gamma\left(\theta p_{t}, 1\right)-\theta p_{t}$ and $\omega_{\theta n, t+1} \sim \Gamma\left(\theta n_{t}, 1\right)-\theta n_{t}$ denote the good and bad macro shocks with time-varying shape parameters $\theta p_{t}$ and $\theta n_{t}$, respectively, that characterize the right and left tail behaviors of the real economic growth. Similarly, $\omega_{q h, t+1} \sim \Gamma\left(q h_{t}, 1\right)-q h_{t}$ and $\omega_{q l, t+1} \sim$ $\Gamma(\overline{q l}, 1)-\overline{q l}$ denote the high and low pure risk aversion shocks, and $\omega_{i l l i q h, t+1} \sim \Gamma\left(i l l i q h_{t}, 1\right)-$ $i l l i q h_{t}$ and $\omega_{i l l i q l, t+1} \sim \Gamma\left(i l l i q l_{t}, 1\right)-i l l i q l_{t}$ denote the high and low pure illiquidity shocks. The six shocks are mutually independent and follow centered gamma distributions with timevarying shape parameters, except that, for simplicity, we characterize the low risk aversion fluctuation as homoskedastic (i.e., $\overline{q l}$ ) 11 Given the moment generating function of gamma shocks, the shape parameters govern the second and higher-order moments of these shocks. ${ }^{12}$ On their dynamic processes, we assume simple AR(1) processes for these shape parameters: $\forall x \in\left[\begin{array}{lllll}\theta p & \theta n & q h & \text { illiqh } & \text { illiql}\end{array}\right]$

$$
x_{t+1}=\mu_{x}+\rho_{x} x_{t}+\sigma_{x} \omega_{x, t+1} .
$$

Importantly, the dynamic framework above assumes non-zero correlations between level and second (or higher-order) moment shocks, which is likely to be realistic for the three fundamental processes of interest. For instance, consistent with Adrian, Boyarchenko, and Giannone (2019) and Bekaert and Popov (2019), when growth spurts are observed this period (a large $\omega_{\theta p, t}$ realization), we might expect a higher chance for future growth spurts (a higher $\theta p_{t}$ from the equation above, assuming $\left.\sigma_{\theta p}>0\right)$. Also, consistent with Colacito, Ghysels, Meng, and Siwasarit (2016), time-varying growth skewness - which is effectively captured by the timevarying shape parameters of growth gamma shocks - is a potentially important determinant of equity risk premiums. Moreover, the conditional variance of the relative risk aversion state

\footnotetext{
${ }^{11}$ This assumption is to capture the possibility that most of the heteroskedasticity in investor risk aversion is driven by high risk aversion events.

${ }^{12}$ For instance, the conditional variance and (unscaled) skewness of the economic growth, $\delta_{\theta, \theta p} \theta p_{t+1}-$ $\delta_{\theta, \theta n} \theta n_{t+1}$, can be derived in closed form as a function of two shape parameters; for instance, $\operatorname{Var}_{t}\left(\theta_{t+1}\right)=$ $\sigma_{\theta, \theta p}^{2} \theta p_{t}+\sigma_{\theta, \theta n}^{2} \theta n_{t}, \operatorname{Skew}_{t}\left(\theta_{t+1}\right)=2 \sigma_{\theta, \theta p}^{3} \theta p_{t}-2 \sigma_{\theta, \theta n}^{3} \theta n_{t}$.
} 
variable (inverse surplus consumption ratio) in Campbell and Cochrane (1999)-type models comoves positively with the the relative risk aversion state variable, suggesting a potentially positive relationship between risk aversion level and volatility (see $\mathrm{Xu}(2021)$ for a detailed proof). Therefore, the use of gamma shocks is suitable for our research as it efficiently summarizes conditional moments with one state variable, which allows us to focus on comparing across the different common risk premium determinants: good and bad macroeconomic uncertainty ( $\theta p_{t}$ and $\theta n_{t}$, respectively), risk aversion $\left(q h_{t}\right)$, and high and low stock market illiquidity uncertainty $\left(i l l i q h_{t}\right.$ and $i l l i q l_{t}$, respectively).

Finally, as illustrated in the loading matrix $\boldsymbol{\Sigma}_{\boldsymbol{m}}$, we allow business cycle (growth) shocks to enter both risk aversion and stock market illiquidity dynamics. We also allow market illiquidity to change with pure investor risk aversion shocks that are orthogonal to business cycle shocks, given recent empirical evidence that stock market liquidity and risk aversion appear positively associated (see e.g. ECB (2007)).

\subsection{Data and estimation}

We follow the empirical macro literature (e.g., Jurado, Ludvigson, and Ng (2015)) and use the change in the log US industrial production as the empirical proxy for economic growth $\theta_{t}$. Our data runs from January 1947 to December 2019 and is obtained from FRED. We use Bates (2006)'s approximate MLE methodology to estimate non-Gaussian fundamental shocks $\left(\omega_{\theta p, t}, \omega_{\theta n, t}\right)$ and uncertainty state variables $\left(\theta p_{t}, \theta n_{t}\right)$. Then, we filter our risk aversion state variable and shocks from the risk aversion state variable $\left(q_{t}\right)$ estimated in Bekaert, Engstrom, and $\mathrm{Xu}$ (forthcoming). Although measuring market-wide risk aversion is an ongoing debate, the Bekaert, Engstrom, and $\mathrm{Xu}$ (forthcoming) measure is potentially more suitable for our framework, given that it is filtered from a wide range of financial and risk variables while being consistent with a HARA utility assumption and equilibrium conditions and controlling for fundamental variable dynamics 13 Moreover, Bekaert, Engstrom, and $\mathrm{Xu}$ (forthcoming)'s measure is available at the monthly frequency. The longest available sample for risk aversion

\footnotetext{
${ }^{13}$ In contrast, Campbell and Cochrane (1999)'s risk aversion would not be suitable for our framework, as the measure is purely driven by past quarterly consumption growth (Wachter (2006)), which is still a fundamental variable. Miranda-Agrippino and Rey (2020) also provide a risk aversion measure, which is the residual of regressing their Global Financial Cycle series on current MSCI world realized return variance. Their measure is available at a higher frequency but is not suitable for our research because we mostly focus on US predictors (for the purposes of interpretation and construction consistency across predictors), while their measure is mostly interpreted as a global risk aversion proxy (using 858 price series from all geographical areas). Nevertheless, the Bekaert-Engstrom-Xu and the Miranda-Agrippino-Rey risk aversion measures are correlated at 0.7, which is not surprising given that the US has the largest market capitalization.
} 
starts in June of 1986. Finally, we follow Amihud (2002) to construct the stock market illiquidity measure $\left(i l l i q_{t}\right)$ using asset returns and volume data of the largest 500 stocks each month from the CRSP NYSE/AMEX/NASDAQ universe, and then filter our illiquidity state variables and shocks from January 1985 to December 2019.

\subsection{Results}

Table 5 shows standard summary statistics of the five time-varying risk premium determinants and Figure 6 shows their estimated dynamics during our sample. Detailed parameter estimates and long-sample time series plots are deferred to Appendix E. We now discuss several key observations about our five common risk premium determinants. First, given that a lower shape parameter indicates a more skewed gamma distribution, evidence from Table 5 implies that there is a higher chance of extreme values from the left tail of the real growth rate than from its right tail; moreover, $\theta p_{t}\left(\theta n_{t}\right)$ is procyclical (countercyclical) given the significant negative (positive) correlation with the NBER recession indicator. According to the first two plots of Figure 6, both good and bad uncertainty state variables are quite persistent. While $\theta p_{t}$ comoves mostly with the cyclical ups and downs, $\theta n_{t}$ captures excessively bad uncertainty events to industrial production, such as the impacts of Hurricane Katrina (September of 2005), the collapse of Lehman Brothers (October of 2008), and the US-China trade war (summer of 2018). The bad uncertainty contributes $67 \%$ (more during recessions) to the total conditional variance of economic growth 14

Second, the risk aversion state variable $q h_{t}$ captures the variability in the pure risk aversion shock that is cleansed from macroeconomic shocks. The estimated $q h_{t}$ process is strictly countercyclical and positively skewed, exhibiting moderate monthly persistence (0.57; Appendix E). The time series plot shows that risk aversion variability could also significantly spike in nonrecession episodes such as the Russian \& LTCM crisis, 9/11, and several corporate scandals during 2000s. To explain the total risk aversion variability 15 we find that macroeconomic shocks account for about $15 \%$.

Third, Amihud (2002)'s illiquidity measure is typically found to be quite persistent; during our sample period, we document a persistent coefficient of 0.95 . Table 5 shows that the high stock market illiquidity uncertainty, $i l l i q h_{t}$, is weakly countercyclical, while the expected

\footnotetext{
${ }^{14}$ The total conditional variance of economic growth is, $\operatorname{Var}_{t}\left(\theta_{t+1}\right)=\delta_{\theta, \theta p}^{2} \theta p_{t}+\delta_{\theta, \theta n}^{2} \theta n_{t}$.

${ }^{15}$ The total conditional variance of risk aversion is, $\operatorname{Var}_{t}\left(q_{t+1}\right)=\delta_{q, \theta p}^{2} \theta p_{t}+\delta_{q, \theta n}^{2} \theta n_{t}+\delta_{q, q h}^{2} q h_{t}+\delta_{q, q l}^{2} \overline{q l}$.
} 
liquidity shock fluctuation, $i l l i q l_{t}$, is acyclical, suggesting that these two state variables may be capturing a financial cycle that is orthogonal to the business cycle. From Figure 6 , illiql $_{t}$ appears more stable than $i l l i q h_{t}$, capturing an asymmetry that is consistent with Amihud (2019). Finally, we find that $73 \%$ of the total stock market illiquidity variability is explained by illiquidity uncertainties (mostly $i l l i q h_{t}$ ) and $26 \%$ by risk aversion, rendering a weak macroeconomic effect through stock market illiquidity state variables ${ }^{16}$

\section{Economic Interpretations}

In this section, we study potential economic interpretations of the dynamics and international predictability of DVP and UVP, which helps us understand the economic sources of the commonality in international equity risk premiums. Section 5.1 describes our estimation strategy; Section 5.2 provides evidence of model fit; and Section 5.3 presents the results.

\subsection{Estimation strategy}

\subsubsection{Loadings of US VP components on common risk premium determinants}

While our conceptual framework does not imply specific dynamics of DVP and UVP, we estimate separate loadings of DVP and UVP on the common risk premium state variables by jointly matching moments of empirical estimates of DVP and UVP in a GMM system ${ }^{17}$ In addition, given the empirical focus of the paper, we consider both constant and time-varying loadings. ${ }^{18}$ While scant research has discussed whether VP exhibits constant or time-varying loadings on its economic determinants, there is strong empirical evidence of time-varying stock return sensitivities on economic shocks (see e.g. Andersen, Bollerslev, Diebold, and Wu (2006), Baele, Bekaert, and Inghelbrecht (2010)), and our parsimonious framework demonstrates that return sensitivities are non-linearly connected to VP dynamics ( $\xi_{2}$ in Equation (13)).

\footnotetext{
${ }^{16}$ The total conditional variance of market illiquidity is, $\operatorname{Var}_{t}\left(i l l i q_{t+1}\right)=\delta_{i l l i q, \theta p}^{2} \theta p_{t}+\delta_{i l l i q, \theta n}^{2} \theta n_{t}+\delta_{i l l i q, q h}^{2} q h_{t}+$ $\delta_{i l l i q, q l}^{2} \overline{q l}+\delta_{\text {illiq,illiqh }}^{2}$ illiqh $_{t}+\delta_{\text {illiq,illiql }}^{2}$ illiqq $_{t}$.

${ }^{17}$ Granted, it is quite natural for one to consider using simple OLS projections to obtain these separate loadings. However, OLS regressions allow for residuals and do not guarantee dynamic moment matching; in addition, OLS regressions suffer from co-linearity given that, by design, our risk premium state variables comove with each other (e.g., risk aversion loads on growth shocks; see details in Section 4 and Appendix E. Both concerns can be jointly resolved using a GMM framework, which makes it appealing.

${ }^{18}$ Although constant loadings are not necessarily realistic, time-varying loadings cannot be straightforwardly implied from a standard no-arbitrage asset pricing framework. The reason is that such a model would involve recursively solving the moment generating functions of product of shocks, which does not always easily guarantee an exponential affine solution.
} 
Specifically, we compute the DVP and UVP candidates, denoted by $\widehat{v p_{t}^{D}}$ and $\widehat{v p_{t}^{U}}$, respectively, given the loading parameter candidates, denoted by $w$ :

$$
\begin{aligned}
& \widehat{v p_{t}^{D}}=v p_{0}^{D}+w_{\theta p, t}^{D} \widehat{\theta p}_{t}+w_{\theta n, t}^{D} \widehat{\theta n}_{t}+w_{q h, t}^{D} \widehat{q h}_{t}+w_{\text {illiqh }, t}^{D} \widehat{i l l i q h}_{t}+w_{i l l i q l, t}^{D} \widehat{i l l i q l}_{t}, \\
& \widehat{v p_{t}^{U}}=v p_{0}^{U}+w_{\theta p, t}^{U} \widehat{\theta p}_{t}+w_{\theta n, t}^{U} \widehat{\theta n}_{t}+w_{q h, t}^{U} \widehat{q h}_{t}+w_{\text {illiqh }, t}^{U} \widehat{i l l i q h}_{t}+w_{\text {illiql, }, \text { illiql }}^{U},
\end{aligned}
$$

where, for $x \in\{\theta p, \theta n, q h, i l l i q h, i l l i q l\}, \widehat{x}$ indicates the estimated risk premium state variables from Section 4 , and $w_{x, t}^{D}$ and $w_{x, t}^{U}$ indicate the corresponding loadings, which, in the time-varying version are linearly spanned by a common economic indicator $z_{t}$ :

$$
\begin{aligned}
& w_{x, t}^{D}=w_{x, 0}^{D}+w_{x, 1}^{D} z_{t}, \\
& w_{x, t}^{U}=w_{x, 0}^{U}+w_{x, 1}^{U} z_{t} .
\end{aligned}
$$

We use the squared real growth innovation as $z_{t}$ to reflect the general observation that the effects of economic shocks on returns are typically intensified in an uncertain economic environment (for reasons such as learning, David and Veronesi (2013), or arbitragers, Hong, Kubik, and Fishman (2012)). Next, we use the empirical estimates of the VP components from Section 2 to generate orthogonality conditions: mean, variance, scaled skewness, scaled kurtosis of DVP and UVP (8 moments), the covariance between DVP and UVP (1), and the fraction of the DVP in total VP (1). Each raw moment condition is then tensor-multiplied with a set of lagged instruments $\left\{1, \theta_{t-1}, q_{t-1}, i l l i q_{t-1}\right\}$. The GMM system has 40 moments and 22 unknowns, and is estimated iteratively.

\subsubsection{Loadings of international EP on common risk premium determinants}

Our core innovation is to exploit the cross-section of country-level predictive coefficients of two global predictors to identify the composition and dynamics of the global equity risk premium at within-one-year horizons. From Equations (14) and (15), one-month-ahead country equity risk premiums have a global part that linearly spans the common risk premium state variables. Because these common risk premium state variables follow $\mathrm{AR}(1)$ processes, the expectation of $\kappa$-month-ahead excess returns, $E P_{\kappa, t}^{i}$, should also linearly span these state variables. As a result, we consider the following consistent framework:

$$
\begin{aligned}
\widehat{E P}_{\kappa, t}^{i} & =v_{\theta p, \kappa, t}^{i} \widehat{\theta p}_{t}+v_{\theta n, \kappa, t}^{i} \widehat{\theta n}_{t}+v_{q h, \kappa, t}^{i} \widehat{q h}_{t}+v_{i l l i q h, \kappa, t}^{i} \widehat{i l l i q h}_{t}+v_{i l l i q l, \kappa, t}^{i} \widehat{i l l i q l}_{t} \\
& + \text { Idiosyncratic Part },
\end{aligned}
$$


where, for $x \in\{\theta p, \theta n, q h, i l l i q h, i l l i q l\}$, the country-level loadings are characterized by both economic and financial integration levels and by current realized variance:

$$
v_{x, \kappa, t}^{i}=v_{x, \kappa, 0}+v_{x, \kappa, 1} \text { EconomicIntegration }^{i}+v_{x, \kappa, 2} \text { FinancialIntegration }^{i}+v_{x, \kappa, 3} z_{t} .
$$

We use the average trade-to-GDP ratio (source: World Bank) to capture a country's economic integration (see e.g. Alesina, Spolaore, and Wacziarg (2000)) and the average total holdings (asset and liability) from country $i$ to the rest of the world (source: IMF, The Coordinated Portfolio Investment Survey) to capture a country's financial integration (see e.g. Schularick and Steger (2010) ${ }^{19}$ EconomicIntegration $^{i}$ and FinancialIntegration ${ }^{i}$ are standardized measures. Table 6 presents the country-level integration proxies (in percents) and classifies countries with relatively high $(\mathrm{H})$, medium/average $(\mathrm{M})$, and low $(\mathrm{L})$ integration for demonstration purposes. The two integration proxies are moderately correlated across countries $(\rho=0.48)$. Finally, note that the EP loadings on common economic determinants are expected to be less time-variant than the VP loadings given our model solution, or a weaker effect of $z_{t}{ }^{20}$

Taken together, the model-implied $\kappa$-month predictive coefficients of DVP and UVP for country $i$ are given by:

$$
\begin{gathered}
\widehat{b_{\kappa}^{i, D}} \equiv \frac{\operatorname{Cov}\left(\widehat{v p_{t}^{D}}, \widehat{E P_{\kappa, t}^{i}}\right)}{\operatorname{Var}\left(\widehat{v p_{t}^{D}}\right)}=\frac{\left(\boldsymbol{V}_{\kappa}^{\prime} \boldsymbol{\Xi} \boldsymbol{W}^{\boldsymbol{D}}\right)}{\left(\boldsymbol{W}^{\boldsymbol{D}} \boldsymbol{\Xi} \boldsymbol{\boldsymbol { W } ^ { D }}\right)}, \\
\widehat{b_{\kappa}^{i, U}} \equiv \frac{\operatorname{Cov}\left(\widehat{\left.v p_{t}^{U}, \widehat{E P_{\kappa, t}^{i}}\right)}\right.}{\operatorname{Var}\left(\widehat{v p_{t}^{U}}\right)}=\frac{\left(\boldsymbol{V}_{\kappa}^{\prime} \boldsymbol{\Xi} \boldsymbol{W}^{\boldsymbol{U}}\right)}{\left(\boldsymbol{W}^{\boldsymbol{U}} \boldsymbol{\Xi} \boldsymbol{\Xi} \boldsymbol{W}^{\boldsymbol{U}}\right)},
\end{gathered}
$$

where $\boldsymbol{V}_{\boldsymbol{\kappa}}$ is a vector matrix consisting of 20 unknown $v$ 's from Equation (21) for each horizon $\kappa$; $\boldsymbol{\Xi}$ is the covariance-variance matrix of $\theta p_{t}, \theta n_{t}, q h_{t}, i l l i q h_{t}, i l l i q l_{t}, \theta p_{t} z_{t}, \theta n_{t} z_{t}, q h_{t} z_{t}$, $i l l i q h_{t} z_{t}$, and $i l l i q l_{t} z_{t} ; \boldsymbol{W}^{\boldsymbol{D}}$ and $\boldsymbol{W}^{\boldsymbol{U}}$ are vector matrices consisting of 10 estimated parameters from Section 5.1.1: see Appendix $\mathrm{F}$ for their exact expressions. The estimation is conducted by minimizing the sum of squared standardized distances between model-implied and empirical country-level predictive coefficients $\left(22 \widehat{b_{\kappa}^{i, D}}, \mathrm{~s}\right.$ and $\left.22 \widehat{b_{\kappa}^{i, U}} \mathrm{~s}\right)$; the empirical estimates of international predictive coefficients of DVP and UVP are discussed in Section 2, We estimate the system one horizon at a time (for twelve horizons) using a grid of 10,000 initial value combinations.

\footnotetext{
${ }^{19}$ The data are obtained from Tables 1 and 8 from https://data.imf.org/?sk= B981B4E3-4E58-467E-9B90-9DE0C3367363\&sId=1481568994271. The first available year is 2001.

${ }^{20}$ Analytically, according to Equations $(13)$ and $[14)$, kernel and return sensitivities to shocks $\left(m_{2}\right.$ 's and $\xi_{2}$ 's, respectively) determine both the VP and EP loadings. A linear approximation to the VP (EP) loading is $2\left(\boldsymbol{\xi}_{\mathbf{2}} \boldsymbol{\Sigma}\right)^{\circ 2} \circ \boldsymbol{m}_{\mathbf{2}} \boldsymbol{\Sigma}\left(-\boldsymbol{m}_{\mathbf{2}} \boldsymbol{\Sigma} \circ \boldsymbol{\xi}_{\mathbf{2}} \boldsymbol{\Sigma}\right)$. Suppose kernel and return sensitivities double; it can be easily shown that the VP loadings would increase much more than that the EP loadings. Economically, while stock and volatility pricing may reflect similar risk factors (and hence VP exhibits predictability), VP is not the appropriate direct proxy for EP as the underlying asset is more non-linear (by design) in VP.
} 


\subsection{Model fit}

Table 7 presents the moment matching results and test specifications of the GMM system for the dynamics of the VP components (Section 5.1.1) with constant loadings $\left(w_{x, 1}^{D}=w_{x, 1}^{U}=0\right.$ in Equation (19) ) or time-varying loadings. The constant-loading model is immediately rejected, according to the Hansen's $J$ overidentification test statistic value and poor moment matching. On the other hand, for the time-varying loading model, we fail to reject the null hypothesis that the extra moments in this model are valid; moreover, all moments are significantly close to their empirical counterparts. In particular, DVP is larger in magnitude and more volatile, explaining an average of $92.7 \%$ of the total variance risk premium during the sample period.

Next, we evaluate the dynamic fit of DVP and UVP. Figure 7 compares the model-implied monthly VP components with their respective empirical estimates. Our model-implied DVP and UVP estimates from the time-varying loading model (solid lines) are highly correlated with their empirical counterparts (dashed lines) at 0.88 and 0.48 , respectively. In constrast, the DVP and UVP estimates implied from the constant-loading model (dotted lines) show weaker correlations with empirical estimates at 0.74 and 0.16 , respectively. Given that the constantloading model fails the overidentification test and exhibits a weaker correlation with empirical estimates, in the remainder of the paper, we focus on the time-varying loading model for the VP components.

Table 8 illustrates the fit of international predictive coefficient estimates of DVP and UVP by evaluating the fit of model-implied mean, median, and standard deviation of the 22 country predictive coefficients at each horizon. From Panel A, the model fits the level and the cross-country dispersion of the DVP predictive coefficients quite well. Most model moments are within the 1.96 standard deviations of the empirical counterparts. If we only consider horizons when most countries' DVP predictive coefficients are significant in the empirical evidence (i.e., horizon between two and seven months), all model moments are statistically close to their empirical counterparts. From Panel B, the model-implied level and cross-country dispersion of UVP predictive coefficients are statistically close to their empirical counterparts, except for the dispersion statistics at the 3- and 4-month horizons. In general, our evidence suggests that the integration measures, as conjectured in Equation (21), have the potential to explain the crosscountry dispersion in the predictive coefficients. This evidence is, to the best of our knowledge, new to the literature. 
Finally, we discuss two other observations from Table 8 that are consistent with the empirical evidence. First, both the mean and the median of country predictive coefficients for the 22 countries are statistically close to the panel-data estimates (in Table 3) and to each other, suggesting that there may not exist major skewness in the cross section of country predictive coefficients. Second, there is more cross-country heterogeneity at shorter horizons, suggesting that there may be more cross-country differences in pricing common/global shocks at the short term than at the long term.

\subsection{Economic interpretations}

We now return to the empirical evidence and discuss economic interpretations of (1) the dynamics of the VP components, (2) their stock return predictability in an "average" country, which speaks to the global- or panel-level interpretations, and (3) their stock return predictability in countries with low/high economic and financial integration levels, which speaks to the country-level interpretations.

\subsubsection{The dynamics of the VP components}

Table 9 presents the estimation results of the parameters from Equation 18 and the variance contribution of each premium state variable (see rows "VARC\%"). From this table, DVP loads strongly and positively on variations in "pure" risk aversion $\left(q h_{t}\right)$ that are not explained by the business cycle fluctuations. According to the variance decomposition results, $q h_{t}$ accounts for most of the explained dynamics of DVP, $62.49 \%$, of which, $10.29 \%$ is explained by the time-varying component of the coefficient. This evidence suggests that DVP increases with pure risk aversion more strongly when the current market and business cycle condition is volatile, given the significant and positive $w_{q h, 1}^{D}$ estimate. The bad economic uncertainty, $\theta n_{t}$, captures about $30 \%$ of the explained DVP dynamics. Different from risk aversion, bad uncertainty may exhibit slightly lower explanatory power in the DVP dynamics when the current business condition is volatile, given the significant but negative $w_{\theta n, 1}^{D}$ estimate. On the other hand, the state variable capturing high-end, right-tail fluctuations in stock market illiquidity, $i l l i q h_{t}$, appears to contribute positively to the DVP dynamics during volatile periods; the corresponding VARC of around $9 \%$ is economically sizable.

Table 10 provides the economic magnitudes of these VP loadings at various values of the current economic condition, which is characterized by the realized variance of economic 
growth, $z_{t}$. Because $z_{t}$ is right skewed and is always greater than 0 , we calibrate several useful scenarios when $z_{t}$ equals the mean, 90th, 95th, and 99th percentile of its distribution. We find that, under normal conditions ( $z_{t}$ at mean), one standard deviation (SD) increase in risk aversion is associated with the largest increase in DVP (around 9 monthly percentage squared), while bad uncertainty shows the second largest increase (around 6), which is consistent with the evidence in Table 9. Under more extreme economic conditions, one SD high illiquidity uncertainty corresponds to an increase of 9.9 monthly percentage squared in DVP, which is comparable in magnitude to the marginal impact of one SD risk aversion (11.3).

From the second parts of Tables 9 and 10 , under normal conditions, good economic uncertainty, risk aversion, and fluctuations in stock market liquidity all contribute positively to the variability of UVP ${ }^{21}$ Earlier in Table 5, we show that good economic uncertainty is a significantly procyclical state variable, while risk aversion and high illiquidity risk are strictly countercyclical. Thus, our evidence suggests that UVP increases with the procyclical good economic uncertainty through the hedging demand of upside volatility risk; in addition, UVP also increases with the countercyclical risk aversion and market illiquidity risk through the general risk compensation intuition (higher compensation demanded when risk aversion and/or pure financial market risk increases). These counteracting effects, with the first channel being slightly stronger, explain the procyclical and relatively less persistent UVP dynamics documented in Section 2.2 ,

Interestingly, the positive relation between good uncertainty and UVP is quite sensitive to the current economic condition. During extremely volatile months when $z_{t}$ is high, good economic uncertainty contributes less positively to UVP, leading to sudden drops in the UVP level (such as the one in October 2008). This is formally captured by the negative $w_{\theta p, 1}^{U}$ coefficient estimate (Table 9) and the decreasing UVP loading on $\theta p_{t}$ as $z_{t}$ increases (Table 10p). One possible explanation is that an economic fallout leads to less demand to hedge against future upside variance risk.

\footnotetext{
${ }^{21}$ The variance contribution is calculated as $\frac{\beta_{x} \operatorname{cov}\left(x_{t}, \widehat{y_{t}}\right)}{\widehat{y t}_{t}} \times 100 \%$, where $x_{t}$ denotes an explanatory variable, $\beta_{x}$ the corresponding loading, and $\widehat{y_{t}}$ the total explained dependent variable. Note that, if $\beta_{x}$ and $\operatorname{cov}\left(x_{t}, \widehat{y_{t}}\right)$ have different signs, the variance contribution from variable $x_{t}$ can be negative. This suggests that $x_{t}$ might also comove with the unexplained part of the dependent variable, which makes implications about that particular explanatory variable not as reliable as those with positive VARCs.
} 


\subsubsection{International stock return predictability}

A Global View. Figure 8-(A) shows the model-implied changes in an average country's equity risk premium (EP) given one SD increase in a common risk premium state variable ${ }^{22}$ Equity risk premiums are expressed in annualized percents. For horizons up to 7 months, where we center the attention, the three main common risk premium sources - US economic uncertainty, risk aversion, and illiquidity uncertainty - contribute positively to the average country's equity risk premium. The sensitivities of global equity risk premiums to these premium state variables change with the horizon. Both good and bad economic uncertainties contribute positively to the global equity risk premium, which is potentially consistent with theoretical suggestions in a pure domestic setting from Segal, Shaliastovich, and Yaron (2015) (e.g., pp.375). However, the positive effects of bad economic uncertainty, $\theta n_{t}$, becomes dominant in contributing to the global equity risk premium at the 4-month or longer horizon. In contrast, risk aversion and pure financial uncertainty (stock market illiquidity uncertainty) have stable and positive effects for all horizons; one SD risk aversion, $q h_{t}$, or high illiquidity uncertainty, $i l l i q h_{t}$, leads to between two and three annualized percent increases in the global equity risk premium. These results suggest that, among economic uncertainty, risk aversion, and financial uncertainty, economic risk compensations may be more crucial at short horizons. To directly demonstrate this point, Figure 9 depicts the variance decomposition of the model-implied global equity risk compensation at various horizons (see solid lines denoted as "MM" for the global-level view), and shows that economic uncertainty explains about $70-80 \%$ at horizons under 7 months.

We next illustrate the relative importance of the five common premium state variables in explaining the predictive coefficients of the VP components. We use a Jackknife exercise. Specifically, we replace the equity premium loading on a particular premium state variable with 0 and recompute the implied predictive coefficient. As a result, the lower the implied coefficient is, the more important the state variable is in explaining the predictability. This can be accomplished given our unique estimation strategy.

Figure 8-(B) depicts the implied coefficients and focuses on horizons with significant pre-

\footnotetext{
${ }^{22}$ While the dynamic fitting of the VP components improves by allowing time-varying loadings on the common risk premium state variables (see earlier discussions in Section 5.2 and evidence in Figure 7), we find little evidence that $z_{t}$ plays an economically important role in determining international equity risk premiums at the horizons of interests. In other words, the $v_{x, \kappa, 3}$ coefficient estimate in Equation 21] is economically small. In Appendix G we compare the EP loadings when $z_{t}$ is $\min \left(z_{t}\right)$ or $\max \left(z_{t}\right)$, and find that they are extremely close. The intuition is first mentioned in Footnote 20 This observation hence motivates the use of $\operatorname{mean}\left(z_{t}\right)$ in creating and discussing Figures 8 and 11
} 
dictability across countries in our empirical evidence. The top plot shows that the DVP predictive coefficient decreases most saliently after deleting the bad economic uncertainty channel, $\theta n_{t}$, or the risk aversion channel, $q h_{t}$; between the two, $\theta n_{t}$ dominates. While $\theta n_{t}$ explains merely $30 \%$ of the DVP dynamics, we find that DVP predicts international stock excess returns mostly through the bad economic risk compensation channel. In addition, the bottom plot shows that the good economic uncertainty channel is potentially crucial for explaining the pattern and magnitude of the international predictability of UVP.

As a validation exercise, Figure 10 depicts the model-implied global equity risk compensation demanded by the US/global investor at 3-, 6-, and 12-month horizons. The first observation is that the model-implied global risk compensations at various horizons are all generally countercyclical, which is consistent with the literature. Second, on average, the global risk compensation is smaller at longer horizons (see the dotted line), which suggests a downwardsloping term structure of common global risk compensation in international equity markets, adding to the recent discussions considering the US equity market only (see e.g. Boguth, Carlson, Fisher, and Simutin (2011), Van Binsbergen, Brandt, and Koijen (2012), Van Binsbergen, Hueskes, Koijen, and Vrugt (2013), Croce, Lettau, and Ludvigson (2015)). Third, the shortterm global risk compensation appears to be particularly higher than the long-term counterpart during high economic uncertainty periods; for instance, the good uncertainty spikes of 1998 and the bad uncertainty spikes of 2007-2008. This finding is consistent with Figure 8, where we show that economic uncertainties may be more important risk premium determinants at short horizons, while risk aversion and pure financial market uncertainty likely determine the whole term structure.

A Cross-Country View. We complement our average country analysis and calibrate the results considering country groups with low and high integration. Specifically, we consider four country groups with low/high economic and financial integration, where "low" ("high") uses the 33th (67th) value of the cross-country integration level (see Table 6).

Figure 11 demonstrates that US/global investors may demand a lower global economic risk compensation but a higher global financial market risk compensation for countries with higher integration (especially financial integration). The former result is potentially consistent with the international risk sharing story where global investors demand a lower risk compensation given a lower cost of capital, greater firm and fundamental investment opportunities, and 
higher expected growth (Bekaert and Harvey (2003); Carrieri, Errunza, and Hogan (2007)); the latter result is potentially consistent with the increasing chance of higher global systemic risk exposure that cannot be diversified away. Moreover, the relative importance of market-wide risk aversion is also slightly higher for countries with higher integration. Note that, while the two integration measures are able to generate a realistic cross-section of predictive coefficients (see Table 8), these integration measures are also moderately correlated at 0.48 ; which suggests that distinguishing the effects of the two integration types is challenging.

Figure 12 conducts similar Jackknife exercises for these four country groups. Panel (A) shows that the high (low) integration country return predictability is mainly through the financial market risk aversion (economic uncertainty) channel, as the bar size drops more significantly after deleting this channel. This result is consistent with Figure 11. As similarly seen in the average country analysis, Panel (B) illustrates a significant role of good uncertainty in explaining the predictability of UVP, which is even more salient for low integration countries.

\section{Conclusion}

Understanding the commonality in international equity risk premiums and the transmission of global risks across international financial markets remains an open debate in the literature. In this paper, we add to this debate by using a novel approach in which we link empirical evidence for the international stock return predictability of US downside and upside variance risk premiums with the implications of an asset pricing framework using data for 22 countries from 1991 to 2019.

We find that the international predictability patterns of DVP (positive and countercyclical) and UVP (smaller in magnitude and procyclical) are considerably different, with DVP being a robust mid-horizon (4-7 month) predictor and UVP a short-horizon (1-3 month) predictor. We link these results to the implications of a conceptual asset pricing framework that takes the perspective of a US/global investor and features heteroskedastic and asymmetric US macroeconomic, financial market (illiquidity), and risk aversion shocks. The main intuition from the model solution is that international stock return predictability should be determined by common economic determinants of the VP components and global equity risk compensations. We find that DVP and UVP predict international stock returns through different common risk premium determinants, mainly bad and good US macroeconomic uncertainties, respectively. 
At the country level, our results also suggest that US/global investors demand a lower global macroeconomic risk compensation but a higher global pure financial market risk compensation for countries with higher integration.

Our approach of linking international predictability evidence with an asset pricing framework allows us to use more information to infer the global nature of risk compensations across time, across horizons, and across countries. This methodology should naturally inspire several extensions of our work, including examining whether global risk premium determinants transmit through local-currency equity risk pricing or through exchange rate channels, involving other international finance puzzles similar to the work in Colacito and Croce (2010) and Colacito, Croce, Gavazzoni, and Ready (2018). Moreover, future work should integrate our findings to existing general equilibrium models with an international perspective. 


\section{References}

Adrian, T., Boyarchenko, N., Giannone, D., 2019. Vulnerable growth. American Economic Review 109, $1263-89$.

Adrian, T., Etula, E., Muir, T., 2014. Financial intermediaries and the cross-section of asset returns. The Journal of Finance 69, 2557-2596.

Aldasoro, I., Avdjiev, S., Borio, C. E., Disyatat, P., 2020. Global and domestic financial cycles: variations on a theme .

Alesina, A., Spolaore, E., Wacziarg, R., 2000. Economic integration and political disintegration. American Economic Review 90, 1276-1296.

Amihud, Y., 2002. Illiquidity and stock returns: cross-section and time-series effects. Journal of financial markets $5,31-56$.

Amihud, Y., 2019. Illiquidity and stock returns: A revisit. Critical Finance Review 8, 203-221.

Andersen, T. G., Bollerslev, T., Diebold, F. X., Wu, G., 2006. Realized beta: Persistence and predictability. Advances in econometrics 20, 1-39.

Andersen, T. G., Bondarenko, O., 2009. Dissecting the market pricing of return volatility. Working paper .

Ang, A., Bekaert, G., 2007. Return predictability: Is it there? Review of Financial Studies 20, 651-707.

Avdjiev, S., Gambacorta, L., Goldberg, L. S., Schiaffi, S., 2020. The shifting drivers of global liquidity. Journal of International Economics 125, 103324.

Baele, L., Bekaert, G., Inghelbrecht, K., 2010. The determinants of stock and bond return comovements. The Review of Financial Studies 23, 2374-2428.

Baele, L., Driessen, J., Ebert, S., Londono, J. M., Spalt, O., 2019. Cumulative prospect theory, option returns, and the variance premium. The Review of Financial Studies 32, 3667-3723.

Bansal, R., Yaron, A., 2004. Risks for the long run: A potential resolution of asset pricing puzzles. The journal of Finance 59, 1481-1509.

Bates, D. S., 2006. Maximum likelihood estimation of latent affine processes. The Review of Financial Studies 19, 909-965.

Bekaert, G., Engstrom, E., 2017. Asset return dynamics under habits and bad environment-good environment fundamentals. Journal of Political Economy 125, 713-760.

Bekaert, G., Engstrom, E., Ermolov, A., 2015. Bad environments, good environments: A non-gaussian asymmetric volatility model. Journal of Econometrics 186, 258-275.

Bekaert, G., Engstrom, E., Xing, Y., 2009. Risk, uncertainty, and asset prices. Journal of Financial Economics 91, 59-82.

Bekaert, G., Engstrom, E., Xu, N. R., forthcoming. The time variation in risk appetite and uncertainty. Management Science .

Bekaert, G., Harvey, C. R., 2003. Emerging markets finance. Journal of Empirical Finance 10, 3-55.

Bekaert, G., Harvey, C. R., Kiguel, A., Wang, X., 2016. Globalization and asset returns. The annual review of financial eocnomics 8, 221-288.

Bekaert, G., Hoerova, M., 2014. The vix, the variance premium and stock market volatility. Journal of Econometrics 183, 181-192.

Bekaert, G., Hoerova, M., Xu, N. R., 2020. Risk, monetary policy and asset prices in a global world. Available at SSRN 3599583.

Bekaert, G., Popov, A., 2019. On the link between the volatility and skewness of growth. IMF Economic Review 67, 746-790. 
Boguth, O., Carlson, M., Fisher, A., Simutin, M., 2011. Dividend strips and the term structure of equity risk premia: A case study of the limits of arbitrage. Unpublished Paper, University of British Columbia, Sauder School of Business .

Bollerslev, T., Marrone, J., Xu, L., Zhou, H., 2014. Stock return predictability and variance risk premia: statistical inference and international evidence. Journal of Financial and Quantitative Analysis 49, 633-661.

Bollerslev, T., Tauchen, G., Zhou, H., 2009. Expected stock returns and variance risk premia. The Review of Financial Studies 22, 4463-4492.

Bonciani, D., Ricci, M., 2020. The international effects of global financial uncertainty shocks. Journal of International Money and Finance 109, 102236.

Britten-Jones, M., Neuberger, A., 2000. Option prices, implied price processes, and stochastic volatility. The Journal of Finance 55, 839-866.

Brunnermeier, M. K., Pedersen, L. H., 2009. Market liquidity and funding liquidity. The review of financial studies 22, 2201-2238.

Campbell, J. Y., Cochrane, J. H., 1999. By force of habit: A consumption-based explanation of aggregate stock market behavior. Journal of political Economy 107, 205-251.

Carrieri, F., Errunza, V., Hogan, K., 2007. Characterizing world market integration through time. Journal of Financial and Quantitative Analysis pp. 915-940.

Colacito, R., Croce, M. M., 2010. The short and long run benefits of financial integration. American Economic Review 100, 527-31.

Colacito, R., Croce, M. M., Gavazzoni, F., Ready, R., 2018. Currency risk factors in a recursive multicountry economy. The Journal of Finance 73, 2719-2756.

Colacito, R., Ghysels, E., Meng, J., Siwasarit, W., 2016. Skewness in expected macro fundamentals and the predictability of equity returns: Evidence and theory. The Review of Financial Studies 29, 2069-2109.

Corsi, F., 2009. A simple approximate long-memory model of realized volatility. Journal of Financial Econometrics $7,174-196$.

Croce, M. M., Lettau, M., Ludvigson, S. C., 2015. Investor information, long-run risk, and the term structure of equity. The Review of Financial Studies 28, 706-742.

David, A., Veronesi, P., 2013. What ties return volatilities to price valuations and fundamentals? Journal of Political Economy 121, 682-746.

De Groot, O., 2015. Solving asset pricing models with stochastic volatility. Journal of Economic Dynamics and Control 52, 308-321.

Drechsler, I., 2013. Uncertainty, time-varying fear, and asset prices. The Journal of Finance 68, 1843-1889.

Drechsler, I., Yaron, A., 2010. What's vol got to do with it. The Review of Financial Studies 24, 1-45.

ECB, 2007. Measuring financial market liquidity and risk aversion interdependence. ECB Financial Stability Review pp. December, 176-181.

Eraker, B., Shaliastovich, I., 2008. An equilibrium guide to designing affine pricing models. Mathematical Finance: An International Journal of Mathematics, Statistics and Financial Economics 18, 519-543.

Fan, J., Imerman, M. B., Dai, W., 2016. What does the volatility risk premium say about liquidity provision and demand for hedging tail risk? Journal of Business and Economic Statistics 34, 519-535.

Feunou, B., Jahan-Parvar, M. R., Okou, C., 2017. Downside variance risk premium. Journal of Financial Econometrics 16, 341-383.

Fulop, A., Li, J., Yu, J., 2015. Self-exciting jumps, learning, and asset pricing implications. The Review of Financial Studies 28, 876-912.

Gabaix, X., 2012. Rare disasters: An exactly solved framework for ten puzzles in macro-finance. The Quarterly Journal of Economics 127, 645-700. 
Graham, J. R., Harvey, C. R., 2005. The long-run equity risk premium. Finance Research Letters 2, $185-194$.

Gromb, D., Vayanos, D., 2002. Equilibrium and welfare in markets with financially constrained arbitrageurs. Journal of financial Economics 66, 361-407.

Held, M., Kapraun, J., Omachel, M., Thimme, J., 2020. Up-and downside variance risk premia in global equity markets. Journal of Banking and Finance 118.

Hong, H., Kubik, J. D., Fishman, T., 2012. Do arbitrageurs amplify economic shocks? Journal of Financial Economics 103, 454-470.

Jurado, K., Ludvigson, S. C., Ng, S., 2015. Measuring uncertainty. American Economic Review 105, 1177-1216.

Kilic, M., Shaliastovich, I., 2019. Good and bad variance premia and expected returns. Management Science 65, 2445-2945.

Kose, M. A., Prasad, E., Rogoff, K., Wei, S.-J., 2009. Financial globalization: a reappraisal. IMF Staff papers $56,8-62$.

Londono, J. M., 2015. The variance risk premium around the world .

Martin, I., 2017. What is the expected return on the market? The Quarterly Journal of Economics 132, 367-433.

Miranda-Agrippino, S., Rey, H., 2020. Us monetary policy and the global financial cycle. The Review of Economic Studies 6, 2754-2776.

Patton, A. J., Sheppard, K., 2015. Good volatility, bad volatility: Signed jumps and the persistence of volatility. Review of Economics and Statistics 97, 683-697.

Rapach, D. E., Strauss, J. K., Zhou, G., 2013. International stock return predictability: what is the role of the united states? The Journal of Finance 68, 1633-1662.

Schularick, M., Steger, T. M., 2010. Financial integration, investment, and economic growth: evidence from two eras of financial globalization. The Review of Economics and Statistics 92, 756-768.

Segal, G., Shaliastovich, I., Yaron, A., 2015. Good and bad uncertainty: Macroeconomic and financial market implications. Journal of Financial Economics 117, 369-397.

Van Binsbergen, J., Brandt, M., Koijen, R., 2012. On the timing and pricing of dividends. American Economic Review 102, 1596-1618.

Van Binsbergen, J., Hueskes, W., Koijen, R., Vrugt, E., 2013. Equity yields. Journal of Financial Economics 110, $503-519$.

Wachter, J. A., 2006. A consumption-based model of the term structure of interest rates. Journal of Financial economics 79, 365-399.

Xu, N. R., 2019. Global risk aversion and international return comovements .

$\mathrm{Xu}$, N. R., 2021. Procyclicality of the comovement between dividend growth and consumption growth. Journal of Financial Economics 139, 288-312.

Zhou, H., 2018. Variance risk premia, asset predictability puzzles, and macroeconomic uncertainty. Annual Review of Financial Economics 10, 481-497. 
Table 1: Expected downside and upside realized variances

This table shows the coefficients associated with the predictors of one-month-ahead (22 days) downside and upside realized variances, in panels A and B, respectively. The specification in column (1) assumes that realized variances follow a Martingale $\left(E\left(r v_{t+1}^{i}\right)=r v_{t}^{i}\right.$, for $i=D, U$ (downside or upside)). For the specifications in columns (2) to (5), we estimate the following regression setting:

$$
E_{t}\left(r v_{t+1 m}^{i}\right)=\hat{\alpha}^{i}+\hat{\gamma}^{\mathbf{i}} \mathbf{X}_{\mathbf{t}}^{\mathbf{i}}
$$

We consider the following predictors, $\mathbf{X}_{\mathbf{t}}$, at time $t$ : the total realized variance calculated over the last month $\left(r v_{t-1 m, t}\right)$ and its downside an upside components $\left(r v_{t-1 m, t}^{i}\right)$; realized semivariances calculated using either the last five days $\left(r v_{t-5 d, t}^{i}\right)$ or the last day of the month $\left(r v_{t-1 d, t}^{i}\right)$; and the downside and upside components of the option-implied variance $\left(i v_{t, t+1 m}^{i}\right)$. All regressions are estimated using daily data. The sample runs from April 1991 to December 2019. Heteroskedasticity and autocorrelation consistent (HAC) standard deviations with 44 lags are reported in parentheses. ${ }^{* * *}\left({ }^{* *},{ }^{*}\right)$ represent significance at the $1 \%(5 \%, 10 \%)$ confidence level. The adjusted $R^{2}$ s are reported at the end of each panel.

\begin{tabular}{|c|c|c|c|c|c|}
\hline & $(1)$ & $(2)$ & $(3)$ & $(4)$ & $(5)$ \\
\hline \multicolumn{6}{|c|}{ Panel A. Downside realized variance } \\
\hline Constant & 0 & $4.17^{* * *}$ & $4.11^{* * *}$ & $3.88^{* * *}$ & $3.18^{* * *}$ \\
\hline & - & $(0.63)$ & $(0.67)$ & $(0.55)$ & $(1.00)$ \\
\hline$r v_{t-1 m, t}$ & & & $\begin{array}{c}0.43 \\
(0.36)\end{array}$ & & \\
\hline$r v_{t-1 m, t}^{D}$ & 1 & $\begin{array}{c}0.62^{* * *} \\
(0.07)\end{array}$ & $\begin{array}{l}0.10 \\
(0.21)\end{array}$ & $\begin{array}{l}0.29^{* *} \\
(0.13)\end{array}$ & $\begin{array}{c}0.23^{* * *} \\
(0.08)\end{array}$ \\
\hline$r v_{t-5 d, t}^{D}$ & & & & $\begin{array}{c}0.29^{* *} \\
(0.13)\end{array}$ & $\begin{array}{l}0.27^{*} \\
(0.15)\end{array}$ \\
\hline$r v_{t-1 d, t}^{D}$ & & & & $\begin{array}{c}0.06^{* * * *} \\
(0.01)\end{array}$ & $\begin{array}{l}0.04^{*} \\
(0.03)\end{array}$ \\
\hline$i v_{t, t+1 m}^{D}$ & & & & & $\begin{array}{c}0.08 \\
(0.10)\end{array}$ \\
\hline Adj. $R^{2}$ & 0.23 & 0.378 & 0.378 & 0.428 & 0.429 \\
\hline \multicolumn{6}{|c|}{ Panel B. Upside realized variance } \\
\hline Constant & $\begin{array}{l}0 \\
-\end{array}$ & $\begin{array}{c}3.73^{* * *} \\
(0.64)\end{array}$ & $\begin{array}{c}3.80^{* * *} \\
(0.64)\end{array}$ & $\begin{array}{c}3.39^{* * *} \\
(0.59)\end{array}$ & $\begin{array}{c}0.84 \\
(0.73)\end{array}$ \\
\hline$r v_{t-1 m, t}$ & & & $\begin{array}{l}-0.60 \\
(0.40)\end{array}$ & & \\
\hline$r v_{t-1 m, t}^{U}$ & 1 & $\begin{array}{c}0.64^{* * *} \\
(0.08)\end{array}$ & $\begin{array}{c}0.61^{* * *} \\
(0.17)\end{array}$ & $\begin{array}{c}0.30^{* *} \\
(0.15)\end{array}$ & $\begin{array}{l}0.07 \\
(0.11)\end{array}$ \\
\hline$r v_{t-5 d, t}^{U}$ & & & & $\begin{array}{c}0.30^{* *} \\
(0.15)\end{array}$ & $\begin{array}{c}0.24 \\
(0.15)\end{array}$ \\
\hline$r v_{t-1 d, t}^{U}$ & & & & $\begin{array}{c}0.05^{* * * *} \\
(0.01)\end{array}$ & $\begin{array}{c}0.03^{* *} \\
(0.01)\end{array}$ \\
\hline$i v_{t, t+1 m}^{U}$ & & & & & $\begin{array}{c}0.57^{* * * *} \\
(0.11)\end{array}$ \\
\hline Adj. $R^{2}$ & 0.29 & 0.414 & 0.433 & 0.461 & 0.499 \\
\hline
\end{tabular}


Table 2: Summary statistics for variance premium components

This table reports time series averages of the monthly risk-neutral and physical expectations of the variances $\left(i v_{t, t+1}\right.$ and $E_{t}\left(r v_{t, t+1}\right)$, respectively) as well as the corresponding monthly variance premiums (VPs). The monthly time series are end-of-month estimates from Table 1. All measures are in units of monthly variancei.e., in annual percentage squared divided by 12 (as commonly used in the literature; see, e.g., Bekaert and Hoerova (2014), Kilic and Shaliastovich (2019), among many others). For VP estimates, we also report standard deviations and minimum and maximum values. The sample runs from April 1991 to December 2019.

\begin{tabular}{|c|c|c|c|c|c|}
\hline & (1) & $(2)$ & $(3)$ & $\overline{(4)}$ & $\overline{(5)}$ \\
\hline \multicolumn{6}{|c|}{ Panel A. DVP } \\
\hline $\operatorname{Mean}\left(i v_{t, t+1}^{D}\right)$ & 23.67 & 23.67 & 23.67 & 23.67 & 23.67 \\
\hline $\operatorname{Mean}\left(E_{t}\left(r v_{t, t+1}^{D}\right)\right)$ & 10.87 & 7.04 & 7.08 & 7.05 & 7.69 \\
\hline $\operatorname{Mean}\left(v p_{t, t+1}^{D}\right)$ & 12.79 & 16.63 & 16.58 & 16.61 & 15.97 \\
\hline$S D\left(v p_{t, t+1}^{D}\right)$ & 11.24 & 14.08 & 14.10 & 13.85 & 13.52 \\
\hline $\operatorname{Min}\left(v p_{t, t+1}^{D}\right)$ & -23.49 & 2.47 & 2.41 & 2.21 & 2.24 \\
\hline $\operatorname{Max}\left(v p_{t, t+1}^{D}\right)$ & 81.25 & 97.91 & 99.64 & 91.00 & 93.05 \\
\hline \multicolumn{6}{|c|}{ Panel B. UVP } \\
\hline $\operatorname{Mean}\left(i v_{t, t+1}^{U}\right)$ & 11.03 & 11.03 & 11.03 & 11.03 & 11.03 \\
\hline $\operatorname{Mean}\left(E_{t}\left(r v_{t, t+1}^{U}\right)\right)$ & 10.50 & 7.07 & 7.02 & 7.34 & 9.76 \\
\hline $\operatorname{Mean}\left(v p_{t, t+1}^{U}\right)$ & 0.53 & 3.96 & 4.01 & 3.69 & 1.26 \\
\hline$S D\left(v p_{t, t+1}^{U}\right)$ & 9.76 & 6.19 & 6.15 & 6.30 & 3.28 \\
\hline $\operatorname{Min}\left(v p_{t, t+1}^{U}\right)$ & -138.25 & -59.87 & -64.41 & -62.93 & -35.48 \\
\hline $\operatorname{Max}\left(v p_{t, t+1}^{U}\right)$ & 23.27 & 31.07 & 22.70 & 26.17 & 9.56 \\
\hline \multicolumn{6}{|c|}{ Panel C. Correlations within models } \\
\hline $\operatorname{Correl}\left(v p_{t, t+1}, v p_{t, t+1}^{D}\right)$ & 0.85 & 0.95 & 0.94 & 0.93 & 0.97 \\
\hline $\operatorname{Correl}\left(v p_{t, t+1}, v p_{t, t+1}^{U}\right)$ & 0.79 & 0.69 & 0.65 & 0.59 & 0.26 \\
\hline $\operatorname{Correl}\left(v p_{t, t+1}^{U}, v p_{t, t+1}^{D}\right)$ & 0.35 & 0.43 & 0.36 & 0.25 & 0.03 \\
\hline
\end{tabular}


Table 3: International predictability of VP and its components

The table reports evidence for the predictability of the variance premium and its components for international stock returns at various horizons of interest (in units of months). Our main specification is the following:

$$
\kappa^{-1} r_{i, t, t+\kappa}=a_{i, \kappa}+a_{\kappa}+b_{\kappa, D} v p_{t, t+1}^{D}+b_{\kappa, U} v p_{t, t+1}^{U}+\epsilon_{i, t+\kappa},
$$

where $r_{i, t, t+\kappa}$ denotes the $\kappa$-month-ahead log excess returns for country $i$ and $v p_{t, t+1}^{D}$ and $v p_{t, t+1}^{U}$ denote DVP and UVP estimates, respectively. We compare our main specification with one in which the coefficients associated with DVP and UVP are homogeneous, which is equivalent to a regression for the predictability of the total VP:

$$
\kappa^{-1} r_{i, t, t+\kappa}=a_{i, \kappa}+a_{\kappa}+b_{\kappa}\left(v p_{t, t+1}^{D}+v p_{t, t+1}^{U}\right)+\epsilon_{i, t+\kappa} .
$$

In both specifications, the coefficients are estimated using ordinary least squares (OLS) where the coefficients associated with VP and its components are restricted to be homogeneous across countries. The VP estimated coefficients and their $h$-lag corrected Newey-West standard errors (in parentheses) are reported along with the adjusted $R^{2}$. "VARC" indicates the variance decomposition of the model. ***

\begin{tabular}{|c|c|c|c|c|c|c|c|c|}
\hline & \multicolumn{2}{|c|}{$\kappa=1$} & \multicolumn{2}{|c|}{$\kappa=3$} & \multicolumn{2}{|c|}{$\kappa=6$} & \multicolumn{2}{|c|}{$\kappa=12$} \\
\hline $\begin{array}{l}v p \\
\text { (SE) }\end{array}$ & $\begin{array}{l}0.1187 \\
(0.3365)\end{array}$ & & $\begin{array}{l}0.2645 \\
(0.1775)\end{array}$ & & $\begin{array}{l}0.3127^{* * *} \\
(0.1088)\end{array}$ & & $\begin{array}{l}0.1604^{* *} \\
(0.0718)\end{array}$ & \\
\hline $\begin{array}{l}v p^{D} \\
(\mathrm{SF})\end{array}$ & & -0.0111 & & $\begin{array}{l}0.2149 \\
(0.1756)\end{array}$ & & $0.2987^{* * *}$ & & $\begin{array}{l}0.1785^{* * *} \\
(0.0692)\end{array}$ \\
\hline $\begin{array}{l}(\mathrm{SE}) \\
{[V A R C \%]}\end{array}$ & & $\begin{array}{l}(0.3360) \\
{[0.0 \%]}\end{array}$ & & $\begin{array}{l}(0.1756) \\
{[43.1 \%]}\end{array}$ & & $\begin{array}{l}(0.1085) \\
{[83.8 \%]}\end{array}$ & & $\begin{array}{l}(0.0092) \\
{[98.0 \%]}\end{array}$ \\
\hline$v p^{U}$ & & $2.0996^{* *}$ & & $1.0198^{*}$ & & $0.5263^{*}$ & & -0.116 \\
\hline (SE) & & $(0.8620)$ & & $(0.5834)$ & & $(0.2883)$ & & $(0.2395)$ \\
\hline [VARC\%] & & [100.0\%] & & [56.9\%] & & [16.2\%] & & [2.0\%] \\
\hline Adj. $R^{2}$ & $0.04 \%$ & $0.82 \%$ & $0.66 \%$ & $0.96 \%$ & $1.67 \%$ & $1.71 \%$ & $0.85 \%$ & $0.99 \%$ \\
\hline
\end{tabular}
$\left(* *,{ }^{*}\right)$ represent significance at the $1 \%(5 \%, 10 \%)$ confidence level. 
Table 4: Robustness tests for the international predictability of VP and its components

The table reports the results from two robustness tests on our main results for the predictability of DVP and UVP in Table 3. Panel A considers the Martingale VP measures (Measure (1) in Tables 1 and 22. Panel B uses our selected VP measures and controls for two traditional macrofinance predictors; the three-month US Treasury bill rate (denoted by bill), which is obtained from FRED; the earnings yield of the S\&P500 index (denoted by $\log \left(E_{t} / P_{t}\right)$ ), where earnings at $t$ is approximated by $\frac{1}{12} \sum_{i=0}^{11} E_{t-i}$, and $E_{t}$ and $P_{t}$ are obtained from Shiller's website. The estimates and their $h$-lag corrected Newey-West standard errors (in parentheses) are reported along with the adjusted $R^{2}$. "VARC" indicates the variance decomposition of the model. ${ }^{* * *}\left({ }^{* *},{ }^{*}\right)$ represent significance at the $1 \%(5 \%, 10 \%)$ confidence level.

\begin{tabular}{|c|c|c|c|c|c|c|c|c|}
\hline \multicolumn{9}{|c|}{ Panel A: Using Martingale VP measures } \\
\hline & \multicolumn{2}{|r|}{$\kappa=1$} & \multicolumn{2}{|c|}{$\kappa=3$} & \multicolumn{2}{|c|}{$\kappa=6$} & \multicolumn{2}{|r|}{$\kappa=12$} \\
\hline $\begin{array}{l}v p \\
(\mathrm{SE})\end{array}$ & $\begin{array}{l}0.3484^{*} \\
(0.2019)\end{array}$ & & \multicolumn{2}{|c|}{$0.3849^{* * *}$} & \multicolumn{2}{|l|}{$\begin{array}{l}0.2136^{* *} \\
(0.0913)\end{array}$} & \multicolumn{2}{|l|}{$\begin{array}{l}0.0510 \\
(0.0761)\end{array}$} \\
\hline$v p^{D}$ & & 0.0319 & & $0.522^{* * *}$ & & $0.4266^{* * *}$ & & $0.2404^{* * *}$ \\
\hline$(\mathrm{SE})$ & & $(0.4482)$ & & $(0.1981)$ & & $(0.1511)$ & & $(0.0857)$ \\
\hline [VARC\%] & & [1.9\%] & & [81.4\%] & & [102.7\%] & & [79.3\%] \\
\hline$v p^{U}$ & & $0.7384^{*}$ & & 0.2162 & & -0.0489 & & $-0.1823^{* *}$ \\
\hline (SE) & & $(0.3847)$ & & $(0.1594)$ & & $(0.1178)$ & & $(0.0805)$ \\
\hline$[V A R C \%]$ & & [98.1\%] & & {$[18.6 \%]$} & & {$[-2.7 \%]$} & & {$[20.7 \%]$} \\
\hline Adj. $R^{2}$ & $0.64 \%$ & $0.94 \%$ & $2.15 \%$ & $2.30 \%$ & $1.19 \%$ & $1.88 \%$ & $0.12 \%$ & $1.18 \%$ \\
\hline \multicolumn{9}{|c|}{ Panel B: Controlling for traditional macrofinance variables } \\
\hline & & $\kappa=1$ & & & & $=6$ & & $\kappa=12$ \\
\hline$v p^{D}$ & & -0.0102 & & 0.2286 & & $0.3089^{* * *}$ & & $0.1339^{*}$ \\
\hline (SE) & & $(0.3532)$ & & $(0.1850)$ & & $(0.1096)$ & & $(0.0745)$ \\
\hline$[V A R C \%]$ & & {$[0.0 \%]$} & & {$[36.6 \%]$} & & {$[68.2 \%]$} & & {$[37.5 \%]$} \\
\hline$v p^{U}$ & & $2.3334^{* * *}$ & & $1.2024^{* *}$ & & $0.7115^{* *}$ & & -0.0624 \\
\hline (SE) & & $(0.9041)$ & & $(0.5989)$ & & $(0.3136)$ & & $(0.2666)$ \\
\hline$[V A R C \%]$ & & {$[93.2 \%]$} & & {$[53.5 \%]$} & & {$[17.2 \%]$} & & {$[0.6 \%]$} \\
\hline bill & & -1.0028 & & -0.5017 & & -0.5886 & & $-1.1898^{* * *}$ \\
\hline$(\mathrm{SE})$ & & $(1.3266)$ & & $(0.7645)$ & & $(0.5456)$ & & $(0.4055)$ \\
\hline$[V A R C \%]$ & & {$[4.4 \%]$} & & [5.1\%] & & {$[8.8 \%]$} & & [60.2\%] \\
\hline $\log \left(\mathrm{E}_{t} / P_{t}\right)$ & & 8.9768 & & 7.9349 & & 7.8022 & & -1.0664 \\
\hline$(\mathrm{SE})$ & & $(12.1486)$ & & $(6.8150)$ & & $(4.8470)$ & & (3.5958) \\
\hline [VARC\%] & & {$[2.5 \%]$} & & {$[4.8 \%]$} & & {$[5.9 \%]$} & & {$[1.7 \%]$} \\
\hline Adj. $R^{2}$ & & $0.96 \%$ & & $1.19 \%$ & & $2.15 \%$ & & $1.93 \%$ \\
\hline
\end{tabular}


Table 5: Summary statistics of risk premium state variables

This table provides summary statistics of our main five risk premium state variables introduced in Section 4 good and bad economic uncertainty $\left(\theta p_{t}\right.$ and $\theta n_{t}$, respectively), expected risk aversion fluctuations $\left(q h_{t}\right)$, and high and low stock market illiquidity uncertainty (illiqh $h_{t}$ and $i l l i q l_{t}$, respectively). The full sample estimation results and detailed dynamic processes are deferred to Appendix $B^{* * *}\left({ }^{* *},{ }^{*}\right)$ represent significance at the $1 \%(5 \%, 10 \%)$ confidence level. The summary statistics are calculated for a sample running from April 1991 to December 2019.

\begin{tabular}{|c|c|c|c|c|c|}
\hline & $\theta p_{t}$ & $\theta n_{t}$ & $q h_{t}$ & $\operatorname{illiqh}_{t}$ & illiql $_{t}$ \\
\hline \multicolumn{6}{|c|}{ Panel A. Univariate statistics, } \\
\hline Mean & 476.020 & 3.342 & 0.838 & 1.191 & 0.702 \\
\hline $\mathrm{SD}$ & 15.176 & 7.798 & 1.107 & 1.376 & 0.046 \\
\hline Skewness & 0.724 & 5.133 & 3.379 & 1.935 & 1.247 \\
\hline \multicolumn{6}{|c|}{ Panel B. Correlation matrix } \\
\hline$\theta p_{t}$ & 1 & & & & \\
\hline$\theta n_{t}$ & $-0.222^{* * *}$ & 1 & & & \\
\hline$q h_{t}$ & -0.070 & $0.191^{* * *}$ & 1 & & \\
\hline$i_{l l i q h_{t}}$ & $0.159^{* * *}$ & 0.084 & $0.115^{* *}$ & 1 & \\
\hline illiql $_{t}$ & $0.348^{* * *}$ & -0.035 & $0.116^{* *}$ & 0.058 & 1 \\
\hline NBER & $-0.182^{* * *}$ & $0.532^{* * *}$ & $0.205^{* * *}$ & $0.142^{* * *}$ & -0.077 \\
\hline Cyclicality & Pro- & Counter- & Counter- & Counter- & A-cyclical \\
\hline
\end{tabular}

Table 6: Country-level economic and financial integration indicators

This table presents the country-level integration proxies: the average trade-to-GDP ratio (source: World Bank; 1989-2018) as the proxy for a country's economic integration, and the average total asset and liability holdings from country $i$ to the rest of the world (source: IMF, The Coordinated Portfolio Investment Survey; 2001-2018) as the proxy for a country's financial integration (Schularick and Steger (2010)). This table also provides a within-variable sort: low, [0th, 33th); middle, [33th,67th); high, [67th, 100th].

\begin{tabular}{lcccc}
\hline \hline & \multicolumn{2}{c}{ Trade-to-GDP } & \multicolumn{2}{c}{ Holdings-to-GDP } \\
& in \% & $\mathrm{L} / \mathrm{M} / \mathrm{H}$ & in $\%$ & $\mathrm{~L} / \mathrm{M} / \mathrm{H}$ \\
\hline Australia & 39.5 & $\mathrm{~L}$ & 106.9 & $\mathrm{~L}$ \\
Austria & 86.9 & $\mathrm{M}$ & 171.8 & $\mathrm{H}$ \\
Belgium & 138.7 & $\mathrm{H}$ & 236.0 & $\mathrm{H}$ \\
Canada & 65.8 & $\mathrm{~L}$ & 121.0 & $\mathrm{M}$ \\
Denmark & 85.0 & $\mathrm{M}$ & 178.4 & $\mathrm{M}$ \\
Finland & 69.1 & $\mathrm{M}$ & 211.8 & $\mathrm{M}$ \\
France & 52.0 & $\mathrm{M}$ & 189.1 & $\mathrm{~L}$ \\
Germany & 64.7 & $\mathrm{M}$ & 148.1 & $\mathrm{M}$ \\
Hong Kong & 309.9 & $\mathrm{H}$ & 330.4 & $\mathrm{H}$ \\
Ireland & 159.4 & $\mathrm{H}$ & 1185.9 & $\mathrm{H}$ \\
Italy & 48.1 & $\mathrm{~L}$ & 121.9 & $\mathrm{~L}$ \\
Japan & 24.6 & $\mathrm{~L}$ & 86.3 & $\mathrm{~L}$ \\
Netherlands & 125.2 & $\mathrm{H}$ & 396.2 & $\mathrm{H}$ \\
New Zealand & 57.7 & $\mathrm{~L}$ & 63.6 & $\mathrm{M}$ \\
Norway & 70.0 & $\mathrm{M}$ & 223.5 & $\mathrm{M}$ \\
Portugal & 66.8 & $\mathrm{M}$ & 141.0 & $\mathrm{M}$ \\
Singapore & 356.6 & $\mathrm{H}$ & 450.7 & $\mathrm{H}$ \\
Spain & 52.1 & $\mathrm{~L}$ & 114.7 & $\mathrm{~L}$ \\
Sweden & 77.0 & $\mathrm{M}$ & 190.8 & $\mathrm{M}$ \\
Switzerland & 99.4 & $\mathrm{H}$ & 302.8 & $\mathrm{H}$ \\
United Kingdom & 52.9 & $\mathrm{H}$ & 236.1 & $\mathrm{~L}$ \\
United States & 24.7 & $\mathrm{~L}$ & 93.7 & $\mathrm{~L}$ \\
\hline
\end{tabular}


Table 7: Model fit: VP component dynamics

This table presents the moment matching results of the GMM system used to estimate the loadings of DVP and UVP on the five risk premium state variables (see details in Section 5.1). Two GMM systems are estimated: one with time-varying loadings (22 unknowns) and one with constant loadings (12 unknowns). Both GMM systems have 40 moments and are estimated using iterative GMM. ** indicates that the model estimate is within $1.645 \mathrm{SD}$ of the empirical point estimate in the same row. Standard model specification statistics and empirical correlations are shown at the end of the table.

\begin{tabular}{rlllll}
\hline \hline & Moment & Empirical & Boot. SE & \multicolumn{2}{c}{ Model } \\
& & & & time-varying & constant \\
\hline 1 & $v p^{D}$ & 15.972 & $(0.725)$ & $16.464^{* * *}$ & 10.05 \\
2 & $v p^{U}$ & 1.265 & $(0.173)$ & $1.241^{* * *}$ & -0.202 \\
3 & $\left(v p^{D}-E\left(v p^{D}\right)\right)^{2}$ & 182.198 & $(33.504)$ & $180.071^{* * *}$ & $175.881^{* * *}$ \\
4 & $\left(v p^{U}-E\left(v p^{U}\right)\right)^{2}$ & 10.755 & $(4.230)$ & $10.701^{* * *}$ & $4.383^{* * *}$ \\
5 & $\left(v p^{D}-E\left(v p^{D}\right)\right)^{3} /\left(S D\left(v p^{D}\right)^{3}\right)$ & 2.656 & $(0.885)$ & $2.752^{* * *}$ & $2.867^{* * *}$ \\
6 & $\left(v p^{U}-E\left(v p^{U}\right)\right)^{3} /\left(S D\left(v p^{U}\right)^{3}\right)$ & -5.001 & $(3.959)$ & $-4.146^{* * *}$ & $0.687^{* * *}$ \\
7 & $\left(v p^{D}-E\left(v p^{D}\right)\right)^{4} /\left(S D\left(v p^{D}\right)^{4}\right)$ & 12.293 & $(4.287)$ & $11.955^{* * *}$ & $12.821^{* * *}$ \\
8 & $\left(v p^{U}-E\left(v p^{U}\right)\right)^{4} /\left(S D\left(v p^{U}\right)^{4}\right)$ & 53.202 & $(45.926)$ & $48.432^{* * *}$ & 7.718 \\
9 & $\left(v p^{D}-E\left(v p^{D}\right)\right) *\left(v p^{U}-E\left(v p^{U}\right)\right)$ & 1.262 & $(8.555)$ & $-1.981^{* * *}$ & $-3.18^{* * *}$ \\
10 & $v p^{D} /\left(v p^{D}+v p^{U}\right)$ & 0.927 & $(0.010)$ & $0.924^{* * *}$ & 0.626 \\
\hline & GMM J Statistics: & & 15.78 & 61.56 \\
& DF: & & 18 & 28 \\
& Hansen's Overidentification Test, p-value: & 0.61 & 0.00 \\
& Dynamic correlation with empirical estimates, DVP: & 0.88 & 0.74 \\
& Dynamic correlation with empirical estimates, UVP: & 0.48 & 0.16 \\
\hline
\end{tabular}


Table 8: Model fit: VP component predictive coefficients

This table provides the model fit results of the international stock return predictive coefficients of the VP components (see details in Section 5.1). To summarize the information, Panels A and B report the average, mean, and cross-country variation of the DVP and UVP predictive coefficients, respectively, and provide closeness tests with their empirical counterparts; ${ }^{* * *}\left({ }^{* *} ;{ }^{*}\right)$ indicates that the model estimate is within the $1.645(1.96 ; 2.576) \mathrm{SD}$ of the empirical point estimate in the same row. Rows in bold indicate horizons with significant predictability for most countries according to our empirical evidence.

\begin{tabular}{|c|c|c|c|c|c|c|c|c|c|}
\hline Panel A & \multicolumn{3}{|c|}{ Average DVP coeff. } & \multicolumn{3}{|c|}{ Median DVP coeff. } & \multicolumn{3}{|c|}{ Cross-country SD DVP coeff. } \\
\hline Horizon & Emp. & $\mathrm{SE}$ & Model & Emp. & $\mathrm{SE}$ & Model & Emp. & $\mathrm{SE}$ & Model \\
\hline 1 & -0.011 & $(0.052)$ & $-0.059^{* * *}$ & -0.036 & $(0.070)$ & $-0.027^{* * *}$ & 0.245 & $(0.027)$ & 0.148 \\
\hline 2 & 0.188 & $(0.043)$ & $0.142^{* * *}$ & 0.151 & $(0.048)$ & $0.177 * * *$ & 0.202 & $(0.025)$ & $0.147^{*}$ \\
\hline 3 & 0.215 & $(0.036)$ & $0.176^{* * *}$ & 0.188 & $(0.032)$ & $0.205^{* * *}$ & 0.171 & $(0.023)$ & $0.130^{* *}$ \\
\hline 4 & 0.226 & $(0.036)$ & $0.186^{* * *}$ & 0.221 & $(0.026)$ & $0.215^{* * *}$ & 0.169 & $(0.024)$ & $0.134 * * *$ \\
\hline 5 & 0.262 & $(0.036)$ & $0.225^{* * *}$ & 0.262 & $(0.031)$ & $0.26^{* * *}$ & 0.169 & $(0.025)$ & $0.128 * * *$ \\
\hline 6 & 0.299 & $(0.036)$ & $0.253^{* * *}$ & 0.289 & $(0.030)$ & $0.287 * * *$ & 0.168 & $(0.025)$ & $0.131 * * *$ \\
\hline 7 & 0.287 & $(0.035)$ & $0.247 * * *$ & 0.265 & $(0.030)$ & $0.284^{* * *}$ & 0.166 & $(0.027)$ & $0.136 * * *$ \\
\hline 8 & 0.235 & $(0.034)$ & $0.202^{* * *}$ & 0.220 & $(0.027)$ & $0.239^{* * *}$ & 0.161 & $(0.028)$ & $0.134^{* * *}$ \\
\hline 9 & 0.214 & $(0.033)$ & $0.181^{* * *}$ & 0.214 & $(0.023)$ & $0.217^{* * *}$ & 0.157 & $(0.028)$ & $0.128^{* * *}$ \\
\hline 10 & 0.189 & $(0.033)$ & $0.164^{* * *}$ & 0.191 & $(0.021)$ & $0.199 * * *$ & 0.155 & $(0.028)$ & $0.125^{* * *}$ \\
\hline 11 & 0.185 & $(0.033)$ & $0.158^{* * *}$ & 0.184 & $(0.022)$ & $0.195^{* * *}$ & 0.153 & $(0.028)$ & $0.132^{* * *}$ \\
\hline 12 & 0.179 & $(0.032)$ & $0.157^{* * *}$ & 0.174 & $(0.023)$ & $0.192^{* * *}$ & 0.149 & $(0.027)$ & $0.127^{* * *}$ \\
\hline Panel B & \multicolumn{3}{|c|}{ Average UVP coeff. } & \multicolumn{3}{|c|}{ Median UVP coeff. } & \multicolumn{3}{|c|}{ Cross-country SD UVP coeff. } \\
\hline Horizon & Emp. & $\mathrm{SE}$ & Model & Emp. & $\mathrm{SE}$ & Model & Emp. & SE & Model \\
\hline 1 & 2.100 & $(0.241)$ & $1.859 * * *$ & 1.999 & $(0.178)$ & $1.807 * * *$ & 1.128 & $(0.203)$ & $0.627^{*}$ \\
\hline 2 & 0.922 & $(0.174)$ & $0.782^{* * *}$ & 0.995 & $(0.150)$ & $0.814^{* * *}$ & 0.814 & $(0.142)$ & $0.450 * *$ \\
\hline 3 & 1.020 & $(0.117)$ & $0.903^{* * *}$ & 1.272 & $(0.137)$ & $0.953 * * *$ & 0.548 & $(0.101)$ & $0.392 * *$ \\
\hline 4 & 1.227 & $(0.106)$ & $1.096^{* * *}$ & 1.309 & $(0.126)$ & $1.175^{* * *}$ & 0.497 & $(0.074)$ & 0.268 \\
\hline 5 & 0.891 & $(0.081)$ & $0.816^{* * *}$ & 0.906 & $(0.120)$ & $0.881 * * *$ & 0.380 & $(0.050)$ & 0.217 \\
\hline 6 & 0.526 & $(0.063)$ & $0.482^{* * *}$ & 0.551 & $(0.073)$ & $0.555^{* * *}$ & 0.293 & $(0.046)$ & $0.224^{* * *}$ \\
\hline 7 & 0.276 & $(0.053)$ & $0.273^{* * *}$ & 0.299 & $(0.083)$ & $0.329^{* * *}$ & 0.247 & $(0.033)$ & $0.188^{* * *}$ \\
\hline 8 & 0.237 & $(0.053)$ & $0.217^{* * *}$ & 0.296 & $(0.083)$ & $0.251^{* * *}$ & 0.250 & $(0.031)$ & 0.158 \\
\hline 9 & -0.009 & $(0.045)$ & $-0.004^{* * *}$ & -0.009 & (0.047) & $0.038^{* * *}$ & 0.209 & $(0.032)$ & 0.126 \\
\hline 10 & -0.069 & $(0.047)$ & $-0.074 * * *$ & -0.049 & $(0.055)$ & $-0.042^{* * *}$ & 0.219 & $(0.036)$ & 0.100 \\
\hline 11 & -0.125 & $(0.048)$ & $-0.127^{* * *}$ & -0.122 & $(0.058)$ & $-0.089^{* * *}$ & 0.225 & $(0.036)$ & 0.109 \\
\hline 12 & -0.116 & $(0.047)$ & $-0.115^{* * *}$ & -0.107 & $(0.056)$ & $-0.08^{* * *}$ & 0.220 & $(0.036)$ & 0.114 \\
\hline
\end{tabular}


Table 9: Loadings of VP components on risk premium state variables

This table presents the estimation results of the GMM framework and the relative importance of the risk premium state variables in driving the dynamics of VPs. Details are presented in Section 5.1. For each GMM iteration, the model-implied DVP and UVP $\left(\widehat{v p_{t}^{D}}\right.$ and $\widehat{v p_{t}^{U}}$, respectively) can be expressed as:

$$
\begin{aligned}
& \widehat{v p_{t}^{D}}=v p_{0}^{D}+w_{\theta p, t}^{D} \widehat{\theta p}_{t}+w_{\theta n, t}^{D} \widehat{\theta n}_{t}+w_{q h, t}^{D} \widehat{q h}_{t}+w_{\text {illiqh }, \text { illiqh }}^{D}+w_{i l l i q l, t}^{D} \widehat{i l l i q l}_{t}, \\
& \widehat{v p_{t}^{U}}=v p_{0}^{U}+w_{\theta p, t}^{U} \widehat{\theta p}_{t}+w_{\theta n, t}^{U} \widehat{\theta n}_{t}+w_{q h, t}^{U}, \widehat{q h}_{t}+w_{\text {illiqh }, \text { illiqh }}+w_{\text {illiql }, t}^{U} \widehat{i l l i q l}_{t},
\end{aligned}
$$

where, for $x \in\{\theta p, \theta n, q h, i l l i q h, i l l i q l\}$, $\widehat{x}$ indicates the estimated risk premium state variables (Section 4 , and $w_{x, t}^{D}$ and $w_{x, t}^{U}$ indicate the corresponding time-varying coefficients:

$$
\begin{aligned}
& w_{x, t}^{D}=w_{x, 0}^{D}+w_{x, 1}^{D} z_{t}, \\
& w_{x, t}^{U}=w_{x, 0}^{U}+w_{x, 1}^{U} z_{t},
\end{aligned}
$$

and $z_{t}$ is the current squared innovation to real economic growth. Standard errors are shown in parentheses and variance decomposition results are shown in the third row ("VARC"). The variance contribution is calculated as $\frac{\beta_{v} \operatorname{cov}\left(v_{t}, \widehat{y_{t}}\right)}{\widehat{y_{t}}} \times 100 \%$, where $v_{t}$ denotes an explanatory variable, $\beta_{v}$ the corresponding loading, and $\widehat{y_{t}}$ the total explained $y$ variable. ${ }^{* * *}\left({ }^{* *},{ }^{*}\right)$ represent significance at the $1 \%(5 \%, 10 \%)$ confidence level.

\begin{tabular}{llllllll}
\hline \hline & & $\theta p_{t}$ & $\theta n_{t}$ & $q h_{t}$ & illiqh $_{t}$ & illiql & Constant \\
\hline DVP & $w_{0}^{D}$ & -0.041 & $0.885^{* * *}$ & $7.762^{* * *}$ & -0.35 & $83.505^{* * *}$ & -32.257 \\
& & $(0.061)$ & $(0.134)$ & $(0.358)$ & $(0.506)$ & $(14.412)$ & $(25.616)$ \\
& {$[$ VARC\%] } & {$[0.46 \%]$} & {$[33.27 \%]$} & {$[52.20 \%]$} & {$[-0.49 \%]$} & {$[9.34 \%]$} & \\
& $w_{1}^{D}$ & 14.143 & $-522.083^{* * *}$ & $5323.575^{* * *}$ & $16282.641^{* * *}$ & $-27746.517^{* * *}$ & \\
& & $(11.003)$ & $(5.474)$ & $(70.288)$ & $(269.496)$ & $(7465.181)$ & \\
& {$[V A R C \%]$} & {$[2.64 \%]$} & {$[-8.97 \%]$} & {$[10.29 \%]$} & {$[8.98 \%]$} & {$[-7.72 \%]$} & \\
\hline UVP & $w_{0}^{U}$ & $0.074^{* *}$ & $0.177^{* * *}$ & $1.19^{* * *}$ & $0.476^{* * *}$ & $-26.99^{* *}$ & -15.935 \\
& & $(0.036)$ & $(0.039)$ & $(0.145)$ & $(0.122)$ & $(13.106)$ & $(11.539)$ \\
& {$[V A R C \%]$} & {$[5.82 \%]$} & {$[-4.04 \%]$} & {$[5.11 \%]$} & {$[6.62 \%]$} & {$[6.04 \%]$} & \\
& $w_{1}^{U}$ & $-76.725^{* * *}$ & $41.821^{* * *}$ & -1.364 & $1306.134^{* * *}$ & 1068.634 & \\
& $(18.526)$ & $(5.932)$ & $(34.542)$ & $(90.690)$ & $(1273.898)$ & \\
& {$[V A R C \%]$} & {$[88.54 \%]$} & {$[-3.74 \%]$} & {$[0.01 \%]$} & {$[-2.54 \%]$} & {$[-1.82 \%]$} & \\
\hline
\end{tabular}

Table 10: Economic magnitude of VP loadings

This table complements Table 9 and provides economic magnitude of the sensitivity of the VP components to each risk premium state variable at four different values of $z_{t}$, the proxy for the current economic condition (sample average, 90th, 95th, and 99th percentiles).

\begin{tabular}{lllllll}
\hline \hline & $z_{t}$ values & $\theta p_{t}$ & $\theta n_{t}$ & $q h_{t}$ & illiqh $_{t}$ & illiql $_{t}$ \\
\hline DVP & $\operatorname{Mean}\left(z_{t}\right)$ & -0.6123 & 6.8424 & 8.6720 & -0.1713 & 3.8341 \\
& $90 \operatorname{th}\left(z_{t}\right)$ & -0.5989 & 6.5886 & 9.0393 & 1.2258 & 3.7543 \\
& $95 \operatorname{th}\left(z_{t}\right)$ & -0.5862 & 6.3463 & 9.3900 & 2.5593 & 3.6782 \\
& $99 \operatorname{th}\left(z_{t}\right)$ & -0.5158 & 5.0125 & 11.3204 & 9.9011 & 3.2588 \\
\hline UVP & $\operatorname{Mean}\left(z_{t}\right)$ & 1.1085 & 1.3868 & 1.3172 & 0.6803 & -1.2443 \\
& $90 \operatorname{th}\left(z_{t}\right)$ & 1.0359 & 1.4071 & 1.3171 & 0.7924 & -1.2412 \\
& $95 \operatorname{th}\left(z_{t}\right)$ & 0.9666 & 1.4265 & 1.3170 & 0.8994 & -1.2383 \\
& $99 \operatorname{th}\left(z_{t}\right)$ & 0.5851 & 1.5334 & 1.3165 & 1.4883 & -1.2221 \\
\hline
\end{tabular}



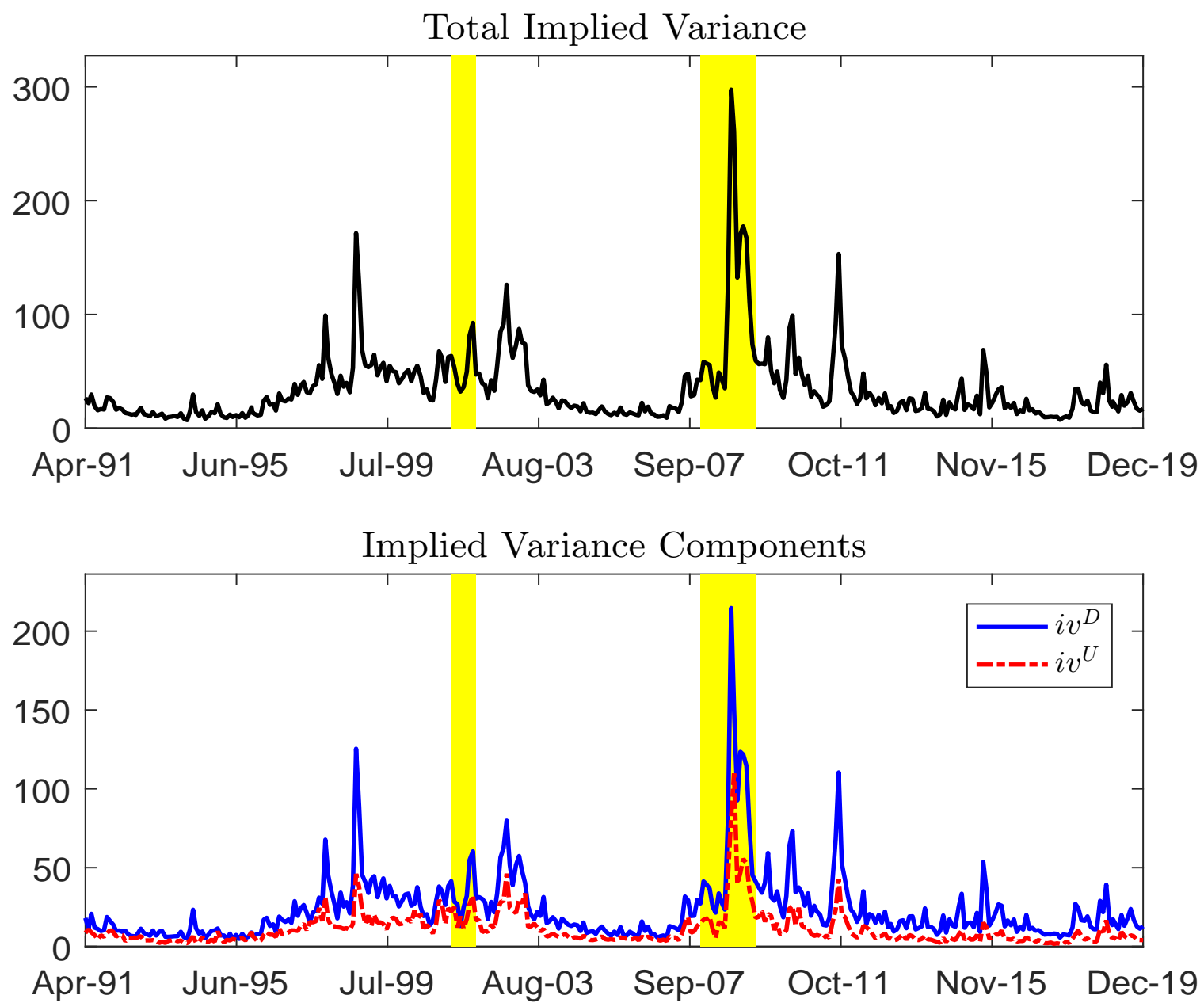

Figure 1: Option-implied variance and its downside and upside components

This figure shows the time series of total option-implied variance (top panel) and its downside and upside components (bottom panel). The construction details for option-implied variances are discussed in Section 2. Measures are in units of monthly percentages (i.e., in the same unit as $V I X$-squared divided by 12 , or annual percentage squared divided by 12 ). 


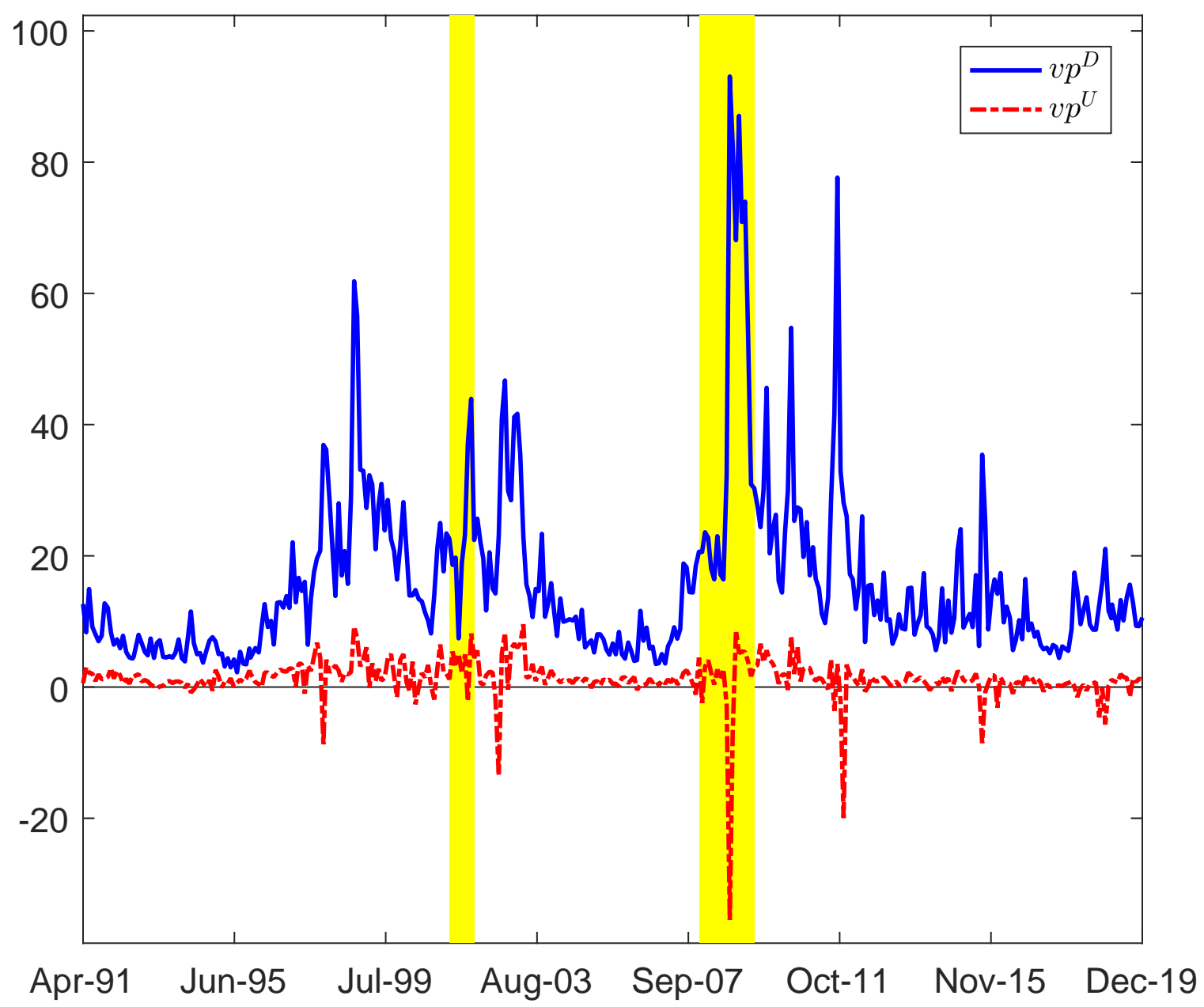

Figure 2: Downside and upside components of the variance risk premium

This figure shows the time series of the downside and upside variance premium components. The construction details of variance risk premiums are discussed in Section 2. The downside (upside) variance risk premium is calculated as the difference between the option-implied downside (upside) variance and the expected downside (upside) realized variance. We use the best forecasts of the downside and upside realized variances from Table 1 (specification (5)). Measures are in units of monthly percentages. 


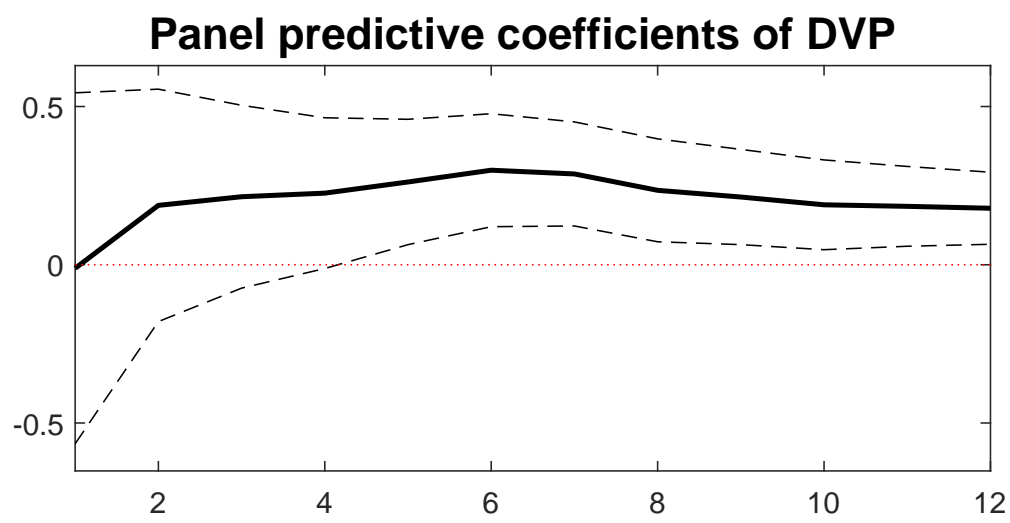

Panel predictive coefficients of UVP

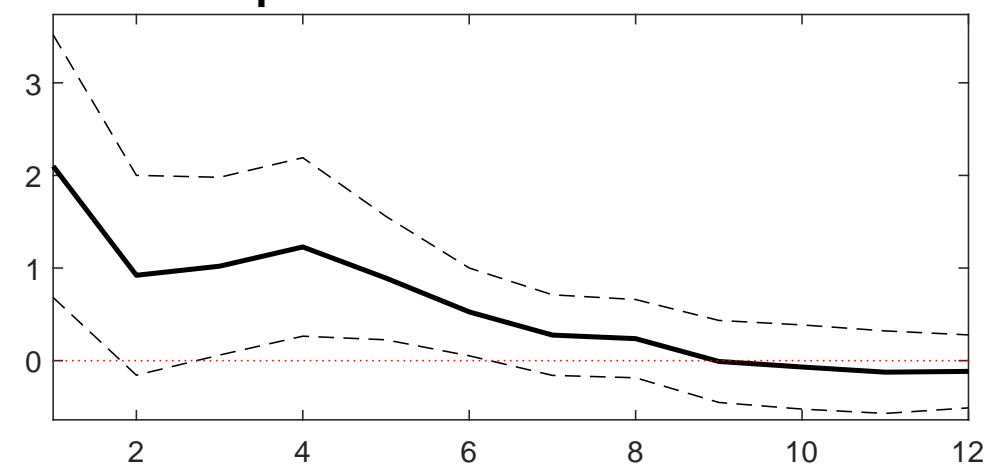

Figure 3: International stock return predictability of DVP and UVP

This figure shows the predictive coefficient estimates of the downside (DVP, top) and upside (UVP, bottom) variance premiums at horizons between 1 and 12 months for the main predictability regression setting:

$$
\kappa^{-1} r_{i, t, t+\kappa}=a_{i, \kappa}+a_{\kappa}+b_{\kappa, d} v p_{t, t+1}^{D}+b_{\kappa, u} v p_{t, t+1}^{U}+\epsilon_{i, t, t+\kappa},
$$

where $r_{i, t, t+\kappa}$ denotes the cumulative $\kappa$-month-ahead log excess returns for country $i$. The dashed lines depict $90 \%$ confidence intervals given Newey-West standard errors. 

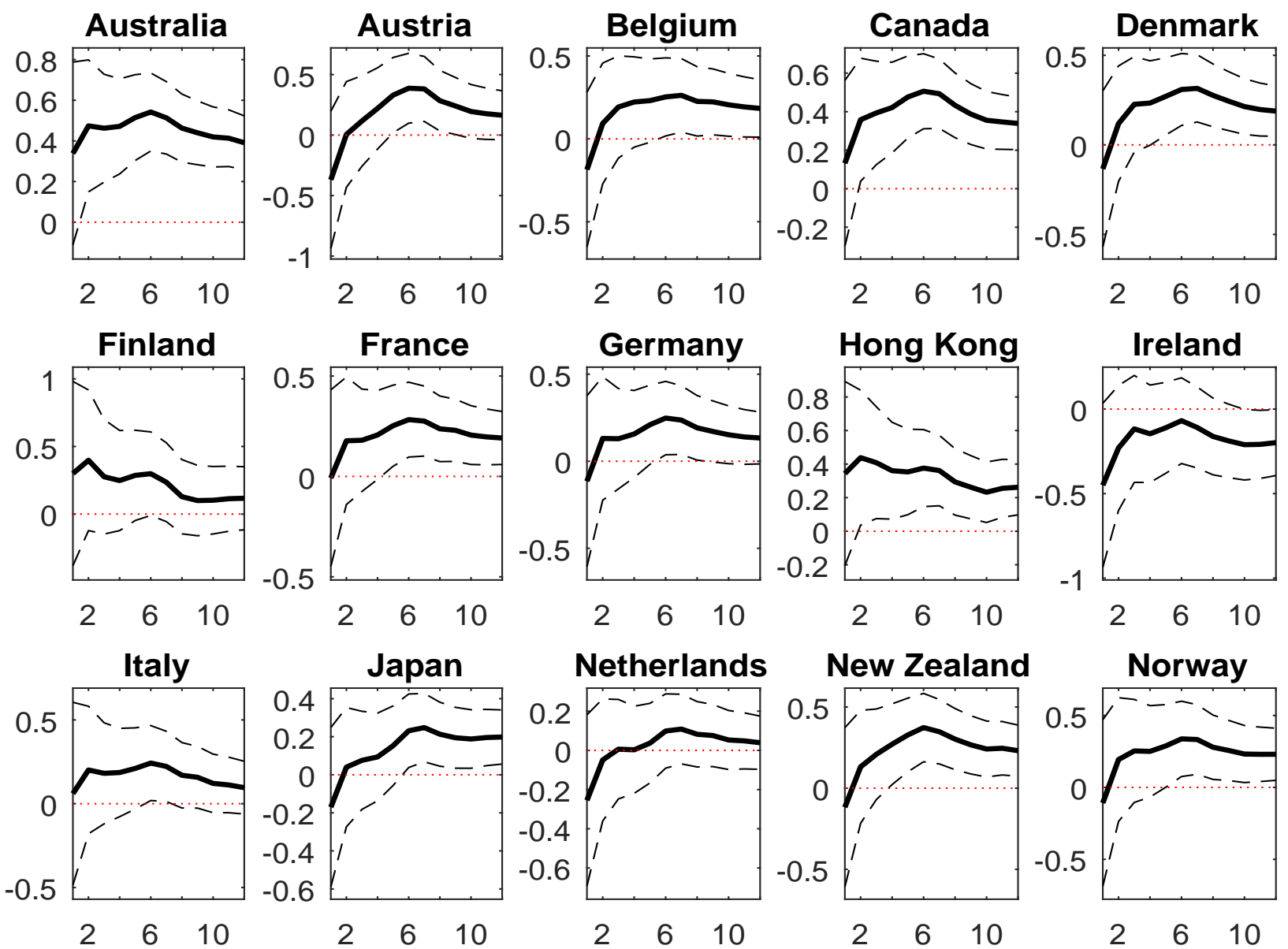

\section{Netherlands}
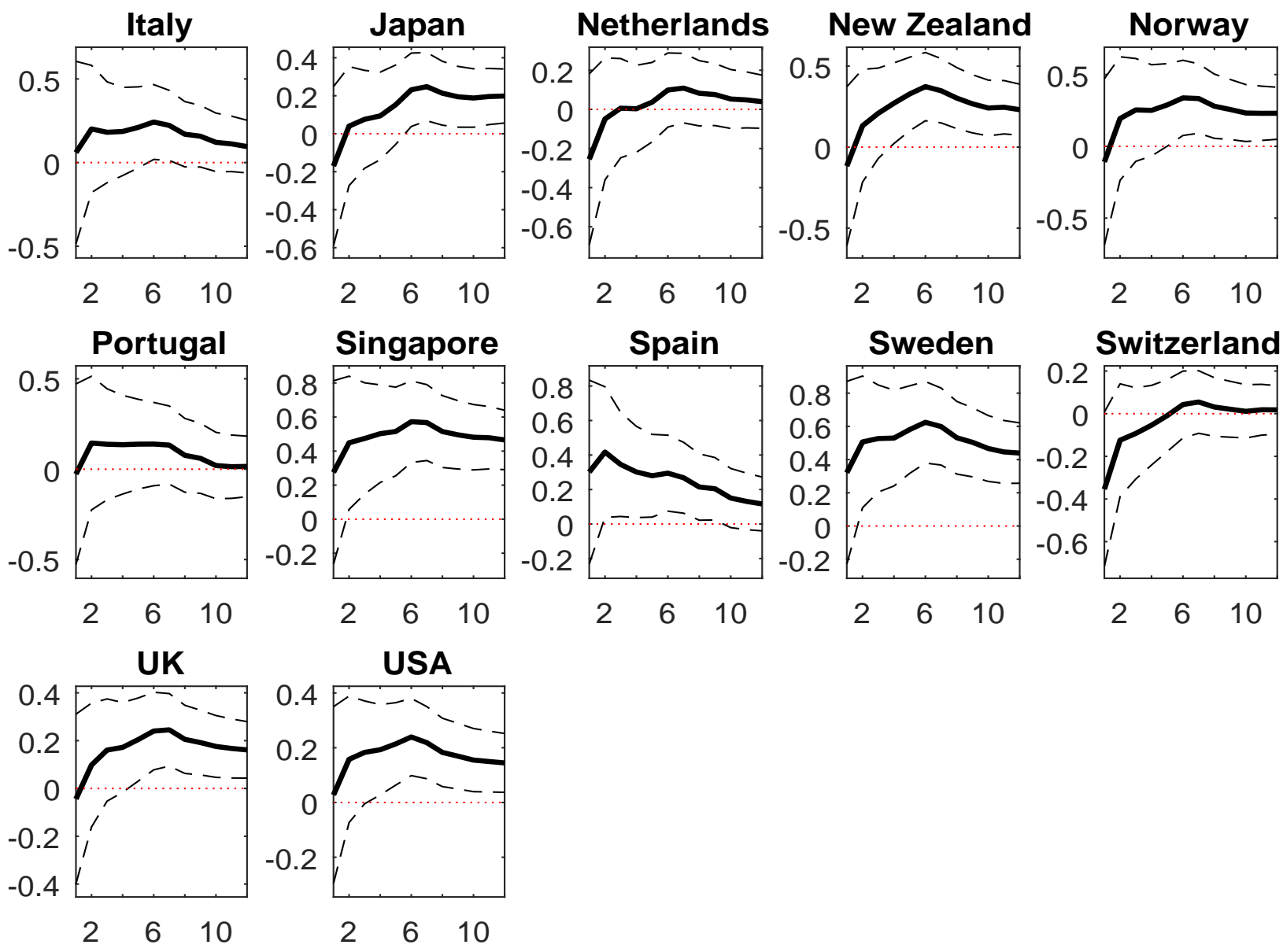

Figure 4: DVP coefficients

This figure shows the predictive coefficient estimates of the downside variance premium (the solid lines) and its $90 \%$ confidence interval given Newey-West standard errors (the dashed lines) at the country level. The regression setting is the following:

$$
\kappa^{-1} r_{i, t, t+\kappa}=a_{i, \kappa}+b_{i, \kappa, d} v p_{t, t+1}^{D}+b_{i, \kappa, u} v p_{t, t+1}^{U}+\epsilon_{i, t, t+\kappa},
$$

where $r_{i, t, t+\kappa}$ denotes the cumulative $\kappa$-month-ahead log excess returns for country $i$. 

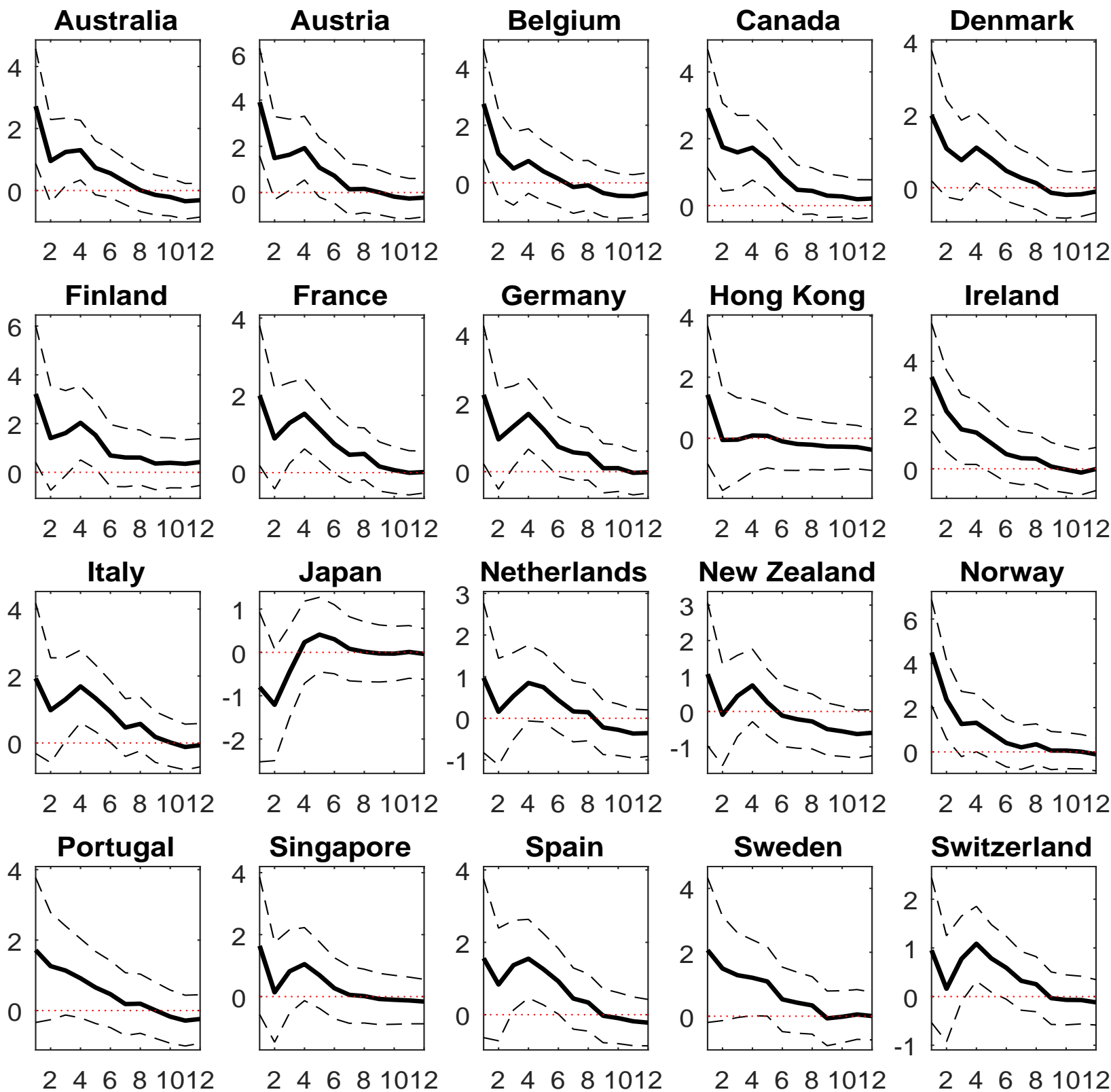

24681012

24681012

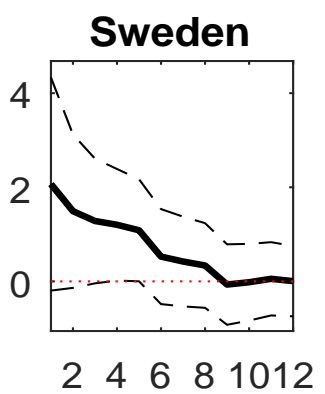

Switzerland

UK

USA
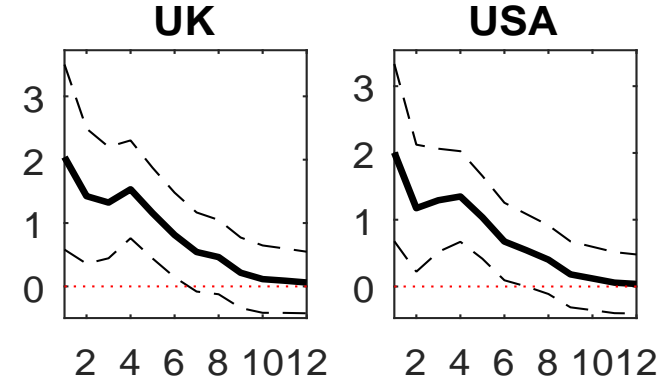

Figure 5: UVP coefficients

This figure shows the predictive coefficient estimates of the upside variance premium (the solid lines) and its $90 \%$ confidence interval given Newey-West standard errors (the dashed lines) at the country level. The regression setting is the following:

$$
\kappa^{-1} r_{i, t, t+\kappa}=a_{i, \kappa}+b_{i, \kappa, d} v p_{t, t+1}^{D}+b_{i, \kappa, u} v p_{t, t+1}^{U}+\epsilon_{i, t, t+\kappa},
$$

where $r_{i, t, t+\kappa}$ denotes the cumulative $\kappa$-month-ahead log excess returns for country $i$. 


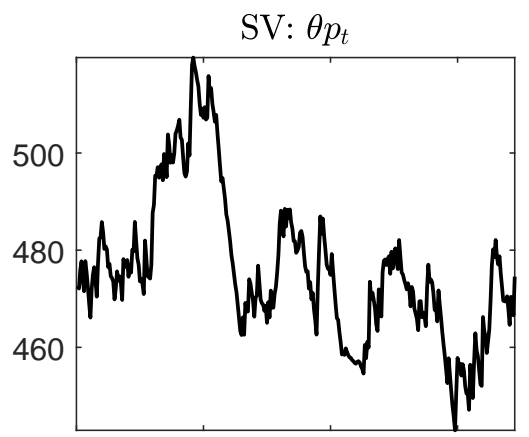

199104199907200711201603

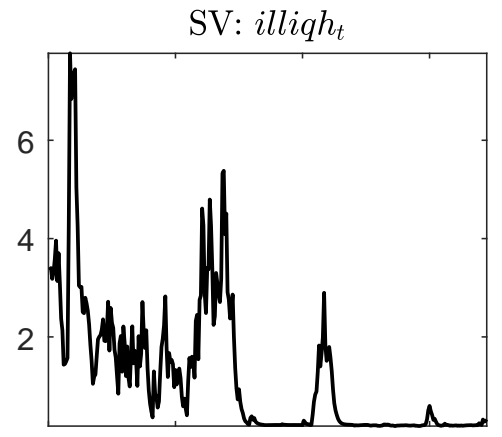

199104199907200711201603
$\mathrm{SV}: \theta n_{t}$

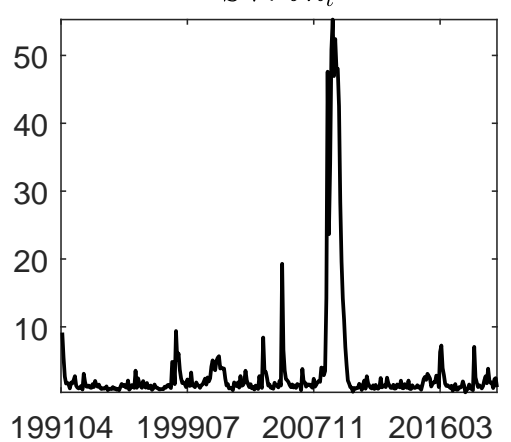

SV: $i l l i q l_{t}$

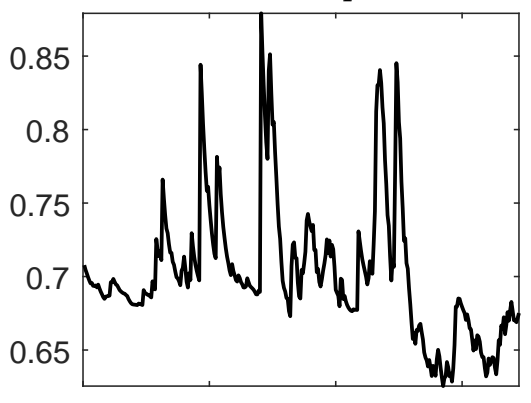

199104199907200711201603
$\mathrm{SV}: q h_{t}$
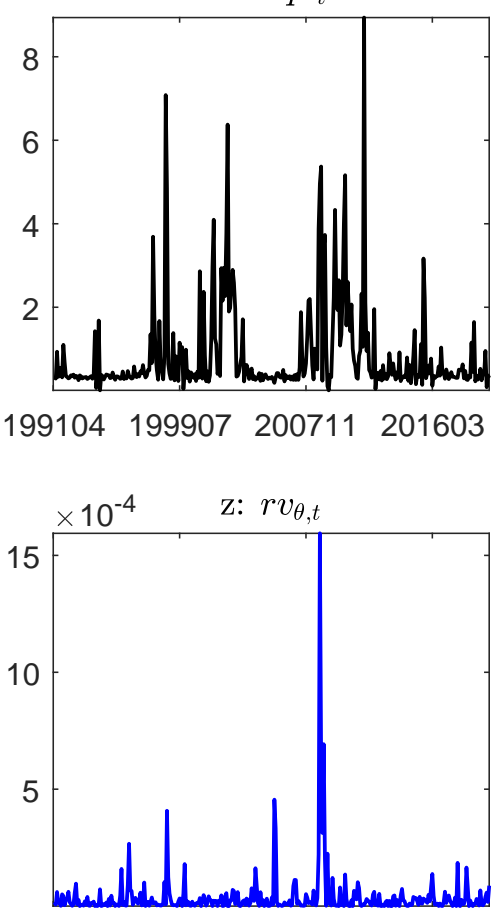

199104199907200711201603

Figure 6: State variable dynamics

This figure shows the dynamics of the estimated risk premium state variables (good and bad economic uncertainty, $\theta p_{t}$ and $\theta n_{t}$, expected risk aversion fluctuations, $q h_{t}$, and high and low stock market illiquidity uncertainty, $i l l i q h_{t}$ and $i l l i q l_{t}$ ) and the time-varying loading instrument (realized variance of economic growth, $z_{t}$ ) for the sample running between April 1991 and December 2019. The corresponding summary statistics are shown in Table 5. The full sample estimation results and detailed dynamic processes are deferred to Appendix B. 
Downside Variance Risk Premium

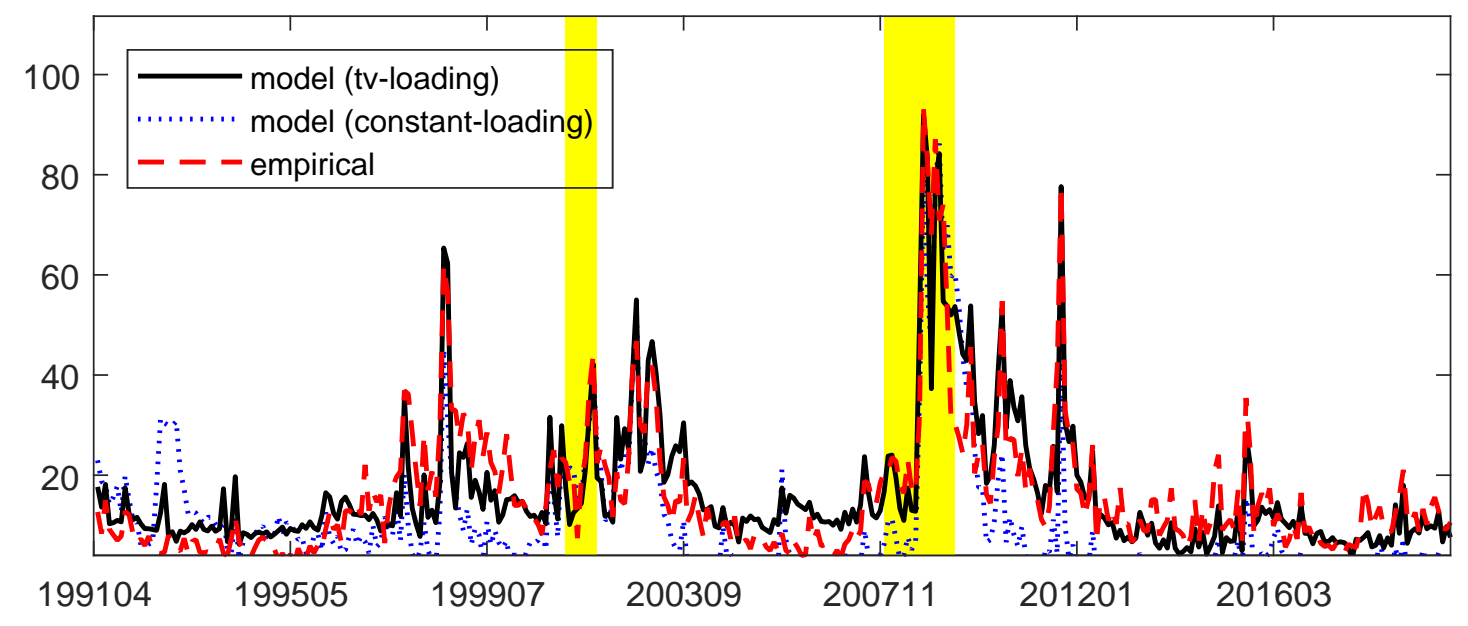

Upside Variance Risk Premium

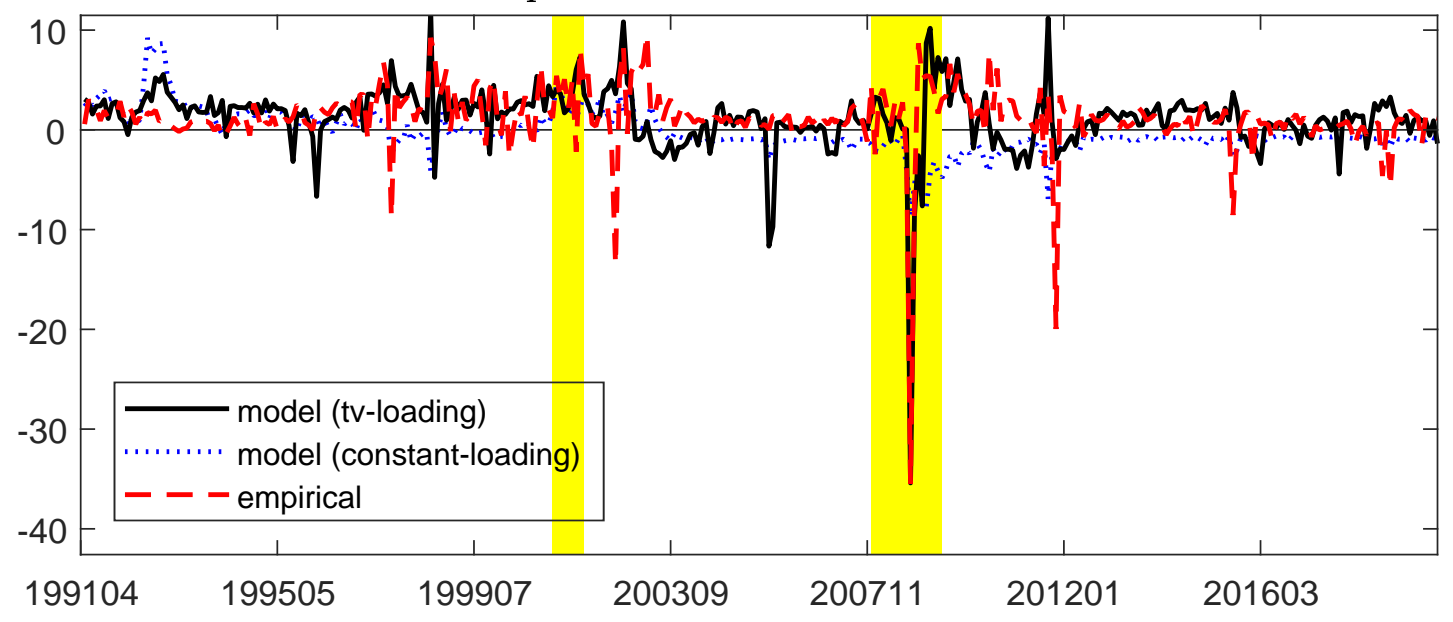

Figure 7: Dynamic fit

This figure shows the dynamics of empirical and model-implied DVP (top) and UVP (bottom) estimates. The empirical estimates, in dashed red lines, are obtained from Section 2 . The model-implied estimates are obtained from Section 5 and we consider both constant (dotted blue lines) and time-varying (solid black lines) loadings. Other estimation details are shown in Table 7 
(A). Changes in EP given 1SD increase in S.V.

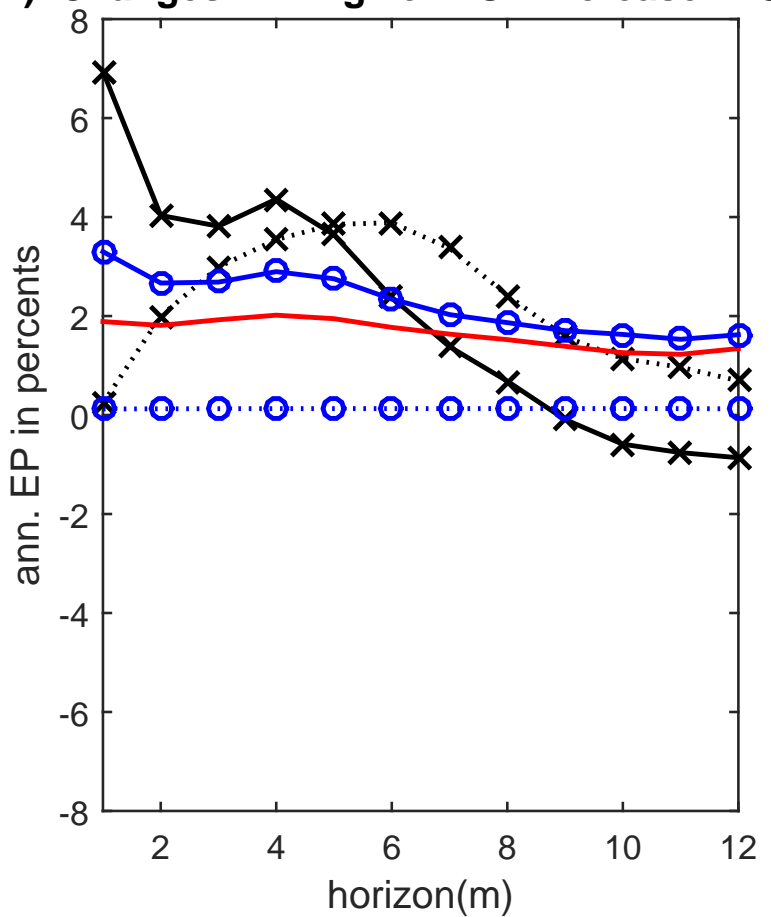

(B). Predictive coefficients w/o a S.V.
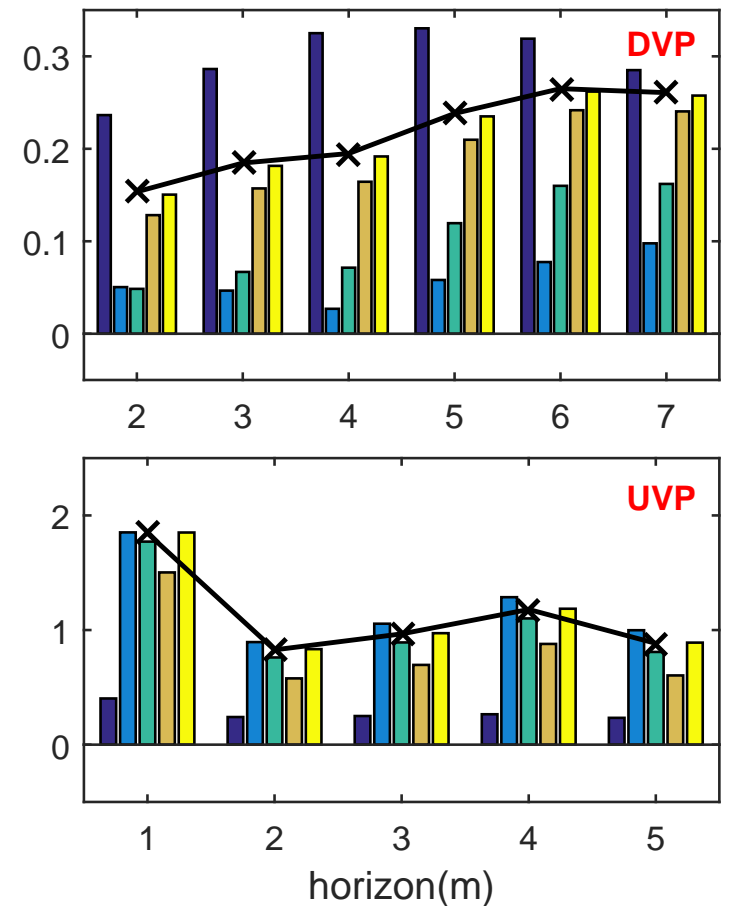

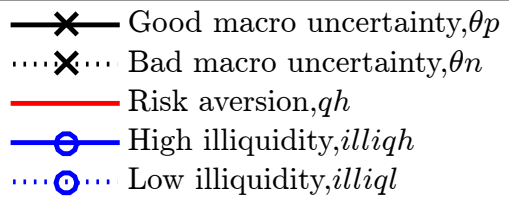

\begin{tabular}{|l}
\hline$\square$ Good macro uncertainty, $\theta p$ \\
\hline Bad macro uncertainty, $\theta n$ \\
\hline Risk aversion, $q h$ \\
\hline High illiquidity, $i l l i q h$ \\
$\square$ Low illiquidity,illiql \\
$\square \quad$ No channel deletion
\end{tabular}

Figure 8: Economic interpretations of international equity risk premiums and stock return predictability: An average-country view

Panel (A) shows the model-implied changes in an average country's equity risk premium (EP) given one SD increase in a US/global risk premium state variable, where an average country is calibrated with median trade-to-GDP and holdings-to-GDP values and EP is expressed in annualized percents for all horizons. Panel (B) shows the implied predictive coefficients after deleting one risk premium state variable in the implied EP at a time; the lower the implied coefficient (the bar size) is, the more important the state variable is in explaining the predictability. This panel focuses on horizons with significant predictability according to the empirical evidence (less than seven months). 

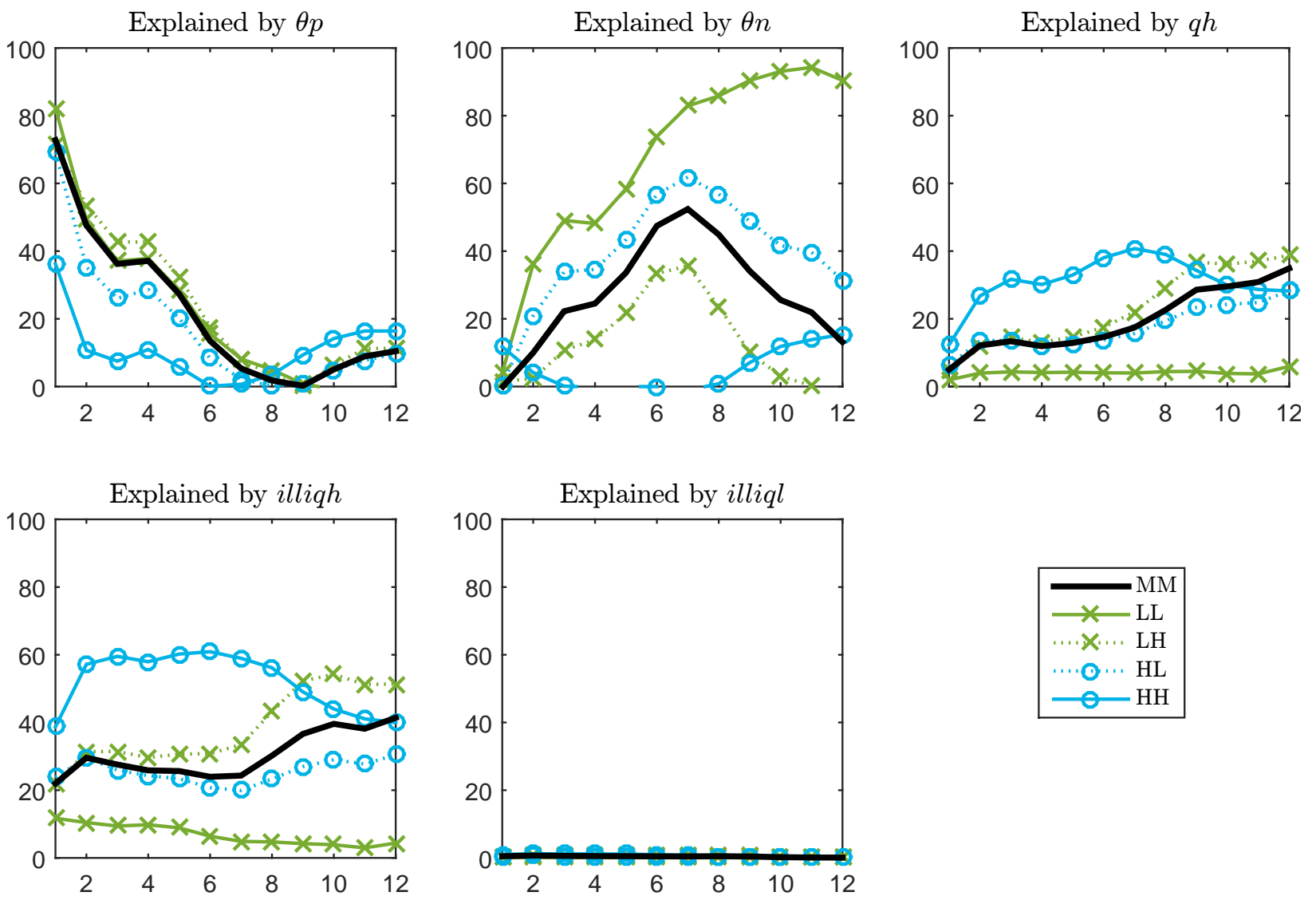

Figure 9: Variance decomposition

This figure shows the variance decomposition (in \%) of the model-implied international equity risk premiums at various horizons. The solid black lines show variance decomposition results for an average country with median economic and financial integration, MM, to make inferences about global risk compensations. The other four lines show results for country groups with various low/high economic and financial integration (see Table 6). 


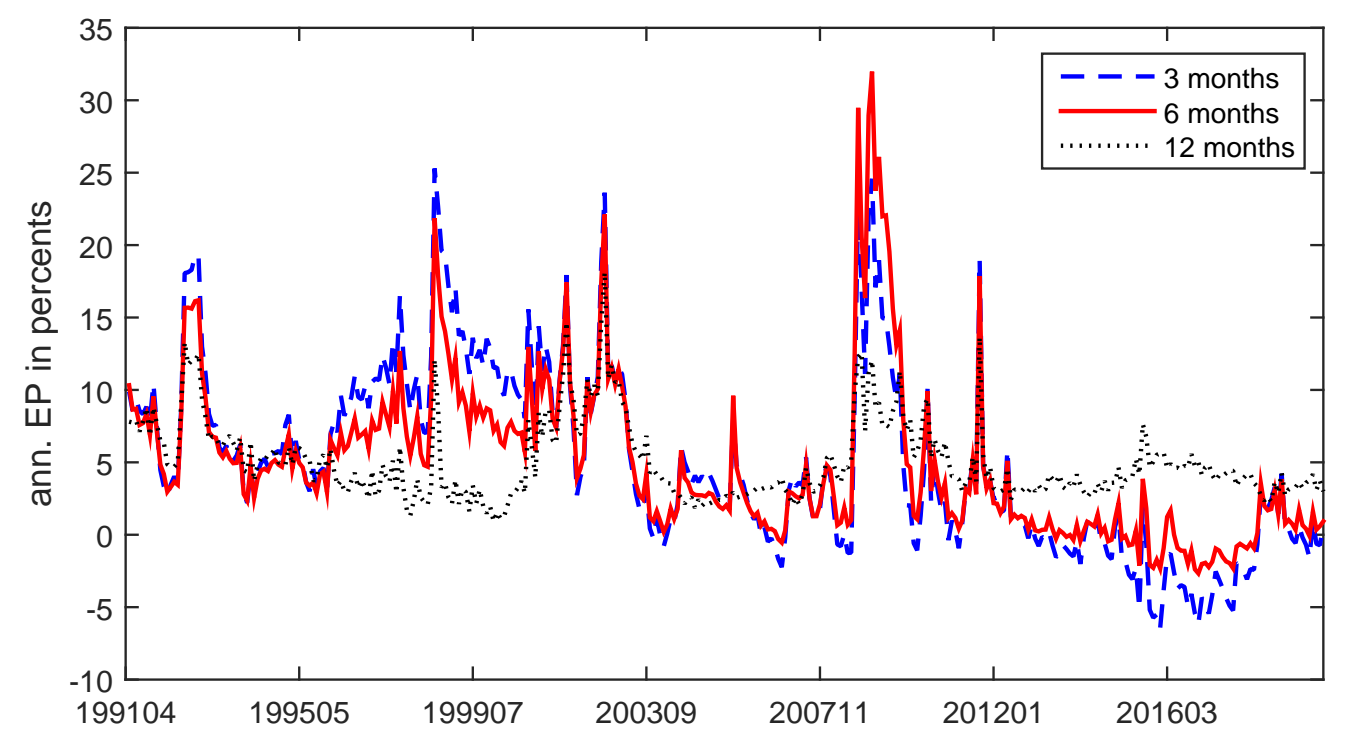

Figure 10: Time variation in model-implied equity risk premiums

This figures shows the time variation in model-implied equity risk premiums for an average country with median economic and financial integration at the 3-, 6-, and 12-month horizons. Equity risk premiums are expressed in annualized percents. 

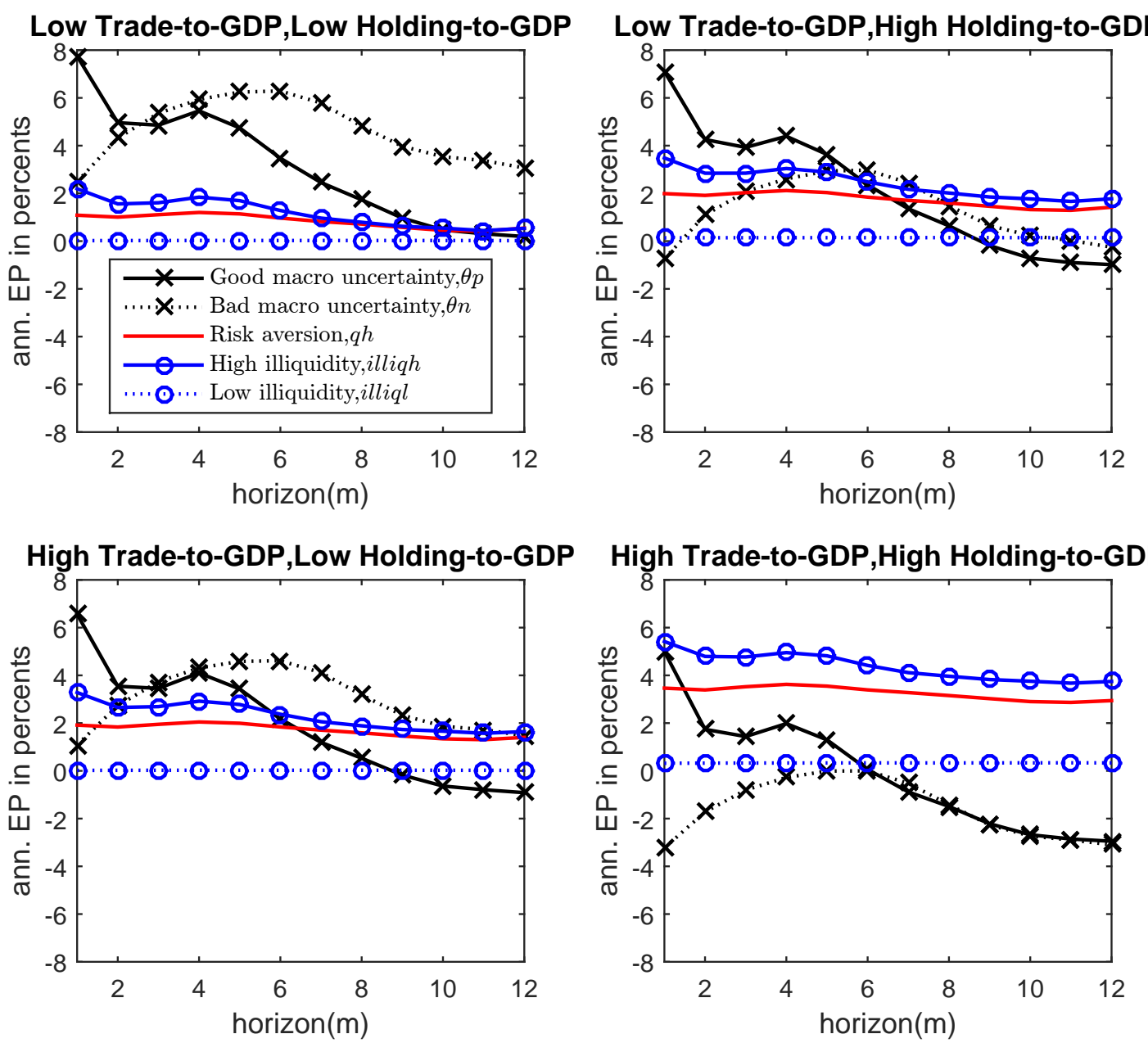

Figure 11: Economic interpretations of international equity risk premiums: A cross-country view

This figure complements Figure 8 (A) with a cross-country view, showing the marginal changes in four country-type equity risk premiums given one SD increase in a common premium state variable. The results are calibrated using low/high economic and financial integration, with low (high) using 33th (67th) percentile value of the 22 countries. See other details in Figure 8. 
(A) DVP predictive coefficients without a state variable

Low Trade-to-GDP,Low Holding-to-GDP

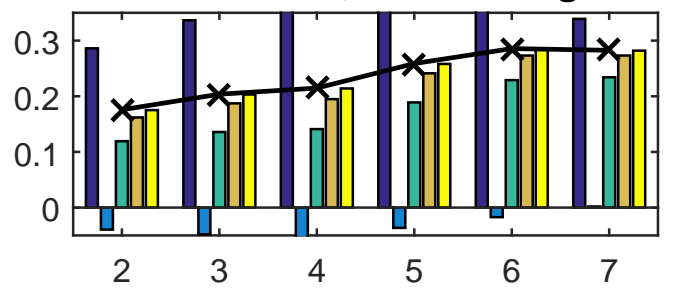

High Trade-to-GDP,Low Holding-to-GDP

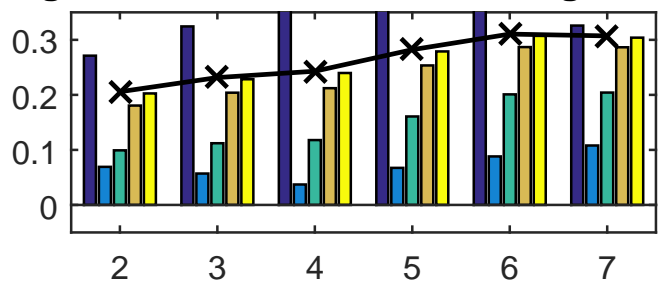

Low Trade-to-GDP,High Holding-to-GDP

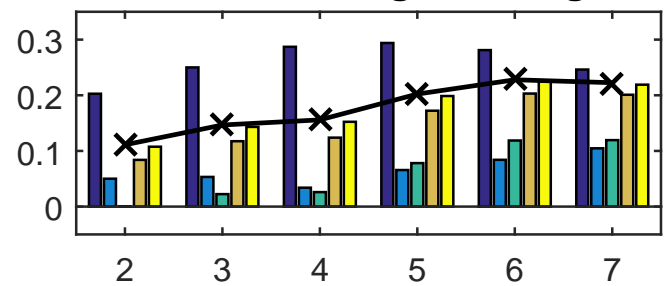

High Trade-to-GDP,High Holding-to-GDP

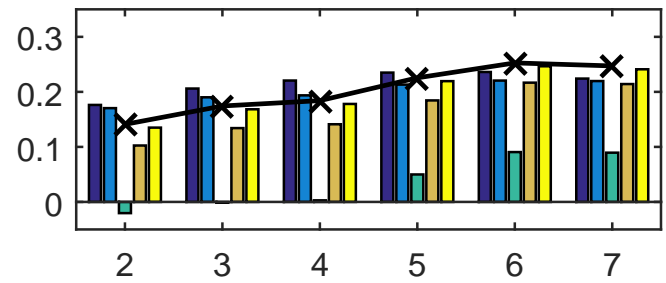

(B) UVP predictive coefficients without a state variable

Low Trade-to-GDP,Low Holding-to-GDP

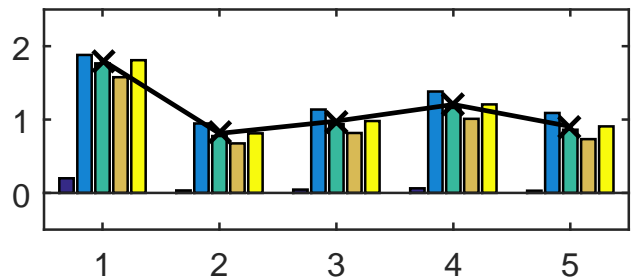

High Trade-to-GDP,Low Holding-to-GDP

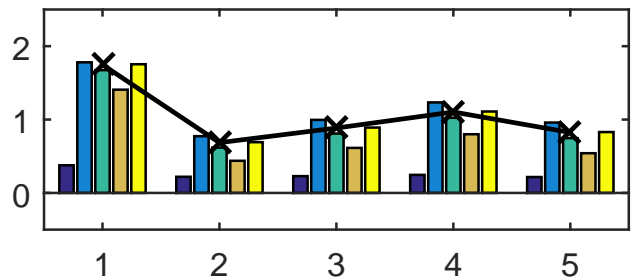

Low Trade-to-GDP,High Holding-to-GDP

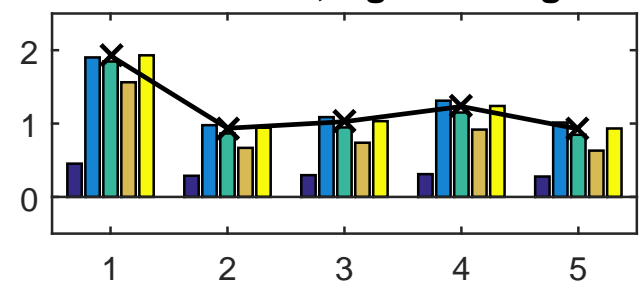

High Trade-to-GDP,High Holding-to-GDP

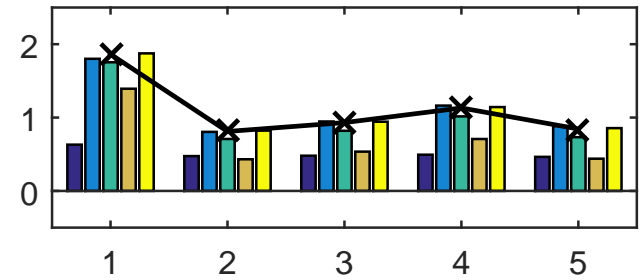

\begin{tabular}{|l|}
\hline Good macro uncertainty, $\theta p$ \\
Bad macro uncertainty, $\theta n$ \\
Risk aversion, $q h$ \\
High illiquidity, illiqh \\
Low illiquidity, illiql \\
$\square$ No channel deletion \\
\hline$\times \quad$ No chand
\end{tabular}

Figure 12: Economic interpretations of international stock return predictability: A cross-country view

This figure complements Figure 8f(B) with a cross-country view, showing the implied predictive coefficients for four country types after deleting one premium state variable in the implied EP at a time. The lower the implied coefficient (bar) is, the more important the state variable is in explaining the predictability. The results are calibrated using low/high economic and financial integration, with low (high) using 33th (67th) percentile value of the 22 countries. See other details in Figure 8 . 


\section{APPENDICES}

\section{A. Additional tables and figures for Section 2}

Table A1: Expected realized variance

This table shows the coefficients associated with the predictors of one-month-ahead (22 days) total realized variance. The specifications are similar to those for realized semivariances in Table 1 The specification in column (1) assumes that realized variance follow a Martingale $\left(E_{t}\left(r v_{t+1 m}\right)=r v_{t}\right)$. For the specifications in columns (2) to (5), we estimate the following regression setting: $E_{t}\left(r v_{t+1}\right)=\hat{\alpha}+\hat{\gamma} \mathbf{X}_{\mathbf{t}}$. We consider the following predictors in matrix $\mathbf{X}$ : the total realized variance calculated over the last month $\left(r v_{t-1 m, t}\right)$; realized variance calculated using either the last five days $\left(r v_{t-5 d, t}\right)$ or the last day of the month $\left(r v_{t-1 d, t}\right)$; and the option-implied variance $\left(i v_{t, t+1 m}\right)$. We report, in parentheses, heteroskedasticity and autocorrelation consistent (HAC) standard deviations with 44 lags. ${ }^{* * *}\left({ }^{* *},{ }^{*}\right)$ represent significance at the $1 \%(5 \%, 10 \%)$ confidence level. The adjusted $R^{2}$ s are reported at the end of the table.

\begin{tabular}{lccccc}
\hline & $(1)$ & $(2)$ & $(3)$ & $(4)$ & $(5)$ \\
\hline Constant & 0 & $7.72^{* * *}$ & $7.72^{* * *}$ & $6.96^{* * *}$ & $4.15^{* * *}$ \\
& - & $(1.28)$ & $(1.28)$ & $(1.10)$ & $(1.56)$ \\
$r v_{t-1 m, t}$ & 1 & $0.64^{* * *}$ & $0.64^{* * *}$ & $0.27^{* * *}$ & 0.12 \\
& - & $(0.08)$ & $(0.08)$ & $(0.10)$ & $(0.09)$ \\
$r v_{t-5 d, t}$ & & & & $0.32^{* *}$ & $0.29^{*}$ \\
& & & & $(0.16)$ & $(0.17)$ \\
$r v_{t-1 d, t}$ & & & & $0.09^{* * *}$ & $0.06^{* *}$ \\
& & & & $(0.02)$ & $(0.02)$ \\
$i v_{t, t+1 m}$ & & & & & $0.21^{*}$ \\
Adj. $R^{2}$ & 0.27 & 0.406 & 0.406 & 0.466 & 0.474 \\
\hline
\end{tabular}

Table A2: Correlations

This table reports correlations among the monthly US downside and upside variance premiums across various measures. Models are reported in Table 1. Panel A (Panel B) reports correlations of DVP (UVP) estimates across measures. The sample runs from April 1991 to December 2019.

\begin{tabular}{|c|c|c|c|c|c|}
\hline & $(1)$ & $(2)$ & $(3)$ & $(4)$ & $(5)$ \\
\hline \multicolumn{6}{|c|}{ A. Correlations across models; DVP } \\
\hline (1) & 1 & & & & \\
\hline (2) & 0.87 & 1 & & & \\
\hline$(3)$ & 0.87 & 0.99 & 1 & & \\
\hline (4) & 0.77 & 0.97 & 0.97 & 1 & \\
\hline (5) & 0.74 & 0.97 & 0.96 & 0.99 & 1 \\
\hline
\end{tabular}

\begin{tabular}{cccccr}
\hline \multicolumn{7}{c}{$(1)$} & $(2)$ & $(3)$ & $(4)$ & $(5)$ \\
\hline \multicolumn{6}{c}{ B. Correlations across models; UVP } \\
\hline$(1)$ & 1 & & & & \\
$(2)$ & 0.80 & 1 & & & \\
$(3)$ & 0.77 & 0.94 & 1.00 & & \\
$(4)$ & 0.77 & 0.90 & 0.88 & 1 & \\
$(5)$ & 0.77 & 0.74 & 0.75 & 0.95 & 1 \\
\hline
\end{tabular}



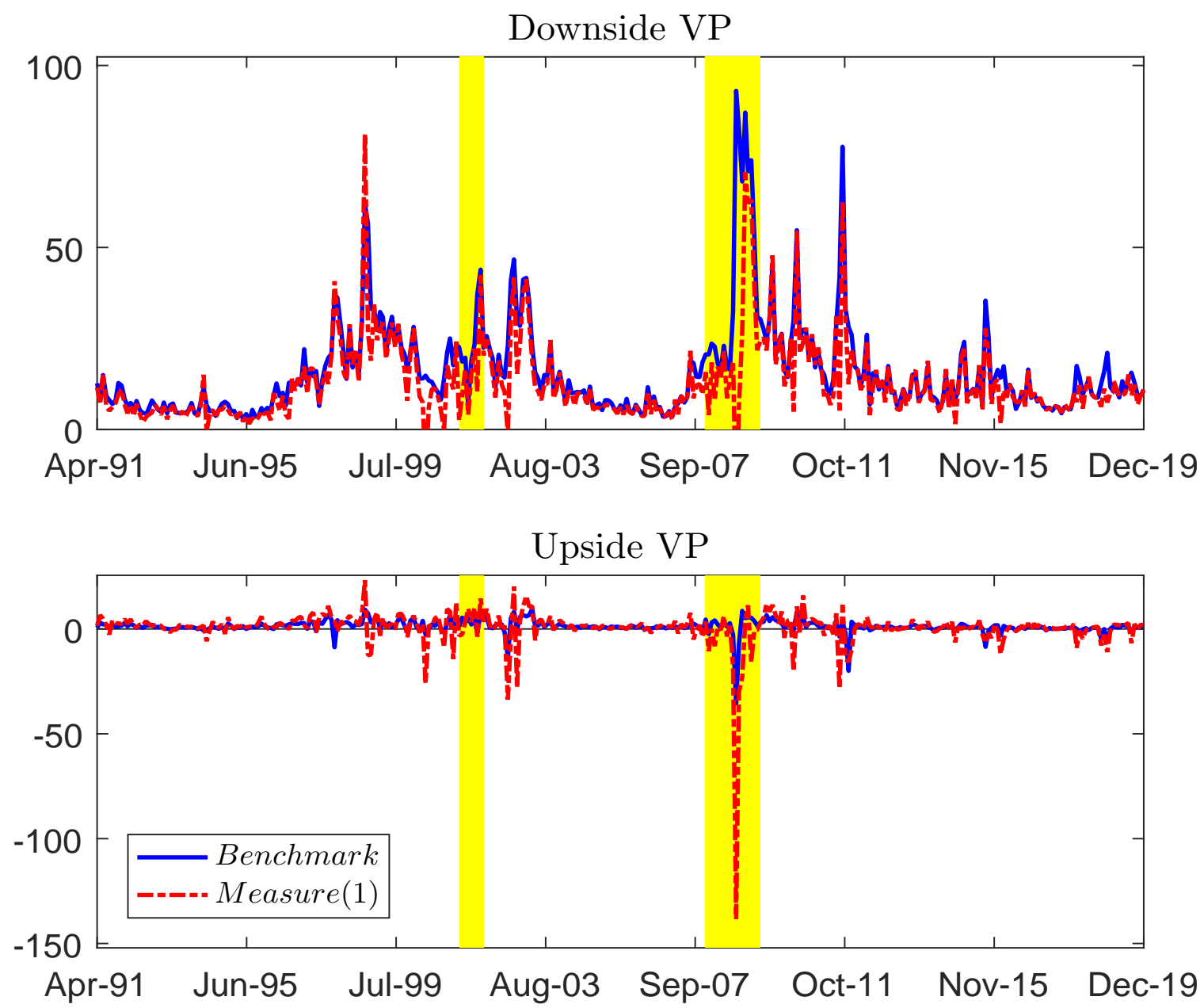

Figure A1: Alternative measures of the VP and its components

The dashed lines denote the Martingale measure, or measure (1) in Tables 1 and 2 The solid lines denote the benchmark VP measures used in the main empirical results (Table 1 and Figure 2). The shaded regions indicate NBER recessions. 

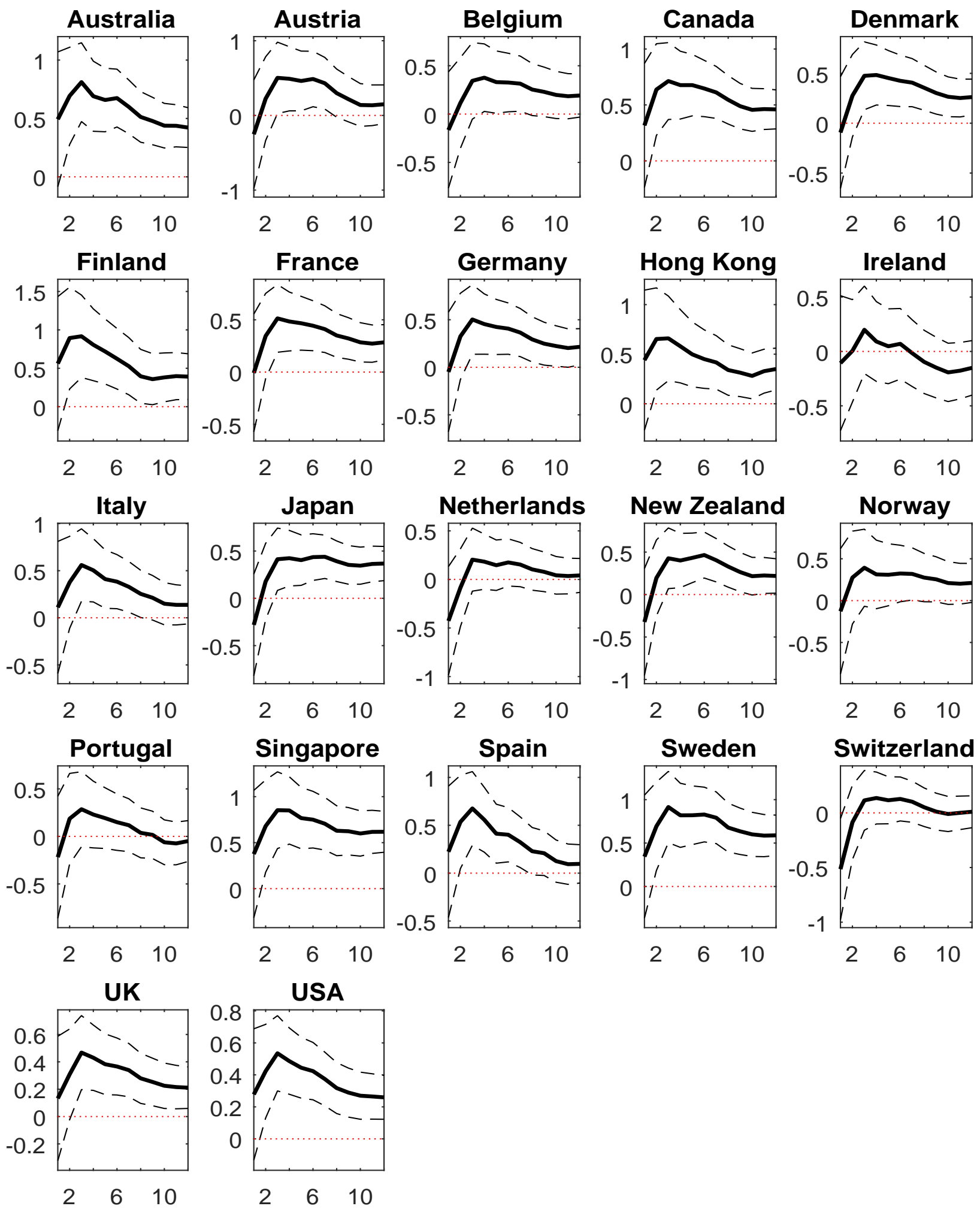

Figure A2: DVP predictive coefficients, alternative VP measure

This figure shows the predictive coefficient estimates of DVP from the country-level predictive regression specification in Equation (7), where predictors DVP and UVP use Measure (1), the Martingale measure (see Table 2). The dashed lines correspond to the $90 \%$ confidence intervals for the given Newey-West standard errors. The model specification is introduced in Section 2.3 . 

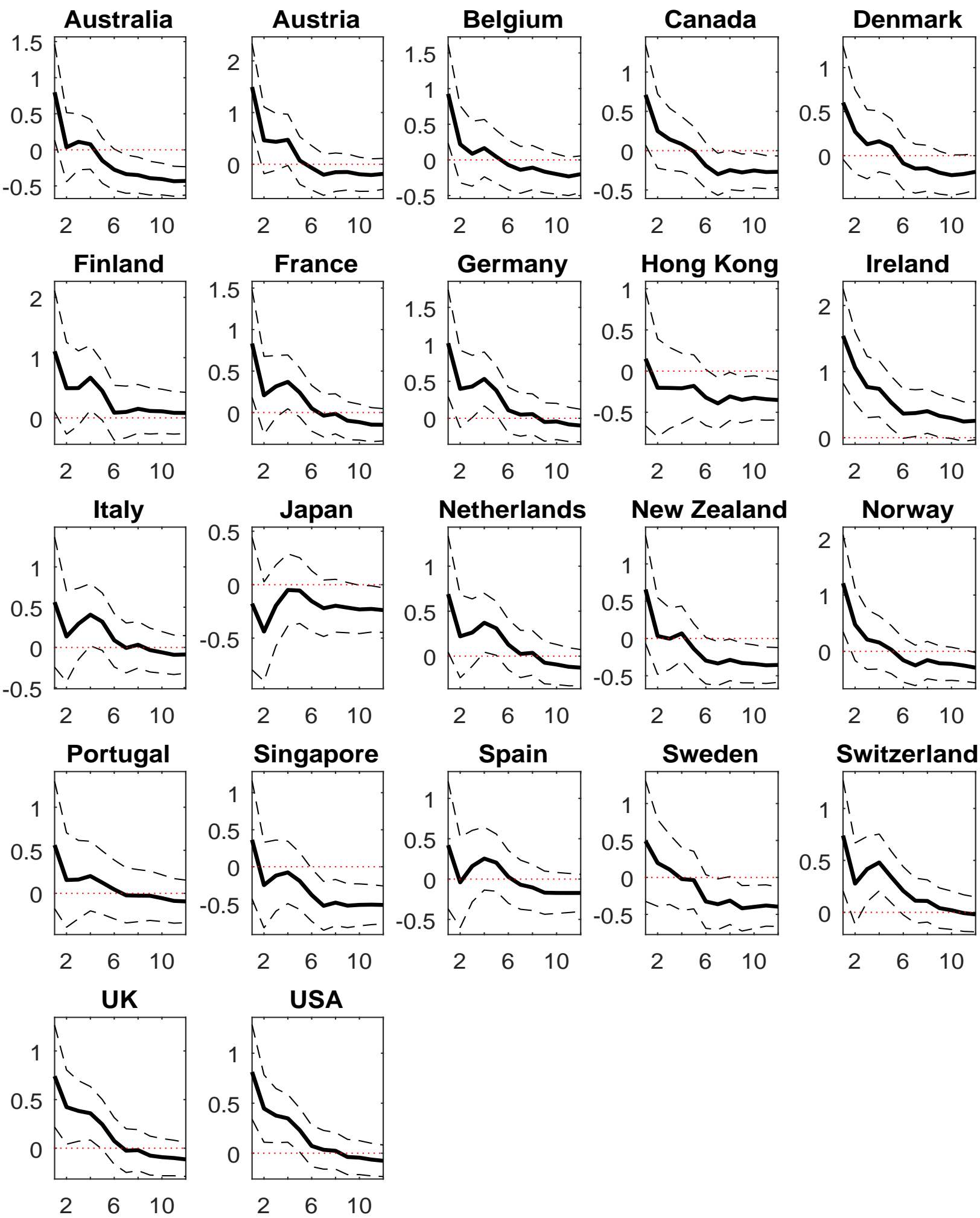

Figure A3: UVP predictive coefficients, alternative VP measure

This figure shows the predictive coefficient estimates of UVP from the country-level predictive regression specification in Equation (7), where predictors DVP and UVP use Measure (1), the Martingale measure (see Table 2). The dashed lines correspond to the $90 \%$ confidence intervals for the given Newey-West standard errors. The model specification is introduced in Section 2.3 . 

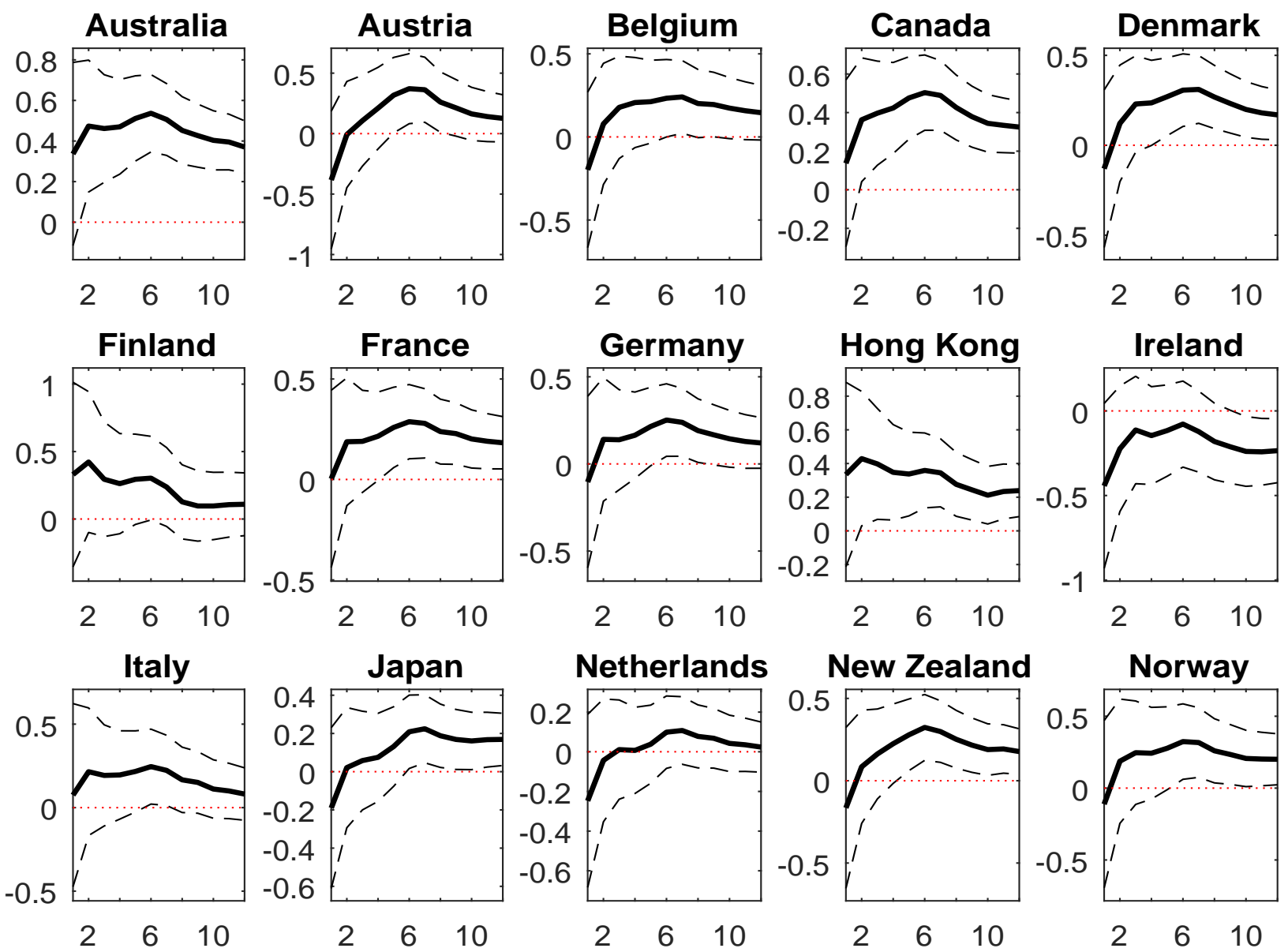

Netherlands
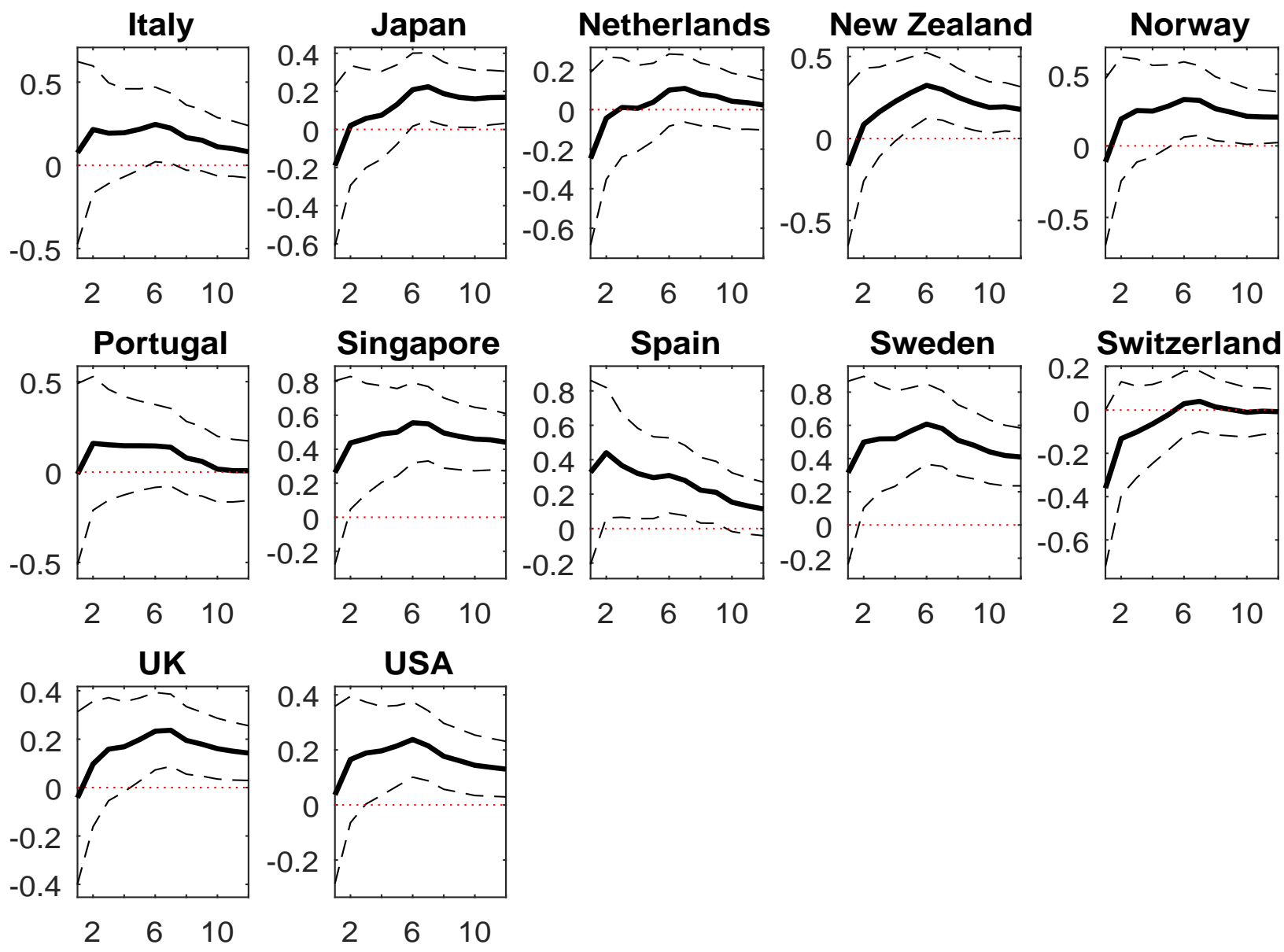

Figure A4: DVP predictive coefficients, model with control predictors

This figure shows the predictive coefficient estimates of DVP from the country-level predictive regression in an extended version of the setting in Equation (8) with control variables (US bill, earnings yield). The dashed lines correspond to the $90 \%$ confidence intervals for the given Newey-West standard errors. The model specification is introduced in Section 2.3 . 

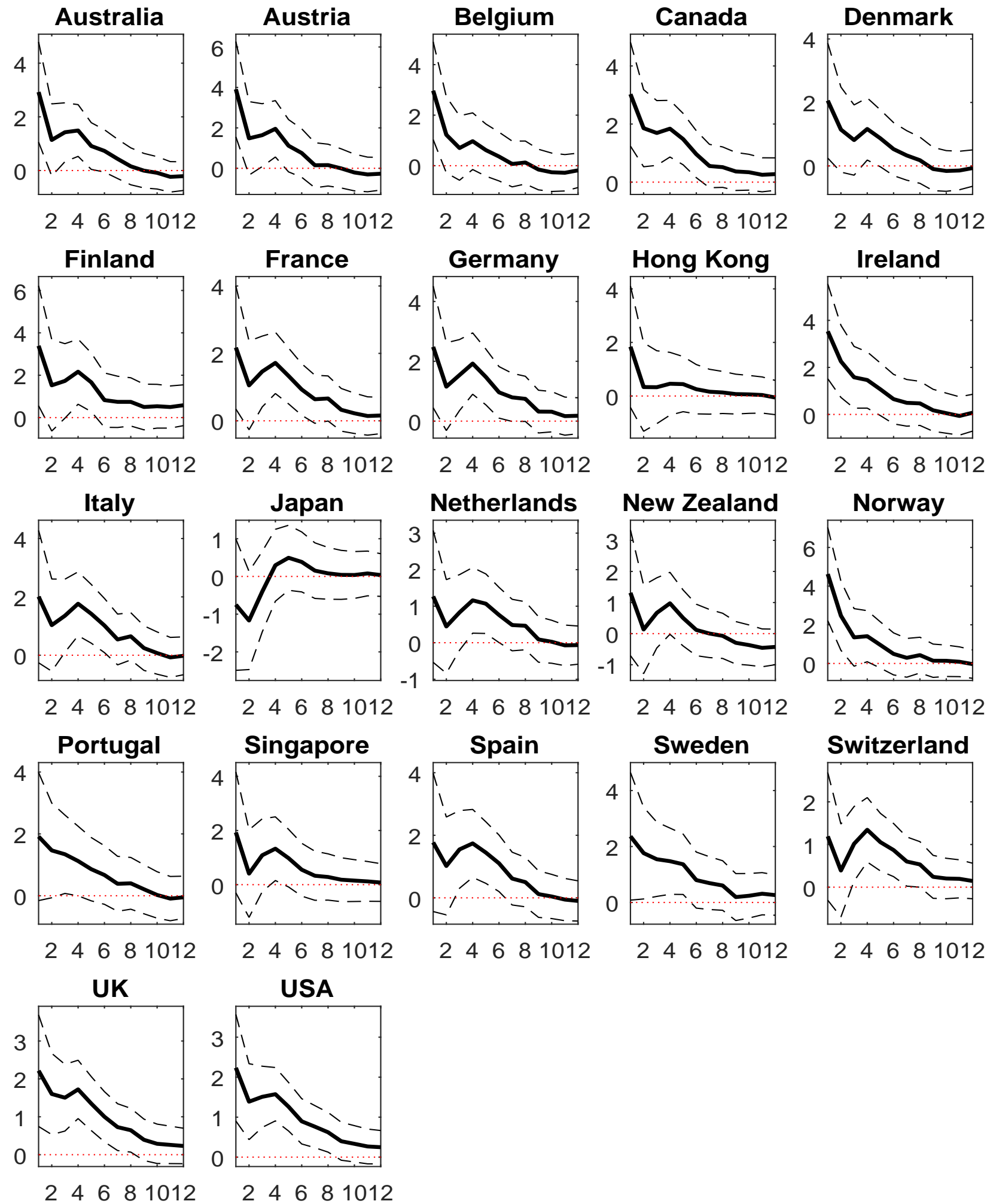

Figure A5: UVP predictive coefficients, model with control predictors

This figure shows the predictive coefficient estimates of UVP from the country-level predictive regression in an extended version of the setting in Equation (8) with control variables (US bill, earnings yield). The dashed lines correspond to the $90 \%$ confidence intervals for the given Newey-West standard errors. The model specification is introduced in Section 2.3 . 


\section{B. Solution for the price-dividend ratio and log stock returns}

Rewrite the dividend growth process and the pricing kernel in a matrix representation, $\Delta d_{t+1}=d_{0}+$ $\boldsymbol{d}_{\mathbf{1}} \boldsymbol{Y}_{\boldsymbol{t}}+\boldsymbol{d}_{\mathbf{2}} \boldsymbol{\Sigma} \boldsymbol{\omega}_{t+1}$ and $m_{t+1}=m_{0}+\boldsymbol{m}_{\mathbf{1}} \boldsymbol{Y}_{\boldsymbol{t}}+\boldsymbol{m}_{\mathbf{2}} \boldsymbol{\Sigma} \boldsymbol{\omega}_{t+\mathbf{1}}$, where $\boldsymbol{Y}_{\boldsymbol{t}}$ and $\boldsymbol{\omega}_{\boldsymbol{t}}$ are the state variable vector and the independent shock vector, respectively. Given the assumptions in Section 3 the US price-dividend ratio can be rewritten as,

$$
P D_{t}=E_{t}\left[M_{t+1}\left(\frac{P_{t+1}+D_{t+1}}{D_{t}}\right)\right]=\sum_{n=1}^{\infty} E_{t}\left[\exp \left(\sum_{j=1}^{n} m_{t+j}+\Delta d_{t+j}\right)\right]
$$

where $m_{t+j}$ indicates the future log US pricing kernel at month $j$ and $\Delta d_{t+j}$ the $j$-th month $\log$ dividend growth rates. Let $F_{t}^{n}$ denote the $n$-th term in the summation, $F_{t}^{n}=E_{t}\left[\exp \left(\sum_{j=1}^{n} m_{t+j}+\Delta d_{t+j}\right)\right]$, and hence $F_{t}^{n} D_{t}$ means the price of zero-coupon equity that matures in $n$ periods. The $P D_{t}$ can be rewritten as $\sum_{n=1}^{\infty} F_{t}^{n}$.

We first prove that, $\forall n \geq 1, F_{t}^{n}$ is an exactly exponential affine function of the state variables using induction. When $n=1, F_{t}^{1}=E_{t}\left[\exp \left(m_{t+1}+\Delta d_{t+1}\right)\right]=E_{t}\left\{\exp \left[\left(m_{0}+d_{0}\right)+\left(\boldsymbol{m}_{\mathbf{1}}+\boldsymbol{d}_{\mathbf{1}}\right) \boldsymbol{Y}_{\boldsymbol{t}}+\left(\boldsymbol{m}_{\mathbf{2}}+\boldsymbol{d}_{\mathbf{2}}\right) \boldsymbol{\Sigma} \boldsymbol{\omega}_{t+1}\right]\right\}=$ $\exp \left(e_{0}^{1}+\boldsymbol{e}_{\mathbf{1}}^{\mathbf{1}} \boldsymbol{Y}_{\boldsymbol{t}}\right)$, where $e_{0}^{1}$ and $\boldsymbol{e}_{\mathbf{1}}^{\mathbf{1}}$ are implicitly defined. Suppose that the $(n-1)$-th term $F_{t}^{n-1}=\exp \left(e_{0}^{n-1}+\boldsymbol{e}_{\mathbf{1}}^{\boldsymbol{n}-\mathbf{1}} \boldsymbol{Y}_{\boldsymbol{t}}\right)$, then

$$
\begin{aligned}
F_{t}^{n} & =E_{t}\left[\exp \left(\sum_{j=1}^{n} m_{t+j}+\Delta d_{t+j}\right)\right] \\
& =E_{t}\{\exp \left(m_{t+1}+\Delta d_{t+1}\right) \underbrace{E_{t+1}\left[\exp \left(\sum_{j=1}^{n-1} m_{t+j+1}+\Delta d_{t+j+1}\right)\right]}_{F_{t+1}^{n-1}}\} \\
& =E_{t}\left[\exp \left(m_{t+1}+\Delta d_{t+1}\right) \exp \left(e_{0}^{n-1}+\boldsymbol{e}_{\mathbf{1}}^{n-1} \boldsymbol{Y}_{\boldsymbol{t + 1}}\right)\right]=\exp \left(e_{0}^{n}+\boldsymbol{e}_{\mathbf{1}}^{n} \boldsymbol{Y}_{\boldsymbol{t}}\right),
\end{aligned}
$$

where $e_{0}^{n}$ and $\boldsymbol{e}_{1}^{n}$ are implicitly defined. Hence, the price-dividend ratio can be solved as $P D_{t}=\sum_{n=1}^{\infty} F_{t}^{n}=$ $\sum_{n=1}^{\infty} \exp \left(e_{0}^{n}+\boldsymbol{e}_{1}^{n} \boldsymbol{Y}_{\boldsymbol{t}}\right)$. The log return can be solved and approximated as,

$$
\begin{aligned}
r_{t+1} & =\ln \left(\frac{P_{t+1}+D_{t+1}}{P_{t}}\right)=\Delta d_{t+1}+\ln \left[\frac{1+\sum_{n=1}^{\infty} \exp \left(e_{0}^{n}+\boldsymbol{e}_{1}^{n} \boldsymbol{Y}_{\boldsymbol{t}+\mathbf{1}}\right)}{\sum_{n=1}^{\infty} \exp \left(e_{0}^{n}+\boldsymbol{e}_{1}^{n} \boldsymbol{Y}_{\boldsymbol{t}}\right)}\right] \\
& \approx \Delta d_{t+1}+\text { const. }+\frac{\sum_{n=1}^{\infty} \exp \left(e_{0}^{n}+\boldsymbol{e}_{1}^{n} \overline{\boldsymbol{Y}}\right) \boldsymbol{e}_{1}^{n}}{\frac{1+\sum_{n=1}^{\infty} \exp \left(e_{0}^{n}+\boldsymbol{e}_{1}^{n} \overline{\boldsymbol{Y}}\right)}{\sum_{n=1}^{\infty} \exp \left(e_{0}^{n}+\boldsymbol{e}_{1}^{n} \overline{\boldsymbol{Y}}\right)}} \boldsymbol{Y}_{\boldsymbol{t}+\mathbf{1}}-\frac{\sum_{n=1}^{\infty} \exp \left(e_{0}^{n}+\boldsymbol{e}_{1}^{n} \overline{\boldsymbol{Y}}\right) \boldsymbol{e}_{1}^{n}}{\sum_{n=1}^{\infty} \exp \left(e_{0}^{n}+\boldsymbol{e}_{1}^{n} \overline{\boldsymbol{Y}}\right)} \boldsymbol{Y}_{\boldsymbol{t}} \\
& =\xi_{0}+\boldsymbol{\xi}_{\mathbf{1}} \boldsymbol{Y}_{\boldsymbol{t}}+\boldsymbol{\xi}_{\mathbf{2}} \boldsymbol{\Sigma} \boldsymbol{\omega}_{\boldsymbol{t}+\mathbf{1}} .
\end{aligned}
$$

Similarly, as the model takes the perspective of a US investor, the price-dividend ratio of country $i$ is modeled as $P D_{t}^{i}=E_{t}\left[M_{t+1}\left(\frac{P_{t+1}^{i}+D_{t+1}^{i}}{D_{t}^{i}}\right)\right]=\sum_{n=1}^{\infty} E_{t}\left[\exp \left(\sum_{j=1}^{n} m_{t+j}+\Delta d_{t+j}^{i}\right)\right]$. Suppose the country $i$ $\log$ dividend growth is $\Delta d_{t+1}^{i}=d_{0}^{i}+\left(\boldsymbol{d}_{\mathbf{1}}^{i} \boldsymbol{Y}_{\boldsymbol{t}}+\boldsymbol{d}_{\mathbf{2}}^{i} \boldsymbol{\Sigma} \boldsymbol{\omega}_{\boldsymbol{t}+\mathbf{1}}\right)+\mu_{t}^{i}+u_{d, t+1}^{i}$, where $\boldsymbol{d}_{\mathbf{1}}^{i}\left(\boldsymbol{d}_{\mathbf{2}}^{i}\right)$ indicates the loadings of country $i$ 's dividend growth on the US lagged state variable levels (state variable shocks), and $\mu_{t}^{i}$ and $u_{d, t+1}^{i}$ indicate the additional country-specific dividend growth mean and shock processes that are orthogonal to the US shocks, respectively. Using the same induction procedure, it can be easily shown that,

$$
\begin{gathered}
P D_{t}^{i}=\sum_{n=1}^{\infty} F_{t}^{n}=\sum_{n=1}^{\infty} \exp \left(e_{0}^{i, n}+\boldsymbol{e}_{\mathbf{1}}^{i, n} \boldsymbol{Y}_{\boldsymbol{t}}+\text { Idiosyncratic Parts }\right) \\
r_{t+1}^{i}=\ln \left(\frac{P_{t+1}^{i}+D_{t+1}^{i}}{P_{t}^{i}}\right)=\xi_{0}^{i}+\boldsymbol{\xi}_{\mathbf{1}}^{i} \boldsymbol{Y}_{\boldsymbol{t}}+\boldsymbol{\xi}_{\mathbf{2}}^{i} \boldsymbol{\Sigma} \boldsymbol{\omega}_{t+\mathbf{1}}+\text { Idiosyncratic Parts. }
\end{gathered}
$$

\section{Solution for the variance risk premium}

The proof is similar to that in Bekaert, Engstrom, and $\mathrm{Xu}$ (forthcoming). First, the US one-period physical conditional return variance can be easily obtained, given that $\omega_{t+1} \sim \Gamma\left(\Omega Y_{t}+e, 1\right)-\left(\Omega Y_{t}+e\right)$, as:

$$
V A R_{t}\left(r_{t+1}\right)=\left(\boldsymbol{\xi}_{\mathbf{2}} \boldsymbol{\Sigma}\right)^{\circ 2}\left(\boldsymbol{\Omega} \boldsymbol{Y}_{\boldsymbol{t}}+\boldsymbol{e}\right),
$$

where "o" indicates element-by-element matrix multiplication. 
Second, the US one-period risk-neutral conditional return variance can be obtained using the moment generating function (MGF) of gamma-distributed shocks. We start from the MGF under the risk-neutral measure:

$$
\begin{aligned}
m g f_{t}^{Q}\left(r_{t+1} ; \nu\right)= & \frac{E_{t}\left[\exp \left(m_{t+1}+\nu r_{t+1}\right)\right]}{E_{t}\left[\exp \left(m_{t+1}\right)\right]} \\
= & \exp \left\{E_{t}\left(m_{t+1}\right)+\nu E_{t}\left(r_{t+1}\right)+\left[-\left(\boldsymbol{m}_{\mathbf{2}}+\boldsymbol{\nu} \boldsymbol{\xi}_{\mathbf{2}}\right) \boldsymbol{\Sigma}-\ln \left(\mathbf{1}-\left(\boldsymbol{m}_{\mathbf{2}}+\boldsymbol{\nu} \boldsymbol{\xi}_{\mathbf{2}}\right) \boldsymbol{\Sigma}\right)\right]\left(\boldsymbol{\Omega} \boldsymbol{Y}_{\boldsymbol{t}}+\boldsymbol{e}\right)\right\} \\
& / \exp \left\{E_{t}\left(m_{t+1}\right)+\left[-\boldsymbol{m}_{\mathbf{2}} \boldsymbol{\Sigma}-\ln \left(\mathbf{1}-\boldsymbol{m}_{\mathbf{2}} \boldsymbol{\Sigma}\right)\right]\left(\boldsymbol{\Omega} \boldsymbol{Y}_{\boldsymbol{t}}+\boldsymbol{e}\right)\right\} \\
& =\exp \left\{\nu E_{t}\left(r_{t+1}\right)+\left[-\boldsymbol{\nu} \boldsymbol{\xi}_{\mathbf{2}} \boldsymbol{\Sigma}+\left[-\ln \left(\mathbf{1}-\left(\boldsymbol{m}_{\mathbf{2}}+\boldsymbol{\nu} \boldsymbol{\xi}_{\mathbf{2}}\right) \boldsymbol{\Sigma}\right)+\ln \left(\mathbf{1}-\boldsymbol{m}_{\mathbf{2}} \boldsymbol{\Sigma}\right)\right]\right]\left(\boldsymbol{\Omega} \boldsymbol{Y}_{\boldsymbol{t}}+\boldsymbol{e}\right)\right\} .
\end{aligned}
$$

The first-order moment is the first-order derivative at $\nu=0$ :

$$
\begin{aligned}
\frac{\partial m g f_{t}^{Q}\left(r_{t+1} ; \nu\right)}{\partial \nu} & =m g f_{t}^{Q}\left(r_{t+1} ; \nu\right) *\left\{E_{t}\left(r_{t+1}\right)+\left[\left(\boldsymbol{m}_{\mathbf{2}}+\boldsymbol{\nu} \boldsymbol{\xi}_{\mathbf{2}}\right) \boldsymbol{\Sigma} \circ \boldsymbol{\xi}_{\mathbf{2}} \boldsymbol{\Sigma} \circ\left(\mathbf{1}-\left(\boldsymbol{m}_{\mathbf{2}}+\boldsymbol{\nu} \boldsymbol{\xi}_{\mathbf{2}}\right) \boldsymbol{\Sigma}\right)^{\circ-1}\right]\left(\boldsymbol{\Omega} \boldsymbol{Y}_{\boldsymbol{t}}+\boldsymbol{e}\right)\right\} \\
E_{t}^{Q}\left(r_{t+1}\right) & =\left.\frac{\partial m g f_{t}^{Q}\left(r_{t+1} ; \nu\right)}{\partial \nu}\right|_{\nu=0} \\
& =E_{t}\left(r_{t+1}\right)+\left[\boldsymbol{m}_{\mathbf{2}} \boldsymbol{\Sigma} \circ \boldsymbol{\xi}_{\mathbf{2}} \boldsymbol{\Sigma} \circ\left(1-\boldsymbol{m}_{\mathbf{2}} \boldsymbol{\Sigma}\right)^{\circ-1}\right]\left(\boldsymbol{\Omega} \boldsymbol{Y}_{\boldsymbol{t}}+\boldsymbol{e}\right)
\end{aligned}
$$

The second-order moment can be derived as follows:

$$
\begin{aligned}
\frac{\partial^{2} m g f_{t}^{Q}\left(r_{t+1} ; \nu\right)}{\partial \nu^{2}} & =m g f_{t}^{Q}\left(r_{t+1} ; \nu\right) *\left\{E_{t}\left(r_{t+1}\right)+\left[\left(\boldsymbol{m}_{\mathbf{2}}+\boldsymbol{\nu} \boldsymbol{\xi}_{\mathbf{2}}\right) \boldsymbol{\Sigma} \circ \boldsymbol{\xi}_{\mathbf{2}} \boldsymbol{\Sigma} \circ\left(\mathbf{1}-\left(\boldsymbol{m}_{\mathbf{2}}+\boldsymbol{\nu} \boldsymbol{\xi}_{\mathbf{2}}\right) \boldsymbol{\Sigma}\right)^{\circ-1}\right]\left(\boldsymbol{\Omega} \boldsymbol{Y}_{\boldsymbol{t}}+\boldsymbol{e}\right)\right\}^{2} \\
& +m g f_{t}^{Q}\left(r_{t+1} ; \nu\right) *\left\{\left[\left(\boldsymbol{m}_{\mathbf{2}}+\boldsymbol{\nu} \boldsymbol{\xi}_{\mathbf{2}}\right) \boldsymbol{\Sigma} \circ\left(\boldsymbol{\xi}_{\mathbf{2}} \boldsymbol{\Sigma}\right)^{\circ 2}-\left(\mathbf{1}-\left(\boldsymbol{m}_{\mathbf{2}}+\boldsymbol{\nu} \boldsymbol{\xi}_{\mathbf{2}}\right) \boldsymbol{\Sigma}\right) \circ\left(\boldsymbol{\xi}_{\mathbf{2}} \boldsymbol{\Sigma}\right)^{\circ 2}\right] \circ\left(\mathbf{1}-\left(\boldsymbol{m}_{\mathbf{2}}+\boldsymbol{\nu} \boldsymbol{\xi}_{\mathbf{2}}\right) \boldsymbol{\Sigma}\right)^{\circ-2}\right\} \\
E_{t}^{Q}\left(r_{t+1}^{2}\right) & =\left.\frac{\partial^{2} m g f_{t}^{Q}\left(r_{t+1} ; \nu\right)}{\partial \nu^{2}}\right|_{\nu=0} \\
& =\left(E_{t}^{Q}\left(r_{t+1}\right)\right)^{2}+\left[\left(\boldsymbol{\xi}_{\mathbf{2}} \boldsymbol{\Sigma}\right)^{\circ 2} \circ\left(\mathbf{1}-\boldsymbol{m}_{\mathbf{2}} \boldsymbol{\Sigma}\right)^{\circ-2}\right]\left(\boldsymbol{\Omega} \boldsymbol{Y}_{\boldsymbol{t}}+\boldsymbol{e}\right) .
\end{aligned}
$$

As a result, the one-period risk-neutral conditional variance is

$$
\begin{aligned}
V A R_{t}^{Q}\left(\widetilde{r}_{t+1}^{i}\right) & =E_{t}^{Q}\left(\left(\widetilde{r}_{t+1}^{i}\right)^{2}\right)-\left(E_{t}^{Q}\left(\widetilde{r}_{t+1}^{i}\right)\right)^{2} \\
& =\left[\left(\boldsymbol{\xi}_{\mathbf{2}} \boldsymbol{\Sigma}\right)^{\circ 2} \circ\left(\mathbf{1}-\boldsymbol{m}_{\mathbf{2}} \boldsymbol{\Sigma}\right)^{\circ-2}\right]\left(\boldsymbol{\Omega} \boldsymbol{Y}_{\boldsymbol{t}}+\boldsymbol{e}\right) .
\end{aligned}
$$

The US variance risk premium is, as displayed in Equation 13 , given by:

$$
V A R_{t}^{Q}\left(\widetilde{r}_{t+1}^{i}\right)-V A R_{t}\left(\widetilde{r}_{t+1}^{i}\right)=\left\{\left(\boldsymbol{\xi}_{\mathbf{2}} \boldsymbol{\Sigma}\right)^{\circ 2} \circ\left[\left(\mathbf{1}-\boldsymbol{m}_{\mathbf{2}} \boldsymbol{\Sigma}\right)^{\circ-2}-\mathbf{1}\right]\right\}\left(\boldsymbol{\Omega} \boldsymbol{Y}_{\boldsymbol{t}}+\boldsymbol{e}\right) .
$$

\section{Solution for the equity risk premiums}

The risk free rate is derived as,

$$
\begin{aligned}
r f_{t} & =-\ln \left\{E_{t}\left[\exp \left(m_{t+1}\right)\right]\right\} \\
& =-\ln \left\{E_{t}\left(m_{t+1}\right)+\left[-\boldsymbol{m}_{\mathbf{2}} \boldsymbol{\Sigma}-\ln \left(\mathbf{1}-\boldsymbol{m}_{\mathbf{2}} \boldsymbol{\Sigma}\right)\right]\left(\boldsymbol{\Omega} \boldsymbol{Y}_{\boldsymbol{t}}+\boldsymbol{e}\right)\right\} .
\end{aligned}
$$

We then impose the no-arbitrage condition, $1=E_{t}\left[\exp \left(m_{t+1}+r_{t+1}\right)\right]$, and obtain the expected excess returns. By expanding the law of one price (LOOP) equation, we obtain:

$$
\begin{aligned}
1 & =E_{t}\left[\exp \left(m_{t+1}+r_{t+1}\right)\right] \\
& =\exp \left\{E_{t}\left(m_{t+1}\right)+E_{t}\left(r_{t+1}\right)+\left[-\left(\boldsymbol{m}_{\mathbf{2}}+\boldsymbol{\xi}_{\mathbf{2}}\right) \boldsymbol{\Sigma}-\ln \left(\mathbf{1}-\left(\boldsymbol{m}_{\mathbf{2}}+\boldsymbol{\xi}_{\mathbf{2}}\right) \boldsymbol{\Sigma}\right)\right]\left(\boldsymbol{\Omega} \boldsymbol{Y}_{\boldsymbol{t}}+\boldsymbol{e}\right)\right\}
\end{aligned}
$$

where $\boldsymbol{m}_{\mathbf{2}}, \boldsymbol{\xi}_{\mathbf{2}}, \boldsymbol{\Sigma}$ and $\boldsymbol{e}$ are constant matrices defined above. Given the risk free rate derived above, the US equity risk premium is, as displayed in Equation (14, given by:

$$
E_{t}\left(r_{t+1}\right)-r f_{t}=\left\{\boldsymbol{\xi}_{\mathbf{2}} \boldsymbol{\Sigma}+\ln \left[\mathbf{1}-\left(\boldsymbol{m}_{\mathbf{2}}+\boldsymbol{\xi}_{\mathbf{2}}\right) \boldsymbol{\Sigma}\right]-\ln \left(\mathbf{1}-\boldsymbol{m}_{\mathbf{2}} \boldsymbol{\Sigma}\right)\right\}\left(\boldsymbol{\Omega} \boldsymbol{Y}_{\boldsymbol{t}}+\boldsymbol{e}\right) .
$$

Similarly, the international equity risk premium is, as displayed in Equation [15, given by:

$$
\begin{aligned}
E_{t}\left(r_{t+1}^{i}\right)-r f_{t} & =\underbrace{\left\{\boldsymbol{\xi}_{\mathbf{2}}^{\boldsymbol{i}} \boldsymbol{\Sigma}+\ln \left[\mathbf{1}-\left(\boldsymbol{m}_{\mathbf{2}}+\boldsymbol{\xi}_{\mathbf{2}}^{i}\right) \boldsymbol{\Sigma}\right]-\ln \left(\mathbf{1}-\boldsymbol{m}_{\mathbf{2}} \boldsymbol{\Sigma}\right)\right\}\left(\boldsymbol{\Omega} \boldsymbol{Y}_{\boldsymbol{t}}+\boldsymbol{e}\right)}_{\text {The Global Compensation Part }} \\
& + \text { Idiosyncratic Parts. }
\end{aligned}
$$

The total country equity risk premiums can also be driven by a pure local risk compensation component, which however is not the focus of the paper and in theory should be un-predictable by common/US predictors, and hence is abbreviated above without loss of generality. 


\section{E. Individual US state variable processes and estimation results}

In this appendix, we complement Section 4 by providing the exact dynamic processes of individual state variables and their detailed estimation results:

$$
\boldsymbol{\Sigma}_{\boldsymbol{m}} \boldsymbol{\omega}_{\boldsymbol{m}, \boldsymbol{t + 1}} \equiv\left[\begin{array}{c}
\theta_{t+1}-E_{t}\left(\theta_{t+1}\right) \\
q_{t+1}-E_{t}\left(q_{t+1}\right) \\
i l l i q_{t+1}-E_{t}\left(i l l i q_{t+1}\right)
\end{array}\right]
$$

where $\theta_{t+1}$ denotes the economic growth, $q_{t+1}$ risk aversion, and $i l l i q_{t+1}$ stock market illiquidity. Our state variable system is estimated and assumed realistic at the monthly frequency.

\section{E.1. Dynamic processes}

The economic growth state variable is assumed to follow a reduced-form dynamic process that captures time-varying expected growth and asymmetric/skewed and heteroskedastic shocks to be potentially consistent with recent work (see, e.g., Adrian, Boyarchenko, and Giannone (2019)):

$$
\theta_{t+1}=\bar{\theta}+\rho_{\theta, \theta}\left(\theta_{t}-\bar{\theta}\right)+\rho_{\theta, \theta p}\left(\theta p_{t}-\overline{\theta p}\right)+\rho_{\theta, \theta n}\left(\theta n_{t}-\overline{\theta n}\right)+\delta_{\theta, \theta p} \omega_{\theta p, t+1}-\delta_{\theta, \theta n} \omega_{\theta n, t+1},
$$

where the conditional mean is subject to an $\operatorname{AR}(1)$ term capturing persistence as well as changes in expected good and bad economic uncertainties capturing the GARCH-in-mean intuition. As in Bekaert, Engstrom, and Xu (forthcoming), the disturbance of the log economic growth is decomposed into two independent centered gamma shocks:

$$
\begin{aligned}
\omega_{\theta p, t+1} & =\Gamma\left(\theta p_{t}, 1\right)-\theta p_{t}, \\
\omega_{\theta n, t+1} & =\Gamma\left(\theta n_{t}, 1\right)-\theta n_{t},
\end{aligned}
$$

where $\omega_{\theta p, t+1}\left(\omega_{\theta n, t+1}\right)$ governs the right-tail (left-tail) dynamics of the growth distribution with shape parameter $\theta p_{t}\left(\theta n_{t}\right)$ determining the conditional higher moments of the growth disturbance shock. For example, given the moment generating function (MGF) of independent gamma shocks, the conditional variance of $\theta_{t+1}$ is $\delta_{\theta, \theta p}^{2} \theta p_{t}+$ $\delta_{\theta, \theta n}^{2} \theta n_{t}$ and the conditional unscaled skewness is $2 \delta_{\theta, \theta p}^{3} \theta p_{t}-2 \delta_{\theta, \theta n}^{3} \theta n_{t}$. Increases in $\theta p_{t}\left(\theta n_{t}\right)$ imply higher (lower) conditional skewness while increasing conditional variance, and hence $\theta p_{t}\left(\theta n_{t}\right)$ can be interpreted as the "good" ("bad") uncertainty state variable. This disturbance structure is one of the non-Gaussian shock assumptions that the literature has explored to realistically model macro or financial state variable processes (see, e.g., Eraker and Shaliastovich (2008), Bekaert, Engstrom, and Xing (2009), Fulop, Li, and Yu (2015), Segal, Shaliastovich, and Yaron (2015), De Groot (2015), Bekaert and Engstrom (2017), Xu (2021)). The dynamics of the good and bad economic uncertainty state variables follow $\mathrm{AR}(1)$ processes:

$$
\begin{aligned}
& \theta p_{t+1}=\overline{\theta p}+\rho_{\theta p}\left(\theta p_{t}-\overline{\theta p}\right)+\sigma_{\theta p} \omega_{\theta p, t+1}, \\
& \theta n_{t+1}=\overline{\theta n}+\rho_{\theta n}\left(\theta n_{t}-\overline{\theta n}\right)+\sigma_{\theta n} \omega_{\theta n, t+1} .
\end{aligned}
$$

Define a macroeconomic state variable vector, $\boldsymbol{Y}_{\boldsymbol{m a c}, \boldsymbol{t}} \equiv\left[\begin{array}{lll}\theta_{t} & \theta p_{t} & \theta n_{t}\end{array}\right]^{\prime}$, and its unconditional mean $\overline{\boldsymbol{Y}_{\boldsymbol{m a c}}} \equiv$ $\left[\begin{array}{lll}\bar{\theta} & \overline{\theta p} & \overline{\theta n}\end{array}\right]^{\prime}$.

The risk aversion state variable, $q_{t}$, evolves over time with a state-dependent conditional mean and a disturbance that is exposed to economic fundamental shocks. The residual is then separated into two independent gamma shocks, $\omega_{q h, t+1}$ and $\omega_{q l, t+1}$, potentially capturing distinct behaviors of the right-tail (high risk aversion) and left-tail (low risk aversion) preference shocks:

$$
\begin{aligned}
q_{t+1} & =\bar{q}+\rho_{q, q}\left(q_{t}-\bar{q}\right)+\rho_{q, q h}\left(q h_{t}-\overline{q h}\right)+\boldsymbol{\rho}_{\boldsymbol{q}, \boldsymbol{m a c}}\left(\boldsymbol{Y}_{\boldsymbol{m a c}, t}-\overline{\boldsymbol{Y}_{\boldsymbol{m a c}}}\right) \\
& +\delta_{q, \theta p} \omega_{\theta p, t+1}+\delta_{q, \theta n} \omega_{\theta n, t+1}+\delta_{q, q h} \omega_{q h, t+1}-\delta_{q, q l} \omega_{q l, t+1}, \\
\omega_{q h, t+1} & =\Gamma\left(q h_{t}, 1\right)-q h_{t}, \\
\omega_{q l, t+1} & =\Gamma(\overline{q l}, 1)-\overline{q l}, \\
q h_{t+1} & =\overline{q h}+\rho_{q h}\left(q h_{t}-\overline{q h}\right)+\sigma_{q h} \omega_{q h, t+1} .
\end{aligned}
$$

The conditional mean of risk aversion evolves with the macro variables (both level and volatility), an AR(1) term, and a high risk aversion state variable $q h_{t}$ that captures the fluctuation of the right-tail risk aversion shock. Given that risk aversion heterskedasticity is likely driven by its right-tail movements when risk aversion is high, we shut down heteroskedasticity coming from the left-tail movements when risk aversion is low to keep the model relatively simple. Note that our risk aversion dynamics are different from those in the literature. First, Bekaert et al. (forthcoming) also assume a pure risk aversion shock that is orthogonal to consumption (fundamental) shocks; they assume its shape parameter same as risk aversion, whereas we elicit a new state variable $q h_{t}$ that does not equal to $q_{t}$ (but should very likely positively correlate with $q_{t}$ empirically, as we do find later). Second, the 
most acknowledged time-varying risk aversion model is Campbell and Cochrane (1999) which assumes that risk aversion is purely driven by changes in real fundamentals. Finally, define $\boldsymbol{Y}_{\boldsymbol{q}, \boldsymbol{t}}=\left[\begin{array}{ll}q_{t} & q h_{t}\end{array}\right]^{\prime}$, and $\overline{\boldsymbol{Y}_{\boldsymbol{q}}}=\left[\begin{array}{ll}\bar{q} & \overline{q h}\end{array}\right]^{\prime}$.

The stock market illiquidity process, $i l l i q_{t}$, is isomorphic:

$$
\begin{aligned}
& i l l i q_{t+1}=\overline{i l l i q}+\rho_{\text {illiq }, \text { illiq }}\left(\text { illiq }_{t}-\overline{i l l i q}\right)+\rho_{i l l i q, i l l i q h}\left(\text { illiqh }_{t}-\overline{i l l i q h}\right)+\rho_{\text {illiq }, \text { illiql }}\left(\text { illiql }_{t}-\overline{i l l i q l}\right) \\
& +\boldsymbol{\rho}_{\text {illiq, mac }}\left(\boldsymbol{Y}_{\text {mac }, t}-\overline{\boldsymbol{Y}_{\text {mac }}}\right)+\boldsymbol{\rho}_{\text {illiq,q }}\left(\boldsymbol{Y}_{q, t}-\overline{\boldsymbol{Y}_{q}}\right) \\
& +\delta_{i l l i q, \theta p} \omega_{\theta p, t+1}+\delta_{i l l i q, \theta n} \omega_{\theta n, t+1}+\delta_{i l l i q, q h} \omega_{q h, t+1}+\delta_{i l l i q, q l} \omega_{q l, t+1}+\delta_{i l l i q, i l l i q h} \omega_{i l l i q h, t+1}-\delta_{i l l i q, i l l i q l} \omega_{i l l i q l, t+1}, \\
& \omega_{\text {illiqh }, t+1}=\Gamma\left(\text { illiqh }_{t}, 1\right)-i l l i q h_{t}, \\
& \omega_{i l l i q l, t+1}=\Gamma\left(\text { illiql }_{t}, 1\right)-\text { illiql }_{t}, \\
& i l l i q h_{t+1}=\overline{i l l i q h}+\rho_{i l l i q h}\left(i l l i q h_{t}-\overline{i l l i q h}\right)+\sigma_{i l l i q h} \omega_{i l l i q h, t+1}, \\
& i l l i q l_{t+1}=\overline{i l l i q l}+\rho_{i l l i q l}\left(i_{l l i q l_{t}}-\overline{i l l i q l}\right)+\sigma_{i l l i q l} \omega_{i l l i q l, t+1},
\end{aligned}
$$

where $i l l i q h_{t}\left(i l l i q l_{t}\right)$ captures the right-tail (left-tail) of the pure illiquidity disturbance that is cleansed from risk aversion and macro shocks.

\section{E.2. Estimation results}

The estimation of the three state variable systems is conducted sequentially given the overlaying shocks.

\begin{tabular}{|c|c|c|c|c|c|c|}
\hline \multicolumn{7}{|c|}{ A. Estimation Results of $\theta_{t}, \theta p_{t}, \theta n_{t}$} \\
\hline$\theta_{t}:$ & $\bar{\theta}$ & $\rho_{\theta, \theta}$ & $\rho_{\theta, \theta p}$ & $\rho_{\theta, \theta n}$ & $\delta_{\theta, \theta p}$ & $\delta_{\theta, \theta n}$ \\
\hline Coeff. & $0.0023^{* * *}$ & $0.3799^{* * *}$ & $4.02 \mathrm{E}-05$ & -0.0001 & $0.0001^{* * *}$ & $0.0028^{* * *}$ \\
\hline $\mathrm{SE}$ & $(0.0003)$ & $(0.0313)$ & $(0.0002)$ & $(0.0012)$ & $(2.81 \mathrm{E}-5)$ & $(0.0003)$ \\
\hline$\theta p_{t}:$ & $\overline{\theta p}$ & $\rho_{\theta p}$ & $\delta_{\theta p}$ & & & \\
\hline Coeff. & $500($ fix $)$ & $0.9979^{* * *}$ & $0.3739 * * *$ & & & \\
\hline $\mathrm{SE}$ & & $(0.0171)$ & $(0.0173)$ & & & \\
\hline$\theta n_{t}:$ & $\overline{\theta n}$ & $\rho_{\theta n}$ & $\delta_{\theta p}$ & & & \\
\hline Coeff. & $10.3362^{* * *}$ & $0.9525^{* * *}$ & $2.2996^{* * *}$ & & & \\
\hline $\mathrm{SE}$ & $(2.0747)$ & $(0.0096)$ & $(0.1907)$ & & & \\
\hline \multicolumn{7}{|c|}{ B. Estimation Results of $q_{t}, q h_{t}$} \\
\hline$q_{t}:$ & $\bar{q}$ & $\rho_{q, q}$ & $\rho_{q, q h}$ & $\rho_{q, \theta}$ & $\rho_{q, \theta p}$ & $\rho_{q, \theta n}$ \\
\hline Coeff. & $0.3266^{* * *}$ & $0.7124^{* * *}$ & -0.0006 & $-3.1851^{* * *}$ & $0.0008 * *$ & 0.0011 \\
\hline \multirow[t]{2}{*}{$\mathrm{SE}$} & $(0.0102)$ & $(0.0355)$ & $(0.0004)$ & $(0.9238)$ & $(0.0003)$ & $(0.0009)$ \\
\hline & $\delta_{q, \theta p}$ & $\delta_{q, \theta n}$ & $\delta_{q, q h}$ & $\delta_{q, q l}$ & & \\
\hline Coeff. & 0.0004 & $0.0185^{* * *}$ & $1.0767 * * *$ & $0.0906^{* * *}$ & $786.6892^{* * *}$ & \\
\hline $\mathrm{SE}$ & $(0.0003)$ & $(0.0034)$ & $(0.0645)$ & $(0.0001)$ & $(102.74)$ & \\
\hline$q h_{t}:$ & $\overline{q h}$ & $\rho_{q h}$ & $\delta_{q h}$ & & & \\
\hline Coeff. & $0.872^{* * *}$ & $0.5677^{* * *}$ & $1.0767^{* * *}$ & & & \\
\hline $\mathrm{SE}$ & $(0.0670)$ & $(0.0307)$ & $(0.0645)$ & & & \\
\hline \multicolumn{7}{|c|}{ C. Estimation Results of $i l l i q_{t}, i l l i q h_{t}, i l l i q l_{t}$} \\
\hline illiq $q_{t}$ & $\overline{i l l i q}$ & $\rho_{\text {illiq }, \text { illiq }}$ & $\rho_{\text {illiq,illiqh }}$ & $\rho_{\text {illiq }, \text { illiql }}$ & & \\
\hline Coeff. & $8.9526^{* * *}$ & $0.9521 * * *$ & 0.0001 & -0.0005 & & \\
\hline $\mathrm{SE}$ & $(0.1311)$ & $(0.0147)$ & $(0.0046)$ & $(0.0044)$ & & \\
\hline & $\rho_{\text {illiq }, \theta}$ & $\rho_{i l l i q, \theta p}$ & $\rho_{i l l i q, \theta n}$ & $\rho_{i l l i q, q}$ & $\rho_{i l l i q, q h}$ & \\
\hline Coeff. & -15.2507 & $0.0186^{*}$ & 0.0145 & $-4.622^{*}$ & $1.5002^{* * *}$ & \\
\hline \multirow[t]{2}{*}{$\mathrm{SE}$} & $(27.2003)$ & $(0.0113)$ & $(0.0317)$ & $(2.5668)$ & $(0.4929)$ & \\
\hline & $\delta_{i l l i q, \theta p}$ & $\delta_{i l l i q, \theta n}$ & $\delta_{i l l i q, q h}$ & $\delta_{i l l i q, q l}$ & $\delta_{i l l i q, i l l i q h}$ & $\delta_{i l l i q, i l l i q l}$ \\
\hline Coeff. & 0.0054 & 0.0345 & $-1.2834^{* *}$ & -0.004 & $2.0855^{* * *}$ & $0.7175^{* * *}$ \\
\hline $\mathrm{SE}$ & $(0.0077)$ & $(0.0988)$ & $(0.5396)$ & $(0.0052)$ & $(0.0351)$ & $(0.0323)$ \\
\hline illiqh $_{t}$ : & $\overline{\text { illiqh }}$ & $\rho_{\text {illiqh }}$ & $\delta_{i l l i q h}$ & & & \\
\hline Coeff. & $1.1458^{* * *}$ & $0.9244^{* * *}$ & $0.4687^{* * *}$ & & & \\
\hline $\mathrm{SE}$ & $(0.0481)$ & $(0.0413)$ & $(0.0103)$ & & & \\
\hline illiql $_{t}$ : & $\overline{i l l i q l}$ & $\rho_{i l l i q l}$ & $\delta_{i l l i q l}$ & & & \\
\hline Coeff. & $0.699^{* * *}$ & $0.8651^{* * *}$ & $0.0219 * * *$ & & & \\
\hline $\mathrm{SE}$ & $(0.0347)$ & $(0.0900)$ & $(0.0025)$ & & & \\
\hline
\end{tabular}
First, the economic growth and uncertainty state variables are estimated using a monthly sample from 1947/02 to 2019/12 and the Approximate Maximum Likelihood (AML) methodology in Bates (2006). Then, the risk aversion measure uses the $q_{t}$ series from Bekaert et al. (forthcoming), from 1986/06 to 2019/12, and is first projected on known macro variables; the disturbance is estimated using Bates (2006)'s. Finally, the stock market illiquidity measure is constructed using Amihud (2002)'s methodology, from 1985/01 to 2019/12, and is first projected on known variables; the disturbance is also estimated using Bates (2006)'s. (Below: ${ }^{* * *}\left({ }^{* *},{ }^{*}\right): 1 \%(5 \%, 10 \%)$ test) 
We next compare the closeness between average conditional moments (mean, variance) and empirical unconditional moments of $\theta_{t+1}, q_{t+1}$, and $i l l i q_{t+1}$. Bold values indicate that the average conditional moments are statistically close to data. Moment matching is expected given the highly specified model assumptions; given that our paper is not about selecting the most efficient dynamic process but obtaining realistic estimates of state variables, we do not expand the model comparison exercise and follow existing evidence and frameworks in the literature.

\begin{tabular}{lllllll}
\hline \hline & \multicolumn{2}{c}{$\theta_{t+1}$} & \multicolumn{2}{c}{$q_{t+1}$} & \multicolumn{2}{c}{ illiq $q_{t+1}$} \\
\hline \multirow{3}{*}{ Mean } & Data & Model & Data & Model & Data & Model \\
& $0.0023^{* * *}$ & $\mathbf{0 . 0 0 2 5}$ & $0.3023^{* * *}$ & $\mathbf{0 . 3 0 4 9}$ & $8.9468^{* * *}$ & $\mathbf{8 . 9 5 7 0}$ \\
& $(0.0003)$ & & $(0.0084)$ & & $(0.0084)$ & \\
Variance & $7.33 \mathrm{E}-05^{* * *}$ & $\mathbf{6 . 1 1 E - 0 5}$ & $0.0091^{* * *}$ & $\mathbf{0 . 0 0 9 4}$ & $6.632^{* * *}$ & $\mathbf{7 . 4 4 3 4}$ \\
& $(7.73 \mathrm{E}-06)$ & & $(0.0018)$ & & $(1.1573)$ & \\
\hline
\end{tabular}

Figures below depict the dynamics of state variables in the macro, risk aversion, and stock market illiquidity systems, respectively: (1) From top to bottom: Economic growth (gray) and its conditional mean (red); good macro uncertainty state variable $\theta p_{t}$; bad macro uncertainty state variable $\theta n_{t}$; total conditional volatility.
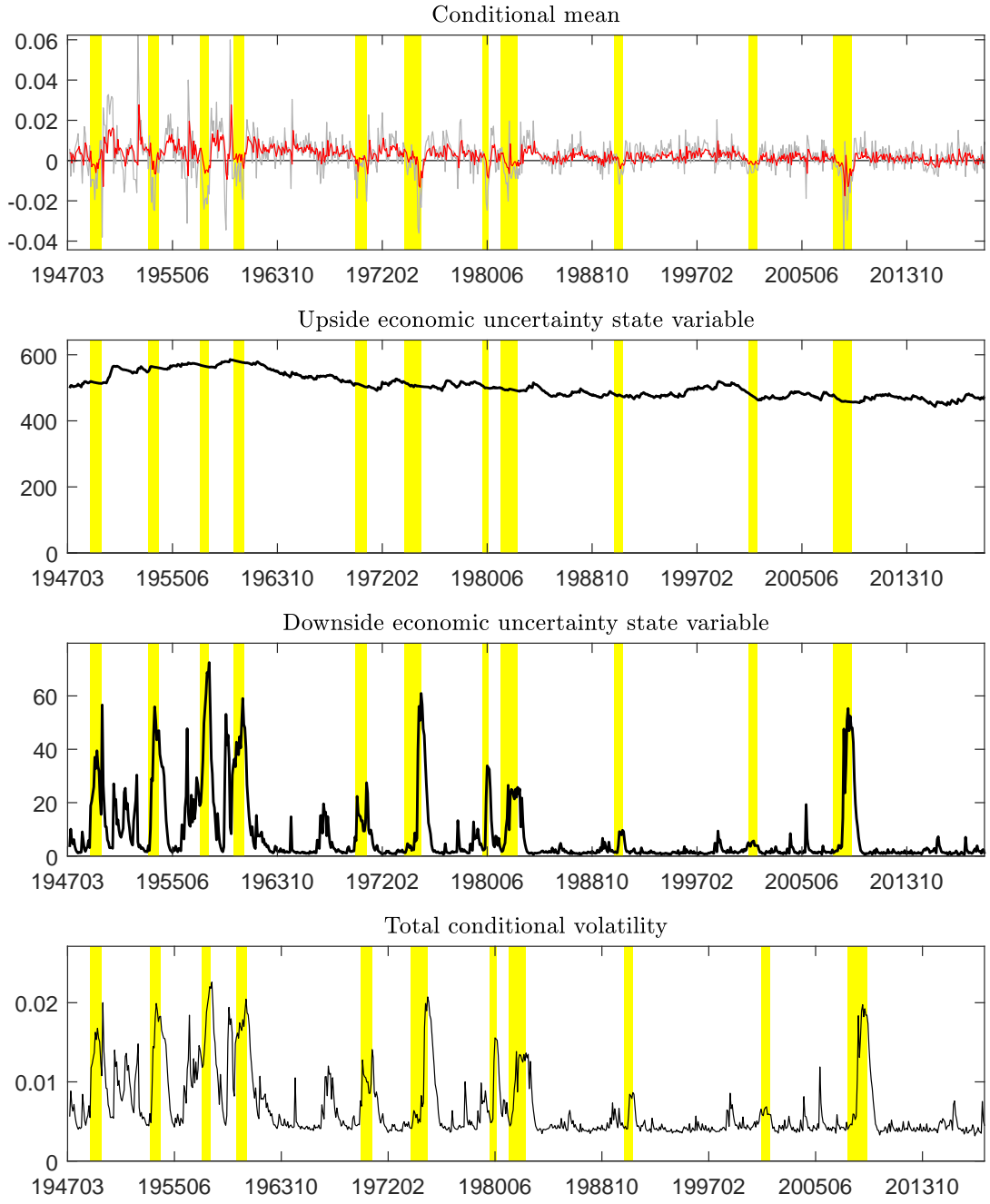

(2) From top to bottom: Risk aversion state variable $q_{t}$ from Bekaert et al. (forthcoming) (gray) and its conditional mean (red); high risk aversion state variable $q h_{t}$; total conditional volatility. 

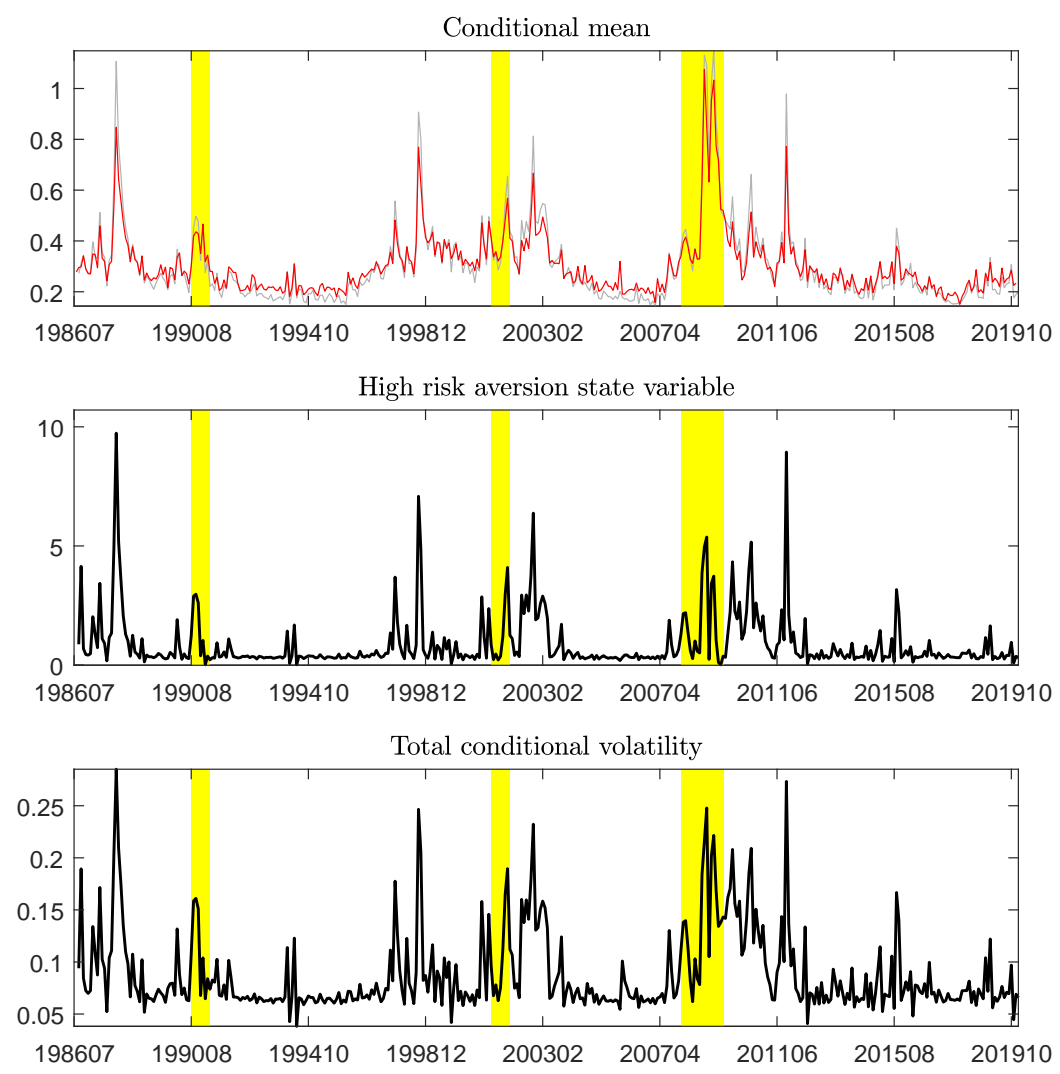

(3) From top to bottom: Stock market illiquidity measure using Amihud (2002)'s method (gray) and its conditional mean (red); high market illiquidity state variable $i l l i q h_{t}$; low market illiquidity state variable $i l l i q l_{t}$; total conditional volatility.
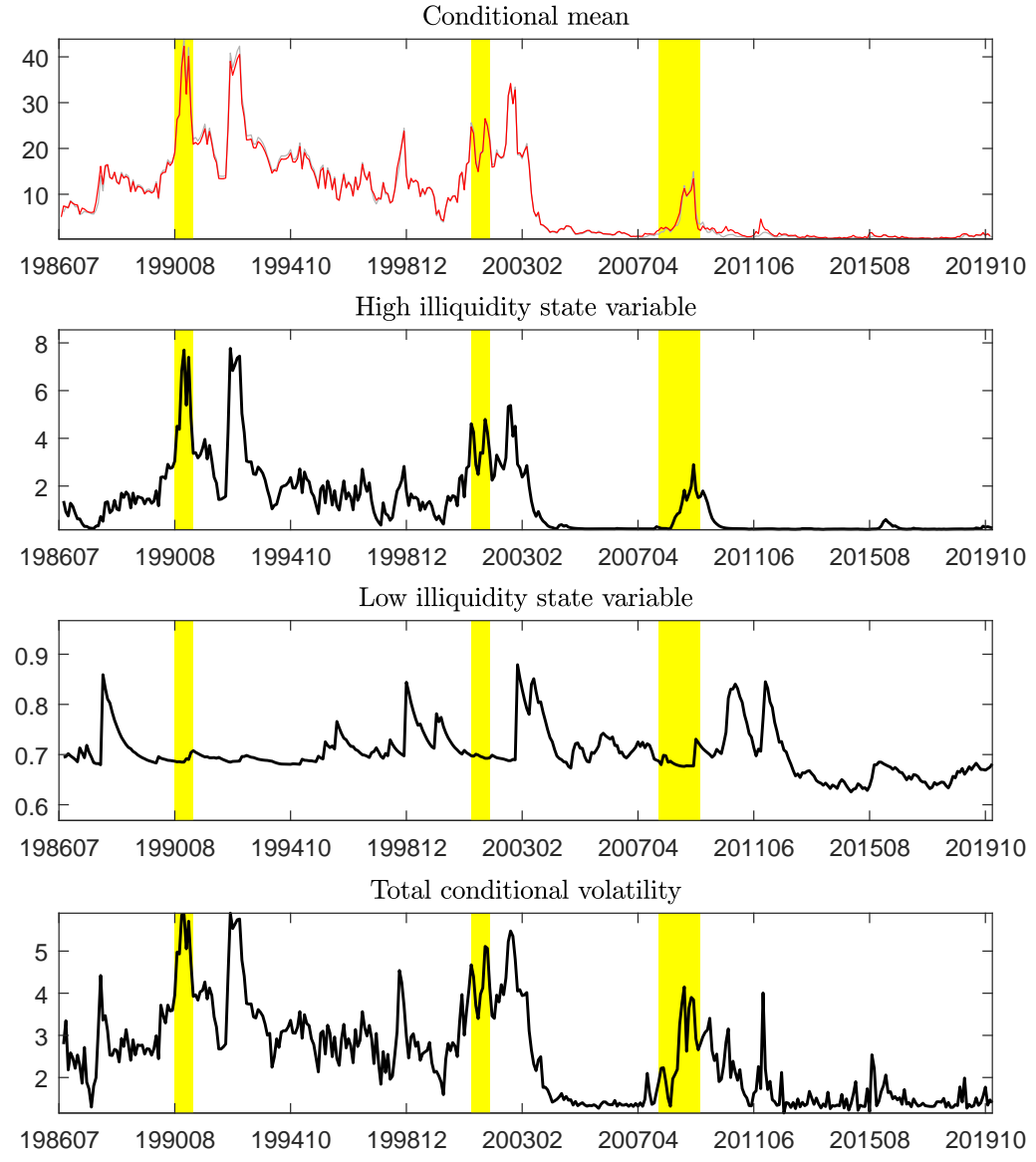


\section{F. Implied international stock return predictive coefficients of DVP and UVP in Section 5.1.2}

In Equation (22), the model-implied $\kappa$-month predictive coefficients of DVP, UVP for country $i$ are:

$$
\begin{gathered}
\widehat{b_{\kappa}^{i, D}} \equiv \frac{\operatorname{Cov}\left(\widehat{v p_{t}^{D}}, \widehat{E P_{\kappa, t}^{i}}\right)}{\operatorname{Var}\left(\widehat{v p_{t}^{D}}\right)}=\frac{\left(\boldsymbol{V}_{\kappa}^{\prime} \boldsymbol{\Xi} \boldsymbol{W}^{D}\right)}{\left(\boldsymbol{W}^{D \prime} \boldsymbol{\Xi} \boldsymbol{W}^{D}\right)}, \\
\widehat{b_{\kappa}^{i, U}} \equiv \frac{\operatorname{Cov}\left(\widehat{v p_{t}^{U}}, \widehat{E P_{\kappa, t}^{i}}\right)}{\operatorname{Var}\left(\widehat{v p_{t}^{U}}\right)}=\frac{\left(\boldsymbol{V}_{\kappa}^{\prime} \boldsymbol{\Xi} \boldsymbol{W}^{\boldsymbol{U}}\right)}{\left(\boldsymbol{W}^{\boldsymbol{U}} \boldsymbol{\Xi} \boldsymbol{\Xi} \boldsymbol{W}^{U}\right)} .
\end{gathered}
$$

- $\forall x \in\{\theta p, \theta n, q h$, illiqh, illiql $\}$, denote $v_{x, \kappa, 0}+v_{x, \kappa, 1}$ EconomicIntegration $^{i}+v_{x, \kappa, 2}$ FinancialIntegration $^{i}$ from Equation 21) by $v_{x, \kappa, \text { const }}^{i}$.

- Matrix $\boldsymbol{V}_{\kappa}$ is a vector matrix consisting of 20 unknown $v$ 's from Equation 21] for each horizon $\kappa$,

$$
\boldsymbol{V}_{\kappa}=\left[\begin{array}{llllllllll}
v_{\theta p, \kappa, \text { const }}^{i} & v_{\theta n, \kappa, \text { const }}^{i} & v_{q h, \kappa, \text { const }}^{i} & v_{i l l i q h, \kappa, \text { const }}^{i} & v_{\text {illiql }, \kappa, \text { const }}^{i} & v_{\theta p, \kappa, 3} & v_{\theta n, \kappa, 3} & v_{q h, \kappa, 3} & v_{\text {illiqh }, \kappa, 3} & v_{\text {illiql }, \kappa, 3}
\end{array}\right]^{\prime} .
$$

- Matrix $\boldsymbol{\Xi}$ is the covariance-variance matrix of $\left[\theta p_{t}, \theta n_{t}, q h_{t}, i l l i q h_{t}, i l l i q l_{t}, \theta p_{t} z_{t}, \theta n_{t} z_{t}, q h_{t} z_{t}\right.$, illiqh $z_{t}$, illiql $z_{t} z_{t}$.

- Matrices $\boldsymbol{W}^{D}$ and $\boldsymbol{W}^{U}$ are vector matrices consisting of 10 known parameters from Section 5.1.1

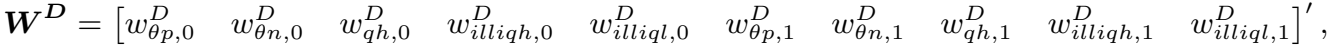

$$
\begin{aligned}
& \boldsymbol{W}^{U}=\left[\begin{array}{llllllllll}
w_{\theta p, 0}^{U} & w_{\theta n, 0}^{U} & w_{q h, 0}^{U} & w_{i l l i q h, 0}^{U} & w_{i l l i q l, 0}^{U} & w_{\theta p, 1}^{U} & w_{\theta n, 1}^{U} & w_{q h, 1}^{U} & w_{\text {illiqh }, 1}^{U} & w_{\text {illiql }, 1}^{U}
\end{array}\right]^{\prime} .
\end{aligned}
$$

\section{G. The role of $z_{t}$ in the global equity risk premium loadings on common risk premium determinants}

This plot complements Figure 8 (A) and Footnote 22 using $z_{t}=\min \left(z_{t}\right)$ and $z_{t}=\max \left(z_{t}\right)$. The message is that $z_{t}$ seems to matter insignificantly in the EP loadings.
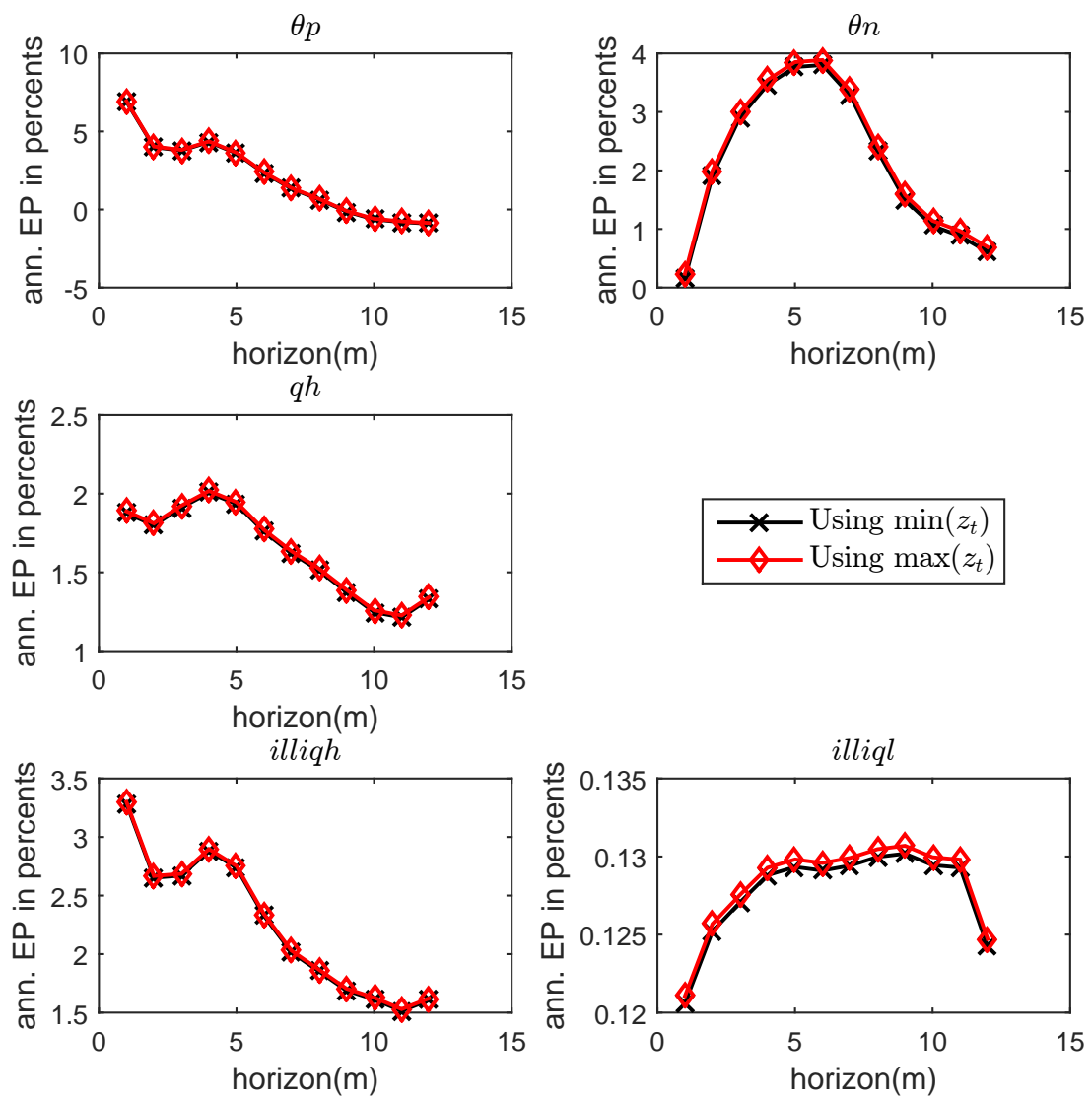